\title{
Epidural analgesia during labour : choices and consequences
}

Citation for published version (APA):

Wassen, M. M. L. H. (2014). Epidural analgesia during labour : choices and consequences. [Doctoral Thesis, Maastricht University]. Maastricht University. https://doi.org/10.26481/dis.20141212mw

Document status and date:

Published: 01/01/2014

DOI:

10.26481/dis.20141212mw

Document Version:

Publisher's PDF, also known as Version of record

\section{Please check the document version of this publication:}

- A submitted manuscript is the version of the article upon submission and before peer-review. There can be important differences between the submitted version and the official published version of record.

People interested in the research are advised to contact the author for the final version of the publication, or visit the DOI to the publisher's website.

- The final author version and the galley proof are versions of the publication after peer review.

- The final published version features the final layout of the paper including the volume, issue and page numbers.

Link to publication

\footnotetext{
General rights rights.

- You may freely distribute the URL identifying the publication in the public portal. please follow below link for the End User Agreement:

www.umlib.nl/taverne-license

Take down policy

If you believe that this document breaches copyright please contact us at:

repository@maastrichtuniversity.nl

providing details and we will investigate your claim.
}

Copyright and moral rights for the publications made accessible in the public portal are retained by the authors and/or other copyright owners and it is a condition of accessing publications that users recognise and abide by the legal requirements associated with these

- Users may download and print one copy of any publication from the public portal for the purpose of private study or research.

- You may not further distribute the material or use it for any profit-making activity or commercial gain

If the publication is distributed under the terms of Article $25 \mathrm{fa}$ of the Dutch Copyright Act, indicated by the "Taverne" license above, 


\section{Epidural analgesia during labour}

\section{choices and consequences}
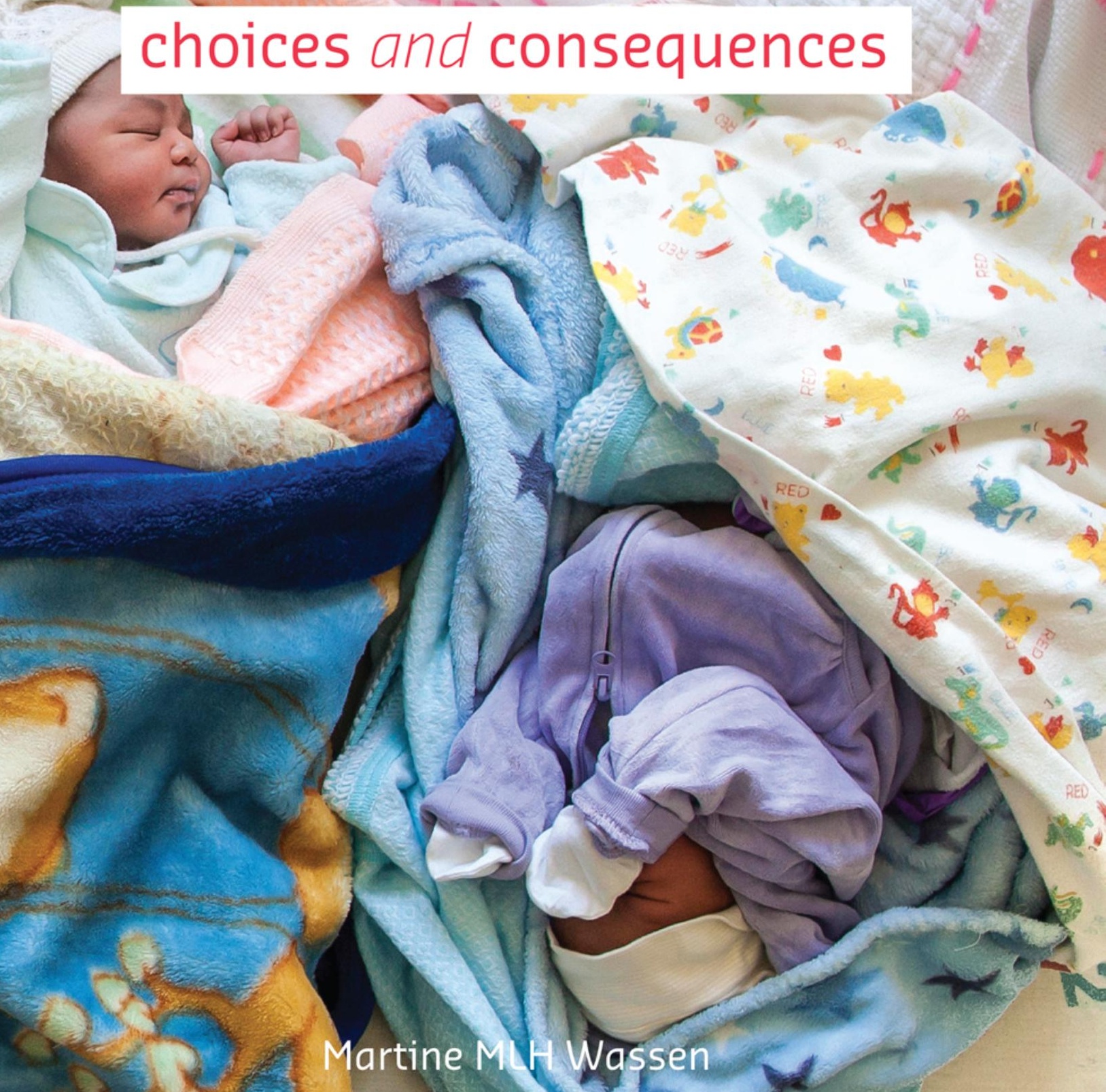

Martine MU Wassen 



\section{Epidural analgesia during labour}

choices and consequences

Martine MLH Wassen 
Epidural analgesia during labour: choices and consequences Thesis, University of Maastricht, the Netherlands

ISBN:

978-90-9028637-2

Author: Martine Wassen

Cover Photo: Lieve Blancquaert. "Birthday" Layout: Christiaan Krabbe, www.ontwerpstudiocontxt.nl Printed by Drukkerij Walters, Maastricht

Copyright $\odot 2014$ M. Wassen, Maastricht

All right reserved. No part of this thesis may be reproduced or transmitted in any form by any means, without permission of the copyright owner. 


\title{
Epidural analgesia during labour: choices and consequences
}

\author{
Proefschrift
}

\author{
ter verkrijging van \\ de graad van doctor aan de Universiteit Maastricht, \\ op gezag van de Rector Magnificus,
}

Prof. dr. L.L.G. Soete

volgens het besluit van het College van Decanen, in het openbaar te verdedigen op

12 december om 12.00 uur

door

\section{Martine MLH Wassen}

geboren 17 februari 1977

te Geleen 


\section{Promotor}

Prof. dr. J.G. Nijhuis

\section{Copromotores}

Dr. F.J.M.E. Roumen, Atrium MC Heerlen

Dr. L.J.M. Smits

\section{Beoordelingscommissie}

Prof. dr. W.F.F.H. Buhre (voorzitter)

dr. E. de Miranda (AMC, Amsterdam)

dr. K.M. Paarlberg (Gelre Ziekenhuis, Apeldoorn)

Prof. dr. M.E.A. Spaanderman

Prof. dr. L.J.I. Zimmermann

Faculteit der Geneeskunde 


\section{Table of contents}

10

Chapter 1

General Introduction and outline of the thesis

20

\section{Chapter 2}

Women's prelabour preference for epidural analgesia:

a cross-sectional study among women from The Netherlands and Belgium Journal of Psychosomatic Obstetrics \& Gynecology 2013;34:22-28.

$36 \quad$ Chapter 3

Epidural analgesia and operative delivery: a ten-year population-based cohort study in The Netherlands

European Journal of Obstetrics \& Gynecology and Reproductive Biology. Accepted

$52 \quad$ Chapter 4

Early versus late epidural analgesia and risk of instrumental delivery in nulliparous women: a systematic review

British Journal of Obstetrics and Gynaecology 2011;118:655-661.

$68 \quad$ Chapter 5

Routine labour epidural analgesia versus labour analgesia on request:

a randomised non-inferiority trial

British Journal of Obstetrics and Gynaecology 2014. May 22. [epub ahead of print].

$84 \quad$ Chapter 6

Neonatal sepsis is mediated by maternal fever in labour

epidural analgesia

Journal of Obstetrics \& Gynaecology 2014;17:1-5.

\section{$98 \quad$ Chapter 7}

Prevalence and predictors of chronic pain after labour and delivery

Current Opinion in Anaesthesiology 2010;23:295-299. 
$110 \quad$ Chapter 8

General Discussion and future perspectives

$122 \quad$ Chapter 9

Valorization

128 Chapter 10

Summary

136 Chapter 11

Samenvatting

143 Chapter 12

144 Publications

147 Curriculum Vitae

148 Dankwoord 

1 General introduction
and outline of the thesis

1 General introduction
and outline of the thesis

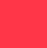

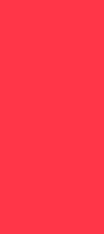




\section{Introduction}

\section{'In pain you shall bring forth children.'}

'Met smart zult gij kinderen baren.'

\section{- Genesis 3:16}

Labour pain can be regarded as one of the most serious kinds of pain. In a survey among 141 labouring women, a high intensity of labour pain was reported. ${ }^{1}$ Among primiparas, $37.9 \%$ rated labour pain as severe and $23.4 \%$ as 'unbearable, intolerable or extremely severe'. Multiparas have lower pain scores; $35.2 \%$ had severe pain, and only $11.1 \%$ rated labour pain as 'unbearable, intolerable or extremely severe',

Labour pain scores have been shown to be higher in comparison with other chronic pain conditions, such as; low-back pain, arthritic pain and pain in non-terminal cancer patients (Figure 1). ${ }^{2}$ Only patients with amputation pain of a digit reported a higher pain score (Figure 1$).^{2}$

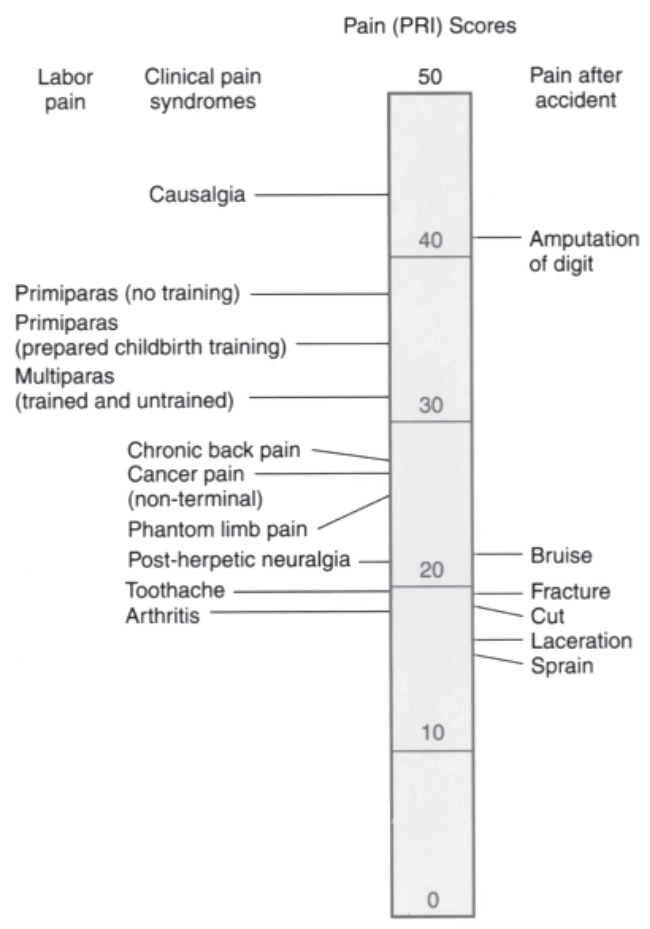

Figure 1. Comparison of pain scores, using the McGill Pain Questionnaire (from: Melzack R. The myth of painless childbirth (The John J. Bonica Lecture). Pain 1984;19(4):321-337. 


\section{Labour Pain}

Labour pain is the result of many complex interactions. Labour pain has a visceral component and a somatic component. ${ }^{3}$ During first stage of labour (onset of labour until full cervical dilatation), visceral pain is generated largely from distension originating from rhythmic uterine contractions, progressive dilatation of the lower uterine segment and cervix, and activation of mechanoreceptors. ${ }^{4}$ Due to uterine contractions myometrial ischemia occurs, causing the release of potassium, bradykinin, histamine, and serotonin, which stimulate chemoreceptors. ${ }^{3,4}$ Visceral afferent impulses are transmitted mainly via the A-delta and $\mathrm{C}$ fibers, which travel with the sympathetic nerves via the hypogastric plexus to enter the lumbar and lower thoracic parts of the sympathetic chain. ${ }^{5}$

Central connection to the spinal cord is via the dorsal root ganglion (Figure 2) and lateral division of the posterior roots of T10-L1. In early labour, visceral afferents pass primarily T11 and T12 dermatomes. With progressing labour, pain is also referred to T10 and L1 dermatomes. Somatic labour pain, primarily related to direct pressure of foetal
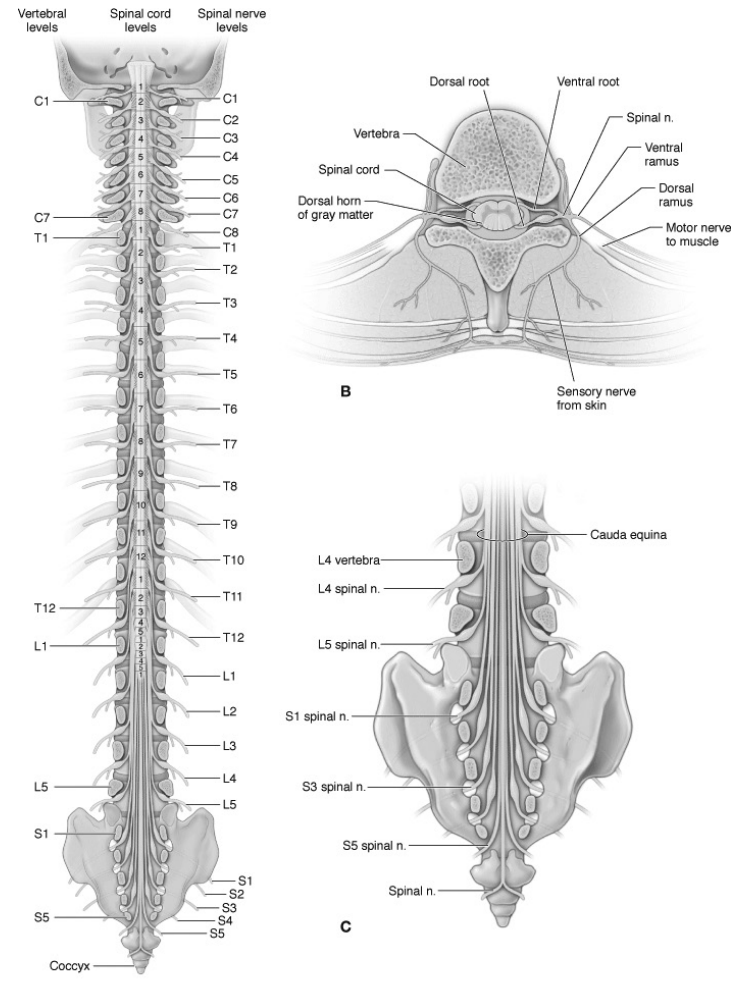
descent, is caused by distension of the vagina, the pelvic floor, and the perineum. Pain is transmitted also via the A-delta and $\mathrm{C}$ fibres but with the parasympathetic bundle in the pudendal nerves, entering the spinal cord via nerve roots S2-S4., ${ }^{4,5}$ The perineum is also innervated by the ilioinguinalis nerve, the genital branch of the genitofemoral nerve, and the posterior femoral cutaneous nerve. ${ }^{4}$

Figure 2. Anatomy spinal cord. Source: Mortan DA, Foreman KB, Albertine KH: The big picture: Gross Anatomy: www.accesmedicine.com 


\section{Pain relief interventions}

The American College of Obstetricians and Gynaecologists and the American Society of Anaesthesiologists issued in 2004 a joint statement indicating that "maternal request is a sufficient justification for pain relief during labour". ${ }^{6}$ Labour pain management strategies include non-pharmacological and pharmacological interventions.

Non-pharmacological interventions of pain management methods are psychological support, hypnosis, biofeedback, intracutaneous or subcutaneous sterile water injections, immersion in water, aromatherapy, relaxation techniques (yoga, music, audio), acupuncture or acupressure, manual methods (massage, reflexology) and transcutaneous electrical nerve stimulation. ${ }^{7}$ Pharmacological interventions of pain management include inhaled analgesia, opioids, non-opioid drugs, local anaesthetic nerve blocks, and epidural and intrathecal injections of local anaesthetics or opioids or both. ${ }^{7}$ Epidural analgesia (EA) offers better pain relief than systemic opioids. ${ }^{8}$ In this thesis we will focus on EA and not on other pain relief methods.

\section{Technique of epidural analgesia}

EA is a central nerve blockade technique, which is achieved by placement of a catheter into the lumbar epidural space, usually at L3-L4 or L4-L5. After identification of the desired intervertebral space and infiltration of a local anaesthetic, a hollow epidural needle is placed in the intervertebral ligaments, characterized by a high degree of resistance to penetration. ${ }^{3}$ The epidural space, in contrast, is recognized by a sudden loss of resistance as the epidural needle enters the epidural space and an epidural catheter is advanced into the space (Figure 3). A local anaesthetic solution, opioid or both can now be administered through the catheter as intermittent rapid doses or as a continuous infusion. ${ }^{3}$ Maintenance of EA may be achieved with intermittent bolus injections, continuous infusion or patient-controlled pump. ${ }^{7}$

Local anaesthetics inhibit the nerve conduction by blocking sodium channels in nerve cell membranes; thereby preventing the propagation of nerve impulses along these fibres. ${ }^{7}$ Blocking impulses from the sensory nerves as they cross the epidural space results in analgesia. ${ }^{7}$ A concentration specific effect of the anaesthetic has been 
known. All modalities of sensation of the blocked nerves will be affected to varying degrees. Administration of a lower-dose anaesthetic (e.g. $0.125 \%$ bupivacaïne) partially selectively blocks painful stimuli while preserving motor function. ${ }^{9}$ Higher concentrations, as used in the earlier years, have been associated with motor blockade resulting in limiting mobility in labour, decreased pelvic tone, and impairment of the bearing down effort in the second stage of labour. ${ }^{7,10}$

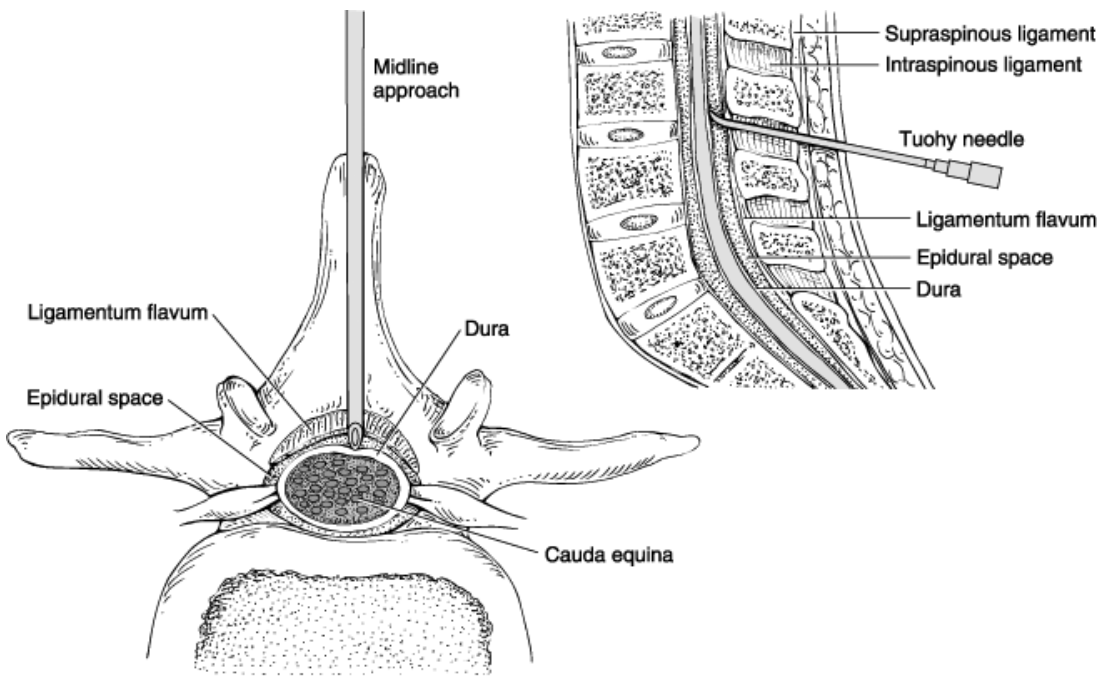

Figure 3. Source: Butterworth IV JF, Mackey DC, Wasnick JD. Chapter 45. Spinal, Epidural, \& Caudal Blocks. Morgan \& Mikhail's Clinical Anesthesiology, 5th ed. New York: McGraw-Hill; 2013.

\section{Managing labour pain in The Netherlands}

In The Netherlands, the obstetrical care-system is based upon three separate levels of care. In first line care, independent midwives and general practitioners attend low risk pregnancies and deliveries at home or in hospital ("outpatient" or midwife-led hospital birth). In second line care, an obstetrician supervises women with increased risk factors, and third line care is provided in centres with facilities for high-risk obstetrics and neonatal intensive care (NICU).

Until very recently, labour analgesia was approached conservatively in The Netherlands because of several reasons. Firstly, for long time the midwifery model of care in The 
Netherlands defined childbirth as a normal physiological process, accepting pain as an accompanying normal phenomenon. ${ }^{11,12}$ Secondly, women who deliver under supervision of an independent primary care midwife are not able to get EA during labour, unless they are referred to an obstetrician in second line. Finally, limited 24/7 availability of labour EA in Dutch hospitals also contributed to this restrictive use and conservative approach of labour pain management. A cross-sectional telephone survey in 2010 showed 24/7 availability in only $57 \%$ of Dutch hospitals. ${ }^{13}$

In 2008, a multidisciplinary guideline about labour pain treatment was initiated by the Dutch Society of Obstetrics and Gynaecology in collaboration with the Dutch Society of Anaesthesiology and mandated by the Royal Dutch association of midwives. ${ }^{14}$ This guideline recommends adequate pain relief upon request for labouring women, with EA as preferred method. ${ }^{14}$ Publication of this guideline and increased knowledge of EA in labouring women have resulted in a gradual increased demand in the past few years. In The Netherlands, the use of EA during labour has risen from 5.4\% in 2003 to $17.9 \%$ in $2012 .^{15,16}$

\section{Adverse effects epidural analgesia and controversial issues}

Although EA appears to be the most effective method in reducing labour pain, unintended adverse effects also accompany EA. In 2011, a Cochrane systematic review included 38 studies involving 9658 women to compare EA with non-epidural or no pain relief during labour on maternal, labour and neonatal outcomes. ${ }^{8}$ Women who received labour EA were at increased risk of having a longer second stage of labour and an increased risk of an instrumental vaginal delivery. ${ }^{8}$ No statistically significant impact on the risk of caesarean section or effect on neonatal status as determined by Apgar scores was found. ${ }^{8}$ Other reported maternal and labour complications include an increased risk in the use of oxytocin, hypotension, motor blockade, maternal fever $\leq 38.0^{\circ} \mathrm{C}$, and urinary retention. ${ }^{8}$

\section{Aim of the thesis}

Requests from women, and increasing knowledge and expertise in regional anaesthesia among obstetricians and midwives, have resulted in an increase in the use of labour 
EA over the past two decades in The Netherlands. In spite of its advantages, increasing maternal request for $E A$, and widespread acceptance among obstetricians, discussion remains regarding the effect of EA on labour outcome. Unfortunately, studies performed up until now, only investigated the impact of EA after maternal request for pain relief. Such studies are biased by the fact, that these women request pain relief possibly because of non-progressing labour or labour complications. As more women demand pain free labour, it is important to have a clear understanding of the benefits, but also the risks and complications of EA.

The lack of evidence about the effect of routine EA on labour outcome gave rise to The Randomised Epidural Analgesia in Term delivering women trial (TREAT). The aim of the TREAT trial was to compare routine EA in labouring women with pain relief on maternal request, on the risk of operative delivery, labour and neonatal outcomes.

\section{Research questions addressed in this thesis}

1. Which factors contribute to prelabour preference for epidural analgesia? (Chapter 1)

2. What are the trends in labour epidural analgesia use and mode of delivery in a 10-year time span in The Netherlands, and what is theeffect of changing epidural analgesia use on operative deliveries in both nulliparous and multiparous women?

(Chapter 2)

3. What do we know about the relation between the timing of epidural analgesia and the rate of caesarean section or instrumental vaginal deliveries?

(Chapter 3)

4. What is the effect of routine epidural analgesia compared to analgesia on request regarding the risk of an operative delivery?

(Chapter 4) 
5. What is the association between neonatal sepsis, based on diagnostic and clinical criteria according to a strict definition, and labour epidural analgesia? (Chapter 5)

6. What do we know about the predictors and prevalence of chronic pain after labour and delivery?

(Chapter 6) 


\section{Reference List}

1. Melzack R, Taenzer P, Feldman P, Kinch RA. Labour is still painful after prepared childbirth training. Can Med Assoc J 1981;125:357-363.

2. Melzack R. The myth of painless childbirth (The John J. Bonica lecture). Pain 1984;19:321-337.

3. Eltzschig HK, Lieberman ES, Camann WR. Regional Anesthesia and Analgesia for Labor and Delivery. NEJM 2003;348:319-332.

4. Vadivelu N, Urman RD, Hines RL. Essentials of Pain Management. 1st ed. New York: Springer; 2011.

5. Fishman SM, Ballantyne JC, Rathmell JP. Bonica's management of pain. 4nd ed. Philadelphia: Lipincott Williams \& Wilkins; 2010.

6. ACOG committee opinion No. 295. Pain relief during labor. Obstet Gynecol 2004;104:213.

7. Jones L, Othman M, Dowswell T, Alfirevic Z, Gates S, Newburn M, Jordan S, Lavender T, Neilson JP. Pain management for women in labour: an overview of systematic reviews (review). Cochrane Database Syst Rev 2012;3:CD009234.

8. Anim-Somuah M, Smyth RM, Jones L. Epidural versus non-epidural or no analgesia in labour. Cochrane Database Syst Rev 2011;12:CD000331.

9. Russell R Reynolds F. Epidural infusion of low-dose bupivacaine and opioid in labour. Does reducing motor block increase the spontaneous delivery rate? Anaesthesia 1996;51:266-273.

10. Thornton JG, Capogna G. Reducing likelihood of instrumental delivery with epidural anaesthesia. Lancet 2001;358:2.

11. DeVries R. A pleasing birth: Midwifery and maternity care in the Netherlands. Amsterdam: Amsterdam University Press;2005.

12. Christiaens $W$, Verhaeghe $M$, Bracke P. Pain acceptance and personal control in pain relief in two maternity care models: a cross national comparison of Belgium and the Netherlands. BMC Health Serv Res 2010;10:268.
13. Wassen MMLH, Buijs C, Nijhuis JG. Availability of epidural analgesia during labor in the Netherlands in 2010 [in Dutch]. Dutch J Obstet Gynaecol 2010;123:397-400.

14. Schuurhuis A, Roumen FJ, de Boer JB; Working Group Anaesthesiology. Practice guideline 'Pharmaceutical pain treatment during labour'; the woman's request is sufficient indication [in Dutch]. Dutch J Medicine 2009;153:A551.

15. The Netherlands Perinatal Registry. Perinatal care in the Netherlands 2003 [in Dutch]. Utrecht: The Netherlands.

16. The Netherlands Perinatal Registry. Perinatal care in the Netherlands 2012 [in Dutch]. Utrecht: The Netherlands. 


\title{
2 Women's prelabour preference for epidural analgesia: a cross-sectional study among women from The Netherlands and Belgium
}

\author{
MMLH WASSEN \\ CMG MIGGIELS \\ R DEVLIEGER \\ W GYSELAERS \\ HJ MERTENS \\ TH HASAART \\ E WIJNEN \\ PA DE REU \\ FJME ROUMEN \\ JG NIJHUIS \\ L SMITS
}

HCJ SCHEEPERS 


\section{Abstract}

\section{Background}

This study describes variables related to women's prelabour preference for epidural analgesia (PEA) in two neighbouring countries with a comparable socio-economic and cultural background.

\section{Methods}

Dutch women in midwifery ( $n=164)$ or obstetrical care $(n=162)$, and Belgian women $(n=188)$ of $\geq 36$ weeks gestation with a singleton in cephalic presentation completed questionnaires on demographic factors, received labour analgesia information, perceived attitude of the caregiver towards epidural analgesia, pain catastrophising and coping with labour pain. Multiple logistic regression analysis was performed with PEA as dependent variable.

\section{Results}

PEA was 9.9\% in Dutch midwifery care, $25.5 \%$ in Dutch obstetrical care and $38.3 \%$ in Belgian care ( $p$ - value $<0.001$ ). In the Netherlands, maternal age of 35 years or older (OR 4.95; $95 \%-\mathrm{Cl} 2.03$ to 12.08 ), positive attitude of the caregiver towards EA (OR 5.83; 95\%-Cl 2.57 to 13.23 ) and a lower degree of coping (OR 3.61; 95\%- $\mathrm{Cl} 2.24$ to 5.82) were independently associated with PEA. In Belgium, only a lower degree of coping was associated with PEA (OR 4.06; 95\%-Cl 2.45 to 6.73 ).

\section{Conclusions}

In both countries, women with a lower degree of coping had a higher PEA. Care setting in The Netherlands was not an independent variable. 


\section{Introduction}

Involvement in decision-making regarding pregnancy, labour and delivery are important factors in satisfaction and childbirth experience ${ }^{1}$, and women are increasingly encouraged to take an active role in this process. ${ }^{2,3}$

Until now, information about the preference and predictors for a request for pain relief during labour is scarce. The amount of pain experienced during labour is a multifactorial process and the result of the objective physiological sensory aspects of pain and its subjective, emotional and psychological aspects. ${ }^{4}$ Epidural analgesia (EA) has been proven to be the most effective method of pain relief during labour and results in increased patient satisfaction compared with other or no analgesia., ${ }^{5,6}$ However, unintended adverse effects also accompany EA. Maternal complications include a significant increase in the risk of hypotension, motor blockade, maternal fever $\geq 38.0^{\circ} \mathrm{C}$ and urinary retention. ${ }^{5} \mathrm{EA}$ may also influence the course of labour. Women with EA have an increased risk in the use of oxytocin, a longer second stage of labour and an increased risk of an instrumental delivery. ${ }^{5}$

The Netherlands and Belgium are neighbouring countries and quite comparable in terms of, for example, language, geographic position and cultural habits, but characterized by differences in EA use and organisation of maternity care. In Belgium, the use of EA during labour is $67 \%$ and in the Netherlands EA use increased to $11 \%$ in $2008 .^{7,8}$ The Dutch obstetrical care-system is subdivided into primary midwifery care in which independent midwives attend low risk pregnancies and deliveries. In case of difficulties during pregnancy and labour, women are referred to obstetrical care under supervision of an obstetrician. In the Netherlands, childbirth is defined as a normal physiological process, resulting in $31 \%$ of all births in midwifery care and $19.0 \%$ home births. ${ }^{9}$ In The Netherlands, about 17 percent of referrals from primary midwifery care to obstetrical care during labour is due to a request for pain relief. ${ }^{9}$ In contrast, $97.9 \%$ of the women in Belgium prefer a hospital delivery and labour pain is perceived as a needless inconvenience..$^{10,11}$ In a study among Dutch women, more than 16 percent of them looked back negatively three years after delivery. ${ }^{12}$ Women who had not been given a choice of pain relief were three times more likely to recall their birth experience negatively. As the demand for EA 
during delivery has been increasing over the years and the choice of pain relief has been associated with a negative recall, it is worthwhile considering the factors that influence preferences and decision-making regarding EA. The decision for (not) choosing EA can be influenced by several factors during pregnancy and labour, for example, parity, low social status, type of hospital and 24-hour availability of an anaesthesiologist. ${ }^{8}$ Further research to understand women's expectations and birth experience is necessary to reduce factors associated with a negative labour experience.

The aim of this cross-national study was to gain insight into prelabour preferences for epidural analgesia (PEA) and to explore independent factors influencing this choice in pain relief and decision-making in The Netherlands and Belgium, which have low and high rate of EA use respectively. The association of demographic factors, care setting, information supply, perceived attitude of the health care professional towards epidural analgesia, pain catastrophising and labour pain coping with PEA was investigated.

\section{Methods}

We gathered data using a cross-sectional survey. Between October 2010 and February 2011, participants were recruited in five Dutch midwifery centers, three Dutch hospitals and two Belgian (Flemish) hospitals. The institutional review board of all participating hospitals approved the study. Women with a gestational age of 36 weeks or more, pregnant with a singleton in cephalic presentation were eligible and asked to participate in the study. They were informed about the aims and methods of the study and gave written informed consent. In the Dutch participating hospitals and midwifery clinics, medical files selected women who fulfilled the inclusion criteria, and questionnaires were sent by mail. If the questionnaires were not returned within two weeks, up to two followup telephone calls were made. Women in Belgium were recruited during their visit to the midwife or obstetrician, and directly filled out the questionnaires during their visit. All questionnaires had to be filled out before the onset of labour and mailed to the primary researcher. 


\section{Questionnaires}

Women who participated in the study were asked to complete four questionnaires.

First, a general medical questionnaire included the following variables: maternal age, obstetrical history, gestational age at inclusion and ethnic origin defined as European and non-European (Mediterranean, Afro-American, Hindustani, Asian). Highest completed education level was divided into primary (elementary school), secondary (high school, vocational school and preparatory school) and tertiary education (higher professional education or Master/Bachelor level).

The second questionnaire concerned their preference for EA and whether, in their opinion, the caregiver had a positive, neutral or negative attitude regarding the use of EA (individual questions and categorisation Appendix I). The third questionnaire assessed catastrophic thinking by the validated Dutch version of the Pain Catastrophising Scale (PCS). ${ }^{13}$ This version has been shown to have good reliability and validity and measures painful experiences in the past and indicates the degree to which one experiences thoughts or feelings during pain..$^{13,14}$ The test consists of a 13-item scale, subdivided into three categories; (i) rumination (four items describing ruminative thoughts, worry and the tendency to increase pain-related thoughts, e.g., 'I keep thinking about how much it hurts'); (ii) magnification (three items describing the way of exaggerating the threat value of pain stimuli, e.g., 'I become afraid that the pain may get worse') and (iii) helplessness (six items reflecting the adoption of a helpless orientation to cope with painful situations, e.g.,'I feel I can't stand it anymore'). The answers on each item ranged from 0 ("not at all) to 4 ("always") on a five-point Likert scale. Higher scores indicate a high degree of rumination (maximum score: 12), magnification (maximum score: 16) and helplessness (maximum score: 24), and reflect a high degree of pain catastrophising.

The fourth and last questionnaire was the Beliefs about Epidural Analgesia Questionnaire (BEAQ) related to coping with labour pain (perceived control). ${ }^{15}$ The BEAQ assesses three items, namely (i) attitude towards EA, (ii) subjective norms and (iii) perceived control that might influence the decision to choose it. ${ }^{15}$ Because the questions pertaining to attitudes and subjective norms were directly correlated to the choice and preference for epidural analgesia, these items were not involved in the data collection. On the other hand, the three questions belonging to the perceived control item (I have confidence in my ability 
to tolerate labour pain, I think I'll be able to give birth without EA, I think I am more able to tolerate pain from childbirth than other pains) reflect the extent of coping with labour pain (a higher score shows a lower degree of coping with labour pain) and were therefore included in the analysis. Questions were answered on a five-point Likert scale ranging from 1 ("completely disagree") to 5 ("completely agree").

\section{Statistical analysis}

Complete case analysis was performed. The chi-square test was used to test associations between categorical variables. We used a two-sided alpha of 0.05 . Univariate analysis assessed the contribution of each variable and the results are presented as odds ratios (ORs) with a 95\% confidence interval $(\mathrm{Cl})$. The primary outcome of PEA was defined as a dichotomous event (EA preference yes vs. no and unknown). A multiple logistic regression analysis was performed to predict significantly independently related variables to the request for EA. Subgroup analysis was performed for The Netherlands and Belgium. Statistical analyses were performed using SPSS $^{\circledR}$ software (version 18.0, SPSS Inc., Chicago, IL, USA). ${ }^{16}$

\section{Results}

During the four-month study period, 891 women were eligible and invited to participate in this study. Overall, 514 (57.7\%) women gave informed consent and returned the questionnaires, of which 326 (63.4\%) were Dutch and 188 (36.6\%) Belgian. The Dutch group consisted of 164 (50.3\%) women in midwifery care and 162 (49.7\%) women in obstetrical care. Response rates in midwifery and obstetrical care were 59.0\% (164/278) and 38.1\% (162/425), respectively. Response rate in the two participating Belgian hospitals was $100 \%$ (188/188). The Crohnbach's $\alpha$ was calculated for the PCS and for the item perceived control of the BEAQ, and were 0.92 and 0.88 , respectively, in this study.

\section{Epidural analgesia preference}

Of the Dutch women, $17.6 \%$ preferred EA, $12.9 \%$ preferred not to use EA and $69.5 \%$ were indecisive (Table I). The preference for EA was significantly different between women 
in midwifery care and obstetrical care ( $p$-value $<0.001)$. Women in midwifery care less often preferred EA compared with women in obstetrical care (9.9\% vs. $25.5 \%)$, more often preferred not to use EA ( $16.8 \%$ vs. $8.9 \%)$ and more often did not make a decision on preference before labour (73.3\% vs. $65.6 \%)$. There were eight missing values of EA preference in The Netherlands. Of the Belgian women, 38.3\% preferred EA, 6.9\% preferred not to use EA and 54.8\% were indecisive (Table I). PEA significantly differed between Dutch and Belgian women. Dutch women less often expressed a preference for EA than Belgian women (17.6\% vs. $38.3 \%)$, more often declined its use $(12.9 \%$ vs. $6.9 \%)$ and were more often indecisive $(69.5 \%$ vs. $54.8 \%)$ ( $p$-value $<0.001)$.

\section{Study characteristics}

The mean age of Dutch women was 31.1 years ( \pm 4.6 ), $50.6 \%$ were nulliparous, $94.4 \%$ of European origin, $55.1 \%$ completed a tertiary education level, $74.5 \%$ were informed about labour analgesia and $17.8 \%$ of the Dutch caregivers had a positive attitude towards EA (Table I).

Belgian women had a mean age of 29.6 years $( \pm 4.4)$, $51.6 \%$ were nulliparous, $89.8 \%$ of European origin, 55.8\% completed tertiary school, 35.1\% were informed about analgesia during labour and $12.8 \%$ of the caregivers had a positive attitude towards EA (Table I). 
Table I. Prelabour epidural analgesia preference and study characteristics

\begin{tabular}{|c|c|c|c|c|c|c|}
\hline \multirow[b]{2}{*}{ Variables } & \multicolumn{4}{|c|}{ The Netherlands } & \multicolumn{2}{|c|}{ Belgium } \\
\hline & $\begin{array}{l}\text { Midwifery care } \\
\qquad(n=164)\end{array}$ & $\begin{array}{l}\text { Obstetrical care } \\
\qquad(n=162)\end{array}$ & $\begin{array}{c}P \\
\text { (Midwifery vs. } \\
\text { Obstetrical) }\end{array}$ & $\begin{array}{l}\text { Total } \\
(n=326)\end{array}$ & $\begin{array}{l}\text { Total } \\
(n=188)\end{array}$ & $\begin{array}{c}P \\
(\mathrm{NL} \text { vs. B) }\end{array}$ \\
\hline $\begin{array}{l}\text { EA preference } \\
\text { Yes } \\
\text { No } \\
\text { Unknown } \\
\text { Missing }\end{array}$ & $\begin{array}{c}16(9.9 \%) \\
27(16.8 \%) \\
118(73.3 \%) \\
3\end{array}$ & $\begin{array}{c}40(25.5 \%) \\
14(8.9 \%) \\
103(65.6 \%) \\
5\end{array}$ & $<0.001$ & $\begin{array}{c}56(17.6 \%) \\
41(12.9 \%) \\
221(69.5 \%) \\
8\end{array}$ & $\begin{array}{c}72(38.3 \%) \\
13(6.9 \%) \\
103(54.8 \%) \\
0\end{array}$ & $<0.001$ \\
\hline $\begin{array}{l}\text { Age (years) } \\
\text { Missing } \\
\text { Parity }\end{array}$ & $\begin{array}{c}30.2 \pm 4.4 \\
0\end{array}$ & $\begin{array}{c}32.1 \pm 4.7 \\
0\end{array}$ & $<0.001^{\star}$ & $\begin{array}{c}31.1 \pm 4.6 \\
0\end{array}$ & $\begin{array}{c}29.6 \pm 4.4 \\
0\end{array}$ & $<0.001^{\star}$ \\
\hline $\begin{array}{l}\text { Nulliparous } \\
\text { Multiparous } \\
\text { Missing }\end{array}$ & $\begin{array}{c}83(50.6 \%) \\
81(49.4 \%) \\
0\end{array}$ & $\begin{array}{c}82(50.6 \%) \\
80(49.4) \\
0\end{array}$ & 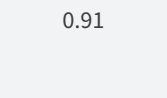 & $\begin{array}{c}165(50.6 \%) \\
161(49.4) \\
0\end{array}$ & $\begin{array}{c}97(51.6 \%) \\
91(48.4 \%) \\
0\end{array}$ & 0.68 \\
\hline $\begin{array}{l}\text { Ethnicity } \\
\text { European } \\
\text { Non-European } \\
\text { Missing }\end{array}$ & $\begin{array}{c}161(98.2 \%) \\
2(1.2 \%) \\
1\end{array}$ & $\begin{array}{c}145(90.1 \%) \\
16(9.9 \%) \\
1\end{array}$ & $<0.001^{\star}$ & $\begin{array}{c}306(94.4 \%) \\
18(5.6 \%) \\
2\end{array}$ & $\begin{array}{c}167(89.8 \%) \\
19(10.2 \%) \\
2\end{array}$ & 0.05 \\
\hline $\begin{array}{l}\text { Education } \\
\text { Primary/secondary } \\
\text { Tertiary } \\
\text { Missing }\end{array}$ & $\begin{array}{c}76(46.6 \%) \\
87(53.4 \%) \\
1\end{array}$ & $\begin{array}{c}70(43.2 \%) \\
92(56.8 \%) \\
0\end{array}$ & 0.54 & $\begin{array}{c}146(44.9 \%) \\
179(55.1 \%) \\
1\end{array}$ & $\begin{array}{c}80(44.2 \%) \\
101(55.8 \%) \\
7\end{array}$ & 0.88 \\
\hline $\begin{array}{l}\text { Information } \\
\text { Yes } \\
\text { No }\end{array}$ & $\begin{array}{l}118(72.4 \%) \\
45(27.6 \%)\end{array}$ & $\begin{array}{l}124(76.5 \%) \\
38(23.5 \%)\end{array}$ & 0.39 & $\begin{array}{l}242(74.5 \%) \\
83(25.5 \%)\end{array}$ & $\begin{array}{c}66(35.1 \%) \\
122(64.9 \%)\end{array}$ & $<0.001^{\star}$ \\
\hline $\begin{array}{l}\text { Missing } \\
\text { Attitude of caregiver }\end{array}$ & 1 & 0 & $<0.001^{\star}$ & 1 & 0 & $0.001^{\star}$ \\
\hline $\begin{array}{l}\text { Positive } \\
\text { Negative }\end{array}$ & $\begin{array}{c}19(11.7 \%) \\
0(0 \%)\end{array}$ & $\begin{array}{c}39(24.1 \%) \\
2(1.2 \%)\end{array}$ & & $\begin{array}{c}58(17.8 \%) \\
2(0.6 \%)\end{array}$ & $\begin{array}{c}24(12.8 \%) \\
0(0 \%)\end{array}$ & \\
\hline Neutral & $144(88.3 \%)$ & $121(74.7 \%)$ & & $265(81.3 \%)$ & $164(87.2 \%)$ & \\
\hline $\begin{array}{l}\text { Missing } \\
\text { PCS }\end{array}$ & 1 & 0 & & 1 & 0 & \\
\hline Rumination & $5.8 \pm 3.6$ & $6.4 \pm 3.9$ & 0.13 & $6.1 \pm 3.7$ & $6.4 \pm 4.1$ & 0.39 \\
\hline Magnification & $2.4 \pm 1.9$ & $2.9 \pm 2.6$ & $0.03^{\star}$ & $2.7 \pm 2.3$ & $3.0 \pm 2.4$ & 0.12 \\
\hline $\begin{array}{l}\text { Helplessness } \\
\text { Missing }\end{array}$ & $\begin{array}{c}4.7 \pm 3.5 \\
3\end{array}$ & $\begin{array}{c}5.7 \pm 4.3 \\
4\end{array}$ & $0.03^{\star}$ & $\begin{array}{c}5.2 \pm 3.9 \\
7\end{array}$ & $5.6 \pm 4.4$ & 0.29 \\
\hline $\begin{array}{l}\text { BEAQ } \\
\text { Coping labour pain } \\
\text { Missing }\end{array}$ & $\begin{array}{c}1.8 \pm 0.9 \\
5\end{array}$ & $\begin{array}{c}2.1 \pm 0.8 \\
3\end{array}$ & $0.02^{\star}$ & $\begin{array}{c}2.0 \pm 0.9 \\
8\end{array}$ & $2.5 \pm 0.93$ & $<0.001^{\star}$ \\
\hline
\end{tabular}


Table II. Results of univariate analysis of variables contributing to prelabour epidural analgesia preference in Dutch and Belgian women

\begin{tabular}{|c|c|c|c|c|c|c|c|c|c|c|c|c|}
\hline \multirow{3}{*}{ Variables } & \multicolumn{6}{|c|}{ The Netherlands $(n=326)$} & \multicolumn{6}{|c|}{ Belgium ( $n=188)$} \\
\hline & \multirow{2}{*}{$\begin{array}{c}\text { Total } \\
n\end{array}$} & \multicolumn{5}{|c|}{ Epidural Analgesia preference } & \multirow{2}{*}{$\begin{array}{c}\text { Total } \\
n\end{array}$} & \multicolumn{5}{|c|}{ Epidural Analgesia preference } \\
\hline & & $\mathrm{n}$ & $\%$ & OR & $95 \%-\mathrm{Cl}$ & $P$ & & $\mathrm{n}$ & $\%$ & OR & $95 \%-\mathrm{Cl}$ & $P$ \\
\hline$<25$ & 26 & 2 & 7.7 & 0.55 & $0.12-2.56$ & 0.449 & 18 & 5 & 27.8 & 0.58 & $0.18-1.81$ & 0.351 \\
\hline $25-29$ & 85 & 8 & 9.4 & 0.69 & $0.28-1.68$ & 0.414 & 76 & 31 & 40.8 & 1.05 & $0.54-2.01$ & 0.895 \\
\hline 30-34 & 130 & 17 & 13.1 & $1.0^{\star}$ & & & 73 & 29 & 39.7 & $1.0^{\star}$ & & \\
\hline$\geq 35$ & 77 & 29 & 37.7 & 4.02 & $2.02-7.99$ & $0.000^{\star \star}$ & 21 & 7 & 33.3 & 0.76 & $0.27-2.11$ & 0.596 \\
\hline Missing & 8 & & & & & & 0 & & & & & \\
\hline \multicolumn{13}{|l|}{ Parity } \\
\hline Nulliparous & 161 & 25 & 15.5 & $1.0^{\star}$ & & & 97 & 34 & 35.1 & $1.0^{\star}$ & & \\
\hline Multiparous & 157 & 31 & 19.7 & 1.34 & $0.75-2.39$ & 0.325 & 91 & 38 & 41.8 & 1.33 & $0.37-1.28$ & 0.238 \\
\hline Missing & 8 & & & & & & 0 & & & & & \\
\hline \multicolumn{13}{|l|}{ Ethnicity } \\
\hline European & 300 & 50 & 16.7 & $1.0^{\star}$ & & & 167 & 65 & 38.9 & $1.0^{*}$ & & \\
\hline Non-European & 16 & 6 & 37.5 & 3.00 & $1.04-8.63$ & $0.042^{\star \star}$ & 19 & 7 & 36.8 & 0.92 & $0.34-2.45$ & 0.860 \\
\hline Missing & 10 & & & & & & 0 & & & & & \\
\hline \multicolumn{13}{|l|}{ Education } \\
\hline Primary/secondary & 143 & 21 & 14.7 & 0.68 & $0.38-1.24$ & 0.209 & 80 & 31 & 38.8 & 1.05 & $0.57-1.92$ & 0.877 \\
\hline Tertiary & 174 & 35 & 20.1 & $1.0^{*}$ & & & 101 & 38 & 37.6 & $1.0^{\star}$ & & \\
\hline Missing & 9 & & & & & & 0 & & & & & \\
\hline \multicolumn{13}{|l|}{ Care setting } \\
\hline Midwifery & 161 & 16 & 9.9 & $1.0^{*}$ & & & 0 & 0 & 0 & & & \\
\hline Obstetrical & 157 & 40 & 25.5 & 3.10 & $1.65-5.81$ & $0.000^{\star \star}$ & 188 & 72 & 38.3 & & & \\
\hline Missing & 8 & & & & & & 0 & & & & & \\
\hline \multicolumn{13}{|l|}{ Information } \\
\hline Yes & 235 & 47 & 20 & $1.0^{\star}$ & & & 66 & 22 & 33.3 & $1.0^{\star}$ & & \\
\hline No & 82 & 9 & 11 & 0.49 & $0.23-1.06$ & 0.069 & 122 & 50 & 41 & 1.39 & $0.74-2.60$ & 0.304 \\
\hline Missing & 9 & & & & & & 0 & & & & & \\
\hline \multicolumn{13}{|l|}{ Attitude caregiver } \\
\hline Positive & 56 & 27 & 48.2 & 7.68 & $3.99-14.78$ & $0.000^{\star \star}$ & 24 & 13 & 54.2 & 2.10 & $0.89-4.99$ & 0.092 \\
\hline Negative & 2 & 1 & 50.0 & 8.25 & $0.50-135.6$ & 0.140 & 0 & 0 & & & & \\
\hline Neutral & 259 & 28 & 10.8 & $1.0^{\star}$ & & & 164 & 59 & 36.0 & $1.0^{\star}$ & & \\
\hline Missing & 9 & & & & & & 0 & & & & & \\
\hline \multicolumn{13}{|l|}{$\mathrm{PCS}^{\star \star \star}$} \\
\hline Total & 317 & 56 & 17.7 & 1.03 & $1.00-1.06$ & $0.043^{\star \star}$ & 184 & 69 & 37.5 & 1.01 & $0.98-1.04$ & 0.540 \\
\hline Rumination & 317 & 56 & 17.7 & 1.08 & $1.00-1.17$ & $0.042^{\star \star}$ & 185 & 70 & 37.8 & 0.99 & $0.92-1.06$ & 0.779 \\
\hline Magnification & 317 & 56 & 17.7 & 1.05 & $0.93-1.18$ & 0.436 & 185 & 70 & 37.8 & 1.03 & $0.91-1.17$ & 0.622 \\
\hline Helplessness & 317 & 56 & 17.7 & 1.08 & $1.01-1.16$ & $0.025^{\star \star}$ & 186 & 71 & 38.2 & 1.04 & $0.97-1.11$ & 0.284 \\
\hline Missing & 9 & & & & & & & & & & & \\
\hline \multicolumn{13}{|l|}{$B E A Q^{\star \star \star}$} \\
\hline Lower coping & 314 & 56 & 17.8 & 3.87 & $2.56-5.585$ & $0.000^{\star \star}$ & 188 & 72 & 38.3 & 3.73 & $2.36-5.91$ & $0.000^{\star \star}$ \\
\hline Missing & 12 & & & & & & & & & & & \\
\hline
\end{tabular}




\section{Variables contributing to prelabour epidural analgesia preference in the Netherlands}

Table II summarises the results of the univariate analysis of variables contributing to PEA in both The Netherlands and Belgium. In The Netherlands, women with PEA were significantly more often 35 years or older (crude OR 4.02; 95\%-Cl 2.02 to 7.99, $p$-value 0.000 ), of non-European origin (crude OR 3.00; 95\%-Cl 1.04 to $8.63, p$-value 0.042 ) and under supervision of obstetrical care (crude OR 3.10; 95\%-CI 1.65 to 5.81, $p$-value 0.000). Women with PEA only just reach significance with a higher score on the PCS (crude OR 1.03; $95 \%-\mathrm{Cl} 1.00$ to $1.06, p$-value 0.043 ) and its subscales rumination (crude OR 1.08; 95\%-Cl 1.00 to 1.17, p-value 0.042) and helplessness (crude OR 1.08; 95\%-Cl 1.01 to 1.16, p-value 0.025). Women with PEA showed a significantly lower degree of coping (crude OR 3.87 ; $95 \%-\mathrm{Cl} 2.56$ to 5.85 , $p$-value 0.000$)$.

Table III shows the results of a multiple logistic regression analysis, which analysed the association of independent variables with PEA. In The Netherlands, women 35 years or older (OR 4.95; 95\%-Cl 2.03 to 12.08 , $p$-value 0.000 ), positive attitude of the caregiver towards epidural analgesia (OR 5.83; 95\%-Cl 2.57 to $13.23, p$-value 0.000 ) and a lower degree of coping (OR 3.61; 95\%-Cl 2.24 to 5.82, $p$-value 0.000 ) were significantly independently associated with PEA.

\section{Variables contributing to prelabour epidural analgesia preference in Belgium}

Univariate analysis (Table II) showed a significantly lower degree of coping for Belgian women with PEA (crude OR 3.73; 95\%-Cl 2.36-5.91, p-value 0.000). A lower degree of coping had the strongest association with PEA as shown in table III (OR 4.06; 95\%-CI 2.456.73, $p$-value 0.000). 
Table III. Results of multivariate logistic regression analysis of variables contributing to prelabour epidural analgesia preference in Dutch and Belgian women

\begin{tabular}{|c|c|c|c|c|c|c|}
\hline \multirow{2}{*}{ Variables } & \multicolumn{3}{|c|}{$\begin{array}{l}\text { The Netherlands } \\
\text { Epidural Analgesia preference }\end{array}$} & \multicolumn{3}{|c|}{$\begin{array}{l}\text { Belgium } \\
\text { Epidural Analgesia preference }\end{array}$} \\
\hline & OR & $95 \%-\mathrm{Cl}$ & $P$ & OR & $95 \%-\mathrm{Cl}$ & $P$ \\
\hline \multicolumn{7}{|l|}{ Age } \\
\hline$<25$ & 0.40 & $0.05-3.41$ & 0.401 & 0.73 & $0.18-2.94$ & 0.656 \\
\hline $25-29$ & 1.14 & $0.41-3.17$ & 0.801 & 1.10 & $0.50-2.36$ & 0.812 \\
\hline $30-34$ & $1.0^{\star}$ & & & $1.0^{\star}$ & & \\
\hline$\geq 35$ & 4.95 & $2.03-12.08$ & $0.000^{\star \star}$ & 1.04 & $0.29-3.73$ & 0.950 \\
\hline \multicolumn{7}{|l|}{ Ethnicity } \\
\hline European & $1.0^{*}$ & & & $1.0^{\star}$ & & \\
\hline \multicolumn{7}{|l|}{ Care setting } \\
\hline Midwifery & $1.0^{*}$ & & & - & & \\
\hline Obstetrical & 1.60 & $0.71-3.64$ & 0.261 & - & & \\
\hline \multicolumn{7}{|c|}{ Attitude caregiver } \\
\hline Positive & 5.83 & $2.57-13.23$ & $0.000^{\star \star}$ & 1.65 & $0.52-5.21$ & 0.392 \\
\hline Negative & 7.44 & $0.38-144.38$ & 0.185 & - & & \\
\hline Neutral & $1.0^{*}$ & & & $1.0^{*}$ & & \\
\hline \multicolumn{7}{|l|}{$\mathrm{PCS}^{\star \star \star}$} \\
\hline Rumination & 1.04 & $0.89-1.22$ & 0.597 & 0.92 & $0.81-1.04$ & 0.192 \\
\hline Magnification & 0.96 & $0.77-1.19$ & 0.690 & 0.96 & $0.81-1.23$ & 0.960 \\
\hline Helplessness & 1.03 & $0.88-1.20$ & 0.730 & 1.07 & $0.94-1.22$ & 0.311 \\
\hline \multicolumn{7}{|l|}{$\mathrm{BEAQ}^{\star \star \star}$} \\
\hline Lower coping & 3.61 & $2.24-5.82$ & $0.000^{\star \star}$ & 4.06 & $2.45-6.73$ & $0.000^{\star \star}$ \\
\hline
\end{tabular}

\section{Discussion}

In both countries; a lower degree of coping labour pain is independently associated with PEA. In The Netherlands, furthermore, maternal age of 35 or older and a positive attitude of the caregiver towards epidural analgesia were significantly independently associated with the prefererıce for epidural analgesia. Remarkably, care setting was not significantly associated with PE in the multivariate analysis. Differences in other factors between care settings could explain this: women in midwifery care are younger and they have better coping skills, reflecting an adequate risk selection mechanism. On the other hand, a more positive attitude of the obstetrical caregiver could also play a role. In our study, only in the Dutch group was maternal age of 35 or older associated with an increased PEA. Other 
studies reported conflicting results about the effect of age on EA use as well. ${ }^{8,17,18}$ In The Netherlands, more women viewed the attitude of their caregiver to EA as "positive" than in Belgium and this had an effect on their PEA. In Belgium, such an effect was lacking; women were informed less often but still overall the PEA was much higher $(38.3 \%$ vs. 17.6\%). This suggests that in The Netherlands, EA is discussed as an option in which the opinion of the caregiver is important, while in Belgium, EA is considered more as general care, and not discussed before labour. It is known that women's preferences are influenced by the caregiver, the medical team and overall the general organisation of the care system. ${ }^{8}$

In The Netherlands as well as in Belgium, women who expressed PEA experienced a lower degree of coping with labour pain before labour started. Veringa et al. recently studied the impact of internal pain control, external pain control, catastrophising and coping with pain on the request for pain relief. ${ }^{19}$ They found catastrophising to be the strongest and independent predictor for the request for pain relief during the first stage of labour (adjusted OR 2.61, 95\%-Cl 1.45 to 4.67). ${ }^{19}$ They, however, measured the request for pain relief in general and not specifically EA and studied low risk nulliparous women.19 Furthermore, the questionnaires are not comparable with those in our study. This study showed no association between pain catastrophising and PEA, which was consistent with earlier research that found no relationship between pain catastrophising and the actual final choice for EA during labour. ${ }^{15}$

To our knowledge, this is the first study to investigate independently related variables to the PEA in The Netherlands with low EA use, and Belgium with a high EA rate. The study has several limitations. First, experience of the previous delivery (EA or not, complicated or not) was not included in the analysis. Secondly, in the analysis we compared women who reported that they preferred EA with all the other women, who either did not prefer EA or did not make a decision about pain relief yet. Finally, response rates between the groups were different and this might have led to sample selection bias.

This study has several clinical implications. We identified some factors that may influence PEA. We noticed different variables to be important in PEA in a country with relatively low EA use like The Netherlands. In Belgium, only a lower degree of coping contributed significantly to PEA and all other factors were not relevant. This finding reflects the 
cultural acceptance of EA in Belgium and confirms the opinion that labour pain is needless inconvenience. With the increasing trend for EA use, it is important to gain insight not only into the risks and benefits of EA, but also the contributing factors to the countryspecific prelabour preference. This educates the caregivers who support women to make an informed choice about labour pain relief. Besides, understanding of prelabour preferences contributes to the birth experience.

In conclusion, in both The Netherlands and Belgium, women with a lower degree of coping had a higher prelabour epidural analgesia preference. Care setting in The Netherlands was not an independent variable. 


\section{Reference List}

1. Hodnett ED. Pain and women's satisfaction with the experience of childbirth: a systematic review. Am J Obstet Gynecol 2002;186:S160-172.

2. Lally JE, Murtagh MJ, Macphail S, Thomson R. More in hope than expectation: a systematic review of women's expectations and experience of pain relief in labour. BMC Med 2008;6:7.

3. Brown JB, Carroll J, Boon H, Marmoreo J. Women's decision-making about their health care: views over the life cycle. Patient Educ Couns 2002;48:225-231.

4. Lowe NK. The nature of labor pain. Am J Obstet Gynecol 2002;186:S16-S24.

5. Anim Somuah M, Smyth R, Howell C. Epidural versus non-epidural or no analgesia in labour. Cochrane Database Syst Rev 2005;4:CD000331.

6. Leighton BL, Halpern SH. The effects of epidural analgesia on labor, maternal, and neonatal outcomes: a systematic review. Am J Obstet Gynecol 2002;186:S69-S77.

7. The Netherlands Perinatal Registry. Reports Perinatal care in the Netherlands [in Dutch]. Utrecht: The Netherlands Perinatal Registry;2003-2008.

8. Le Ray C, Goffinet F, Palot M, Garel M, Blondel B. Factors associated with the choice of delivery without epidural analgesia in women at low risk in France. Birth 2008;35:171-178.

9. The Netherlands Perinatal Registry. Perinatal Care in the Netherlands [in Dutch]. Utrecht: The Netherlands Perinatal Registry;2007-2009.

10. Christiaens W, Verhaeghe M, Bracke P. Pain acceptance and personal control in pain relief in two maternity care models: a cross national comparison of Belgium and the Netherlands. BMC Health Serv Res 2010;10:268.

11. Intermutualistisch Agentschap: Prenatal Care in Belgium (Dutch title: Prenatale zorg in België). IMA 2007.
12. Rijnders $M$, Baston $H$, Schönbeck $Y$, van der Pal K, Prins M, Green J, Buitendijk S. Perinatal factors related to negative or positive recall of birth experience in women 3 years postpartum in the Netherlands. Birth 2008;35:107-116.

13. Sullivan MJL, Bishop SR, Pivik J. The Pain Catastrophizing Scale: development and validation. Psychol Assess 1995;7:524-532.

14. Van Damme S, Crombez G, Bijttebier P, Goubert L, Van Houdenhove B. A confirmatory factor analysis of the pain catastrophizing scale: invariant factor structure across clinical and non-clinical populations. Pain 2002;96:319-324.

15. Van den Bussche E, Crombez G, Eccleston C, Sullivan MJ. Why women prefer epidural analgesia during childbirth: the role of beliefs about epidural analgesia and pain catastrophizing. Eur J Pain 2007;11:275-282.

16. SPSS ${ }^{\circledR}$ software, version 18.0, SPSS Inc. Chicago, IL, USA

17. Hueston WJ, McClaflin RR, Mansfield CJ, Rudy M. Factors associated with the use of intrapartum epidural analgesia. Obstet Gynecol 1994;84:579-582.

18. Harkins J, Carvalho B, Evers A, Mehta S, Riley ET. Survey of the Factors Associated with a Woman's Choice to Have an Epidural for Labor Analgesia. Anesthesiol Res Pract 2010;2010:1-8.

19. Veringa I, Buitendijk S, de Miranda E, de Wolf S, Spinhoven P. Pain cognitions as predictors of the request for pain relief during the first stage of labor: a prospective study. J Psychosom Obstet Gynecol 2011;32:119-125. 


\section{Appendix I}

Questions about epidural analgesia preference, labour analgesia information and caregiver's attitude.

Choose one of the three options below:

$\square$ I would choose epidural analgesia during labour.

$\square$ I would never choose epidural analgesia during labour.

$\square$ I do not know yet if I would choose epidural analgesia during labour.

1. Have you had information about labour pain management during your pregnancy?

$\square$ Yes

$\square$ If no, continue with question number 5 .

2. On whose initiative this information was given?

Own initiative

$\square$ Initiative of the caregiver (doctor/ midwife)

3. Were the various methods of labour pain management discussed?

$\square$ Yes

$\square$ No

4. Were the advantages and disadvantages of the several methods of labour pain management discussed?

$\square$ Yes

$\square$ No

5. How was the attitude of your caregiver towards epidural analgesia?

Positive

Neutral

Negative

Do not know 
3 Epidural analgesia and

operative delivery:

a ten-year population

based cohort study in

The Netherlands

\author{
MMLH WASSEN \\ CWPM HUKKELHOVEN \\ HCJ SCHEEPERS \\ LJM SMITS \\ JG NIJHUIS \\ FJME ROUMEN
}




\section{Abstract}

\section{Objective}

To describe trends in the use of epidural analgesia (EA) and to evaluate the association of EA with operative deliveries.

\section{Study Design}

In this population-based, retrospective cohort study, women with an intention to deliver vaginally of a term, cephalic, singleton between 2000 and 2009 ( $n=1378$ 458) were included. Main outcome measures were labour EA rates, unplanned caesarean section (CS), and instrumental vaginal delivery (IVD) including deliveries by either vacuum or forceps. Data were obtained from the Perinatal Registry of the Netherlands and logistic regression analyses were used.

\section{Results}

Among nulliparous, EA use almost tripled over the 10-year span (from $7.7 \%$ to $21.9 \%$ ), while rates of CS and IVD did not change much ( $+2.8 \%$ and $-3.3 \%$, respectively). Among multiparous, EA use increased from $2.4 \%$ to $6.8 \%$, while rates of CS and IVD changed slightly $(+0.8 \%$ and $-0.7 \%$, respectively). Multivariable analysis showed a positive association of EA with CS, which weakened in ten years, from an adjusted OR of $2.35(95 \%-\mathrm{Cl}, 2.18$ to $2.54)$ to $1.69(95 \%-\mathrm{Cl}, 1.60$ to $1.79 ; \mathrm{p}<0.001)$ in nulliparous, and from an adjusted $\mathrm{OR}$ of $3.17(95 \% \mathrm{Cl}, 2.79$ to 3.61$)$ to $2.56(95 \% \mathrm{Cl}, 2.34$ to $2.81 ; \mathrm{p}<0.001)$ in multiparous women. $\mathrm{A}$ weak inverse association between EA and IVD was found among nulliparous (adjusted OR, $0.76 ; 95 \%-\mathrm{Cl}, 0.75$ to 0.78 ), and a positive one among multiparous women (adjusted OR, 2.08; 95\%-Cl, 2.00 to 2.16). Both associations grew slightly weaker over time.

\section{Conclusions}

A near triplication of EA use in The Netherlands in ten years was accompanied by relatively stable rates of operative deliveries. The association between EA and operative delivery became weaker. This supports the idea that EA is not an important causal factor of operative deliveries. 


\section{Introduction}

Throughout the years, many studies have been conducted to study the association of the use of epidural analgesia during labour (EA) with an increased risk of operative delivery. Earlier literature suggested that EA was associated with an increased risk of caesarean section (CS) ${ }^{1-4}$ More recent randomized controlled trials ${ }^{5,6}$ and systematic reviews, ${ }^{7-9}$ however, concluded that EA does not increase the CS rate. A Cochrane systematic review did reveal an increased risk of instrumental vaginal delivery (IVD) (RR, 1.42; 95\%-CI, 1.28 to 1.57 ; 23 trials, 7935 women), but no increased risk of CS (RR, 1.10; 95\%-Cl, 0.97 to 1.25; 27 trials, 8417 women). ${ }^{10}$ Furthermore, a systematic review showed no increased risk of CS or IVD for nulliparous women receiving early EA at three centimetres or less cervical dilation in comparison with late EA. ${ }^{11}$

In many countries, the use of EA during labour still increases. ${ }^{12-16}$ Traditionally, in The Netherlands, labour EA use was restricted. However, EA use increased from 5.4\% in 2003 to $17.9 \%$ in 2012. ${ }^{17}$ This trend was attributable to a decreased reluctance of caregivers towards EA and the increasing request of labouring women for effective pain relief. Besides, the publication of a multidisciplinary guideline of the Dutch Societies of Obstetrics \& Gynaecology, and Anaesthesiology in 2008, advising adequate pain relief upon request for labouring women, with EA as the preferred method also contributed to the increased use. ${ }^{18}$

The increase in EA rate in the past ten years allows us to study the effect of a more liberal EA use on the rate of operative deliveries. The purpose of this study was to evaluate whether the increasing trend of EA use over a period of ten years in our country was accompanied by an increase of CS or IVD (including deliveries by either vacuum or forceps) rates, as might be expected under the condition of a strong causal association between the two. We also assessed whether the association between EA and CS/IVD rates weakened over time, as might be expected in an era in which use of EA becomes more liberal and less problem-driven. 


\section{Materials and Methods}

\section{Study population}

Data for this retrospective cohort study were obtained from the Perinatal Registry of the Netherlands (PRN). This nationwide database contains the linked and validated data from three registries: the national obstetric database for midwives (LVR-1), which includes the home deliveries that account for about $22 \%$ of all deliveries; the national obstetric database for gynaecologists (LVR-2); and the national neonatal/paediatric database (LNR). The PRN database includes $96 \%$ of the approximately 180000 yearly deliveries in the Netherlands that occur after 16 weeks' gestation. ${ }^{17}$

For the present study, data were collected on women who delivered between January 1 , 2000 and January 1, 2010. The study population included women who delivered live born singletons in cephalic position between $37^{+0}$ weeks $-<42^{+0}$ weeks' gestation. Women with a planned CS and women who delivered foetuses with congenital anomalies were excluded from analysis. The trial was reported in concordance with the STROBE statement. ${ }^{19}$

\section{Outcome measures}

The primary study outcome was operative delivery, defined as either unplanned CS, or IVD (including deliveries by either vacuum or forceps).

\section{Statistical analysis}

Labour characteristics in nulliparous and multiparous women were evaluated using contingency tables and chi-square analysis. Logistic regression analyses were used to study the association between EA and our primary outcomes. For each outcome we calculated the odds ratio (OR) and 95\% confidence interval ( $\mathrm{Cl}$ ) and adjusted for potential confounders known to be related to EA and CS or IVD. Potential confounders related to EA and CS or IVD were selected from literature or on clinical experience. The following potential antepartum confounders were selected: socioeconomic status (based on the mean household income level of the neighbourhood, with neighbourhood determined by the first four digits of the woman's postal code); conception by in vitro fertilisation techniques; ${ }^{20,21}$ parity; ${ }^{22-24}$ maternal age; ${ }^{22-25}$ and western ethnicity (defined as European). ${ }^{26}$ The selected potential intrapartum confounders were: gestational age at delivery: ${ }^{23}$ start 
of labour (induced versus spontaneous);21-24 oxytocin augmentation; $22,24,25$ referral during pregnancy or labour (from midwifery care to obstetrical care); delivery under supervision of a midwife or obstetrician; ${ }^{22,27}$ prolonged rupture of membranes, defined as a period of greater than 24 hours from rupture to delivery; time of start pushing (only women who reached a fully dilated cervix);22 and fetal head position (occiput, face, brow or other and unknown head presentation). ${ }^{22,28}$ The fetal birth weight was also included in the analysis. ${ }^{24}$ We also investigated trends in the association between EA and operative delivery over time by including interaction terms between EA and year in the statistical models. In addition, logistic regression analysis was used to investigate trends in EA and operative delivery over the 10-year study period. All $p$-values of $<0.05$ were considered statistically significant. Missing values were imputed once with single imputation ${ }^{29}$, because only a small percentage of data were missing (0.85\%), using R software (The R Foundation, Vienna, Austria). ${ }^{30-32}$ All other analyses were performed using SAS software, version 9.1 (SAS Institute, Cary, NC, USA).

\section{Results}

A total of 1798943 deliveries were registered in the PRN between 2000 and 2009. Of these, 1378458 deliveries were included in the present study. A total of 616063 (44.7\%) deliveries were to nulliparous women and 762395 (55.3\%) were to multiparous women (Figure 1). The characteristics of the study participants are outlined in Table 1. 
Figure 1. Study population flowchart

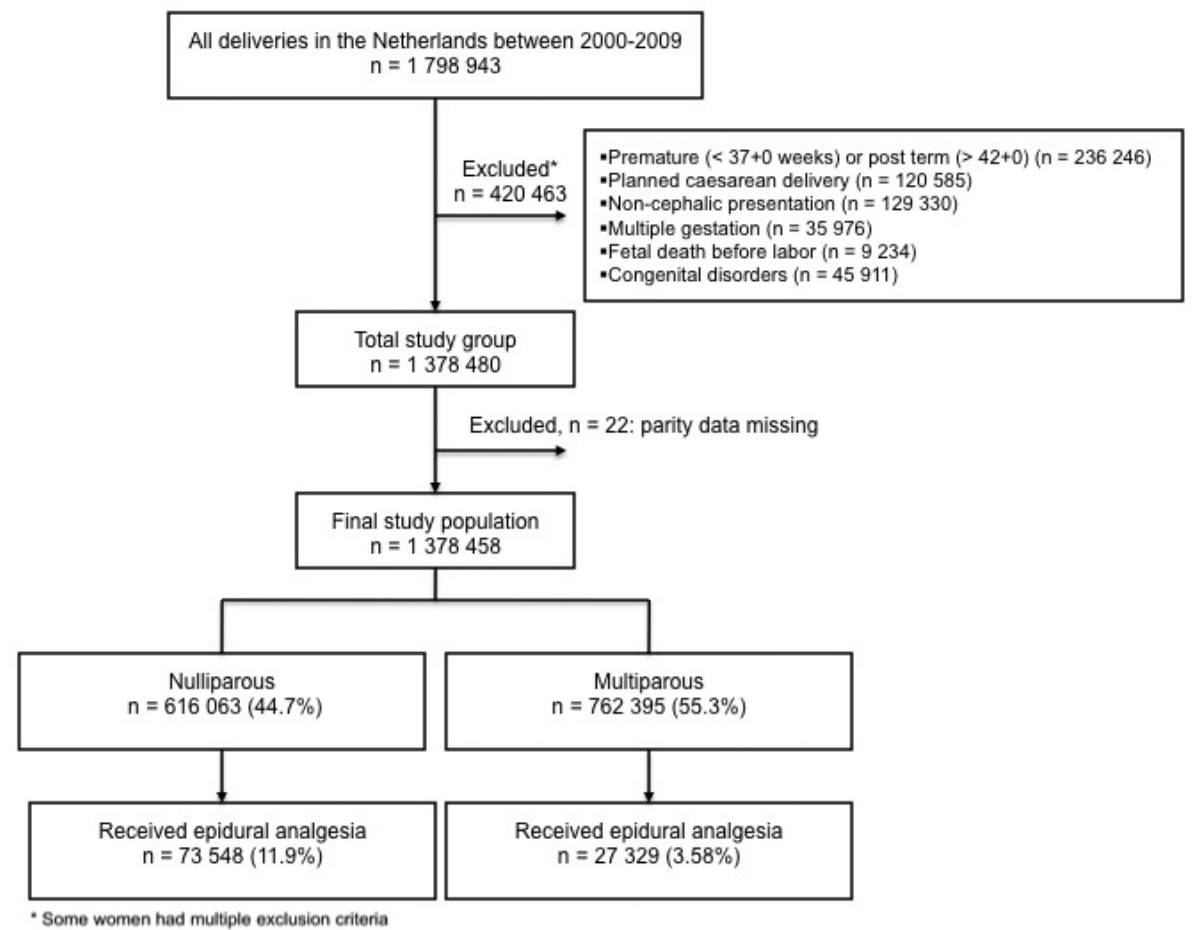

Labour EA was used in 73548 (11.9\%) nulliparous women, and in 27329 (3.6\%) multiparous women. Figure 2 shows the trends for the use of labour EA and proportion of CS and IVD, in both nulliparous and multiparous women, over the study period. In nulliparous women (Figure 2a), EA use increased from $7.7 \%$ to $21.9 \%$, while CS rate did not increase much (from $9.0 \%$ to $11.8 \% ; p<0.001$ ), and the proportion of IVDs decreased by $3.3 \%$ (from $22.7 \%$ to $19.4 \% ; p<0.001$ ). In multiparous women (Figure $2 \mathrm{~b}$ ), EA use increased from $2.4 \%$ to $6.8 \%$, while the percentage of CSs slightly increased (from $3.8 \%$ to $4.6 \% ; p<0.0001$ ), and the rate of IVDs decreased by $0.7 \%$ ( $4.1 \%$ to $3.4 \% ; p<0.001)$. 
Table I. Maternal, pregnancy and labour characteristics for nulliparous and multiparous women

\begin{tabular}{|c|c|c|}
\hline & $\begin{array}{l}\text { Nulliparous } \\
\text { ( } \mathrm{n}=616063)\end{array}$ & $\begin{array}{l}\text { Multiparous } \\
\text { ( } \mathrm{n}=762 \text { 395) }\end{array}$ \\
\hline Maternal age (y) & $28.6 \pm 4.8$ & $31.7 \pm 4.4$ \\
\hline Missing data & $94(0.0)$ & $104(0.0)$ \\
\hline Western ethnicity & $526556(86.0)$ & $626197(82.7)$ \\
\hline Missing data & $3465(0.6)$ & $5350(0.7)$ \\
\hline \multicolumn{3}{|l|}{ Socioeconomic status } \\
\hline - high & $138607(22.8)$ & $182545(24.3)$ \\
\hline - middle & $273857(45.1)$ & 347095 (46.2) \\
\hline - low & $194435(32.0)$ & $222121(29.6)$ \\
\hline Missing data & $9164(1.5)$ & $10634(1.4)$ \\
\hline IVF conception & $7419(1.8)$ & $3428(0.9)$ \\
\hline Missing data & 0 & 0 \\
\hline Gestational age (wk) & $39.5 \pm 1.2$ & $39.5 \pm 1.1$ \\
\hline Missing data & 0 & 0 \\
\hline Pregnancy and delivery midwifery care & $187250(30.4)$ & $381614(50.1)$ \\
\hline $\begin{array}{l}\text { Pregnancy and delivery obstetrical care } \\
\text { Referral midwifery to obstetrical care }\end{array}$ & $65535(10.6)$ & $131530(17.3)$ \\
\hline - during pregnancy & $131085(21.3)$ & $152760(20.0)$ \\
\hline - during first stage labour & $229836(37.4)$ & $94399(12.4)$ \\
\hline Missing data & $2357(0.4)$ & $2092(0.3)$ \\
\hline Labour induction & $78502(12.8)$ & $102055(13.4)$ \\
\hline Missing data & $1106(0.2)$ & $917(0.1)$ \\
\hline Oxytocin augmentation & 194827 (31.6) & $101501(13.3)$ \\
\hline Missing data & 0 & 0 \\
\hline PROM & 67459 (11.2) & $36143(4.7)$ \\
\hline Missing data & $11445(1.9)$ & $38076(5.0)$ \\
\hline Epidural analgesia & 73548 (11.9) & 27329 (3.6) \\
\hline Missing data & 0 & 0 \\
\hline Systemic analgesia & $94870(15.4)$ & 54364 (7.1) \\
\hline Missing data & 0 & 0 \\
\hline \multicolumn{3}{|l|}{ Time of start of pushing ${ }^{\star}$} \\
\hline •00.00-07.59h & $168134(29.4)$ & 248507 (33.8) \\
\hline • 08.00-17.59h & $266381(46.6)$ & $334633(45.5)$ \\
\hline • $18.00-23.59 \mathrm{~h}$ & $137166(24.0)$ & $152933(20.8)$ \\
\hline Missing data & 0 & 0 \\
\hline \multicolumn{3}{|l|}{ Fetal head position } \\
\hline - occiput presentation & $569861(92.5)$ & $735103(96.4)$ \\
\hline - face presentation & $761(0.1)$ & $1205(0.2)$ \\
\hline - brow presentation & $966(0.2)$ & $992(0.1)$ \\
\hline - Other or unknown & $44475(7.2)$ & $25095(3.3)$ \\
\hline \multicolumn{3}{|l|}{ Mode of delivery } \\
\hline - spontaneous & $426502(69.2)$ & $702748(92.2)$ \\
\hline - instrumental vaginal & $126979(20.6)$ & $28356(3.72)$ \\
\hline - unplanned caesarean section & $62582(10.2)$ & $31291(4.10)$ \\
\hline Missing data & 0 & 0 \\
\hline Birth weight (g) & $3428 \pm 471$ & $3594 \pm 488$ \\
\hline Missing data & 0 & 0 \\
\hline
\end{tabular}

Data are presented as mean

( \pm standard deviation) or as $\mathrm{n}(\%)$

IVF: in vitro fertilization; PROM: prolonged rupture of membrane

${ }^{*} \mathrm{n}=571681$ in nulliparous women and $n=736073$ in multiparous women 
Results of multivariable logistic regression analysis showed a positive association between EA use in labour and unplanned CS in both nulliparous women (adjusted OR, 1.99; 95\%-Cl, 1.95 to 2.03) and multiparous women (adjusted OR, 2.86; 95\%-Cl, 2.76 to 2.97). As shown in Figures 3 and 4, a gradual but statistically significant decline in the association between EA and unplanned CS was noted per year with advancing years; this decline was independent of parity. In nulliparous women, the adjusted OR changed from 2.35 in 2000 (95\%-Cl, 2.18 to 2.54) to 1.69 in 2009 (95\%-Cl, 1.60 to 1.79; $p<0.001$ ). In multiparous women, the adjusted OR decreased from 3.17 in 2000 (95\%-Cl, 2.79 to 3.61) to 2.56 in 2009 (95\%-Cl, 2.34 to $2.81 ; \mathrm{p}<0.001)$ in 2009.

The association between EA use in labour and IVD over the total ten-year period was negative among nulliparous women, (adjusted OR, 0.76; $95 \%-\mathrm{Cl}, 0.75$ to 0.78 ), and positive in multiparous women (adjusted OR, 2.08; 95\%-Cl, 2.00 to 2.16). As shown in Figures 3 and 4, the negative association between EA and an IVD in nulliparous women somewhat weakened over the years, namely from an adjusted OR of 0.77 in 2000 (95\%-Cl, 0.72 to 0.83 ) to an adjusted OR of 0.88 in 2009 (95\%-Cl, 0.84 to 0.92; p < 0.001). In multiparous women, the adjusted OR slightly weakened over the years from 2.23 in 2000 (95\%-Cl, 1.95 to 2.56 ) to 2.04 in 2009 (95\%-Cl, 1.85 to 2.26 ; $\mathrm{p}=0.78)$.

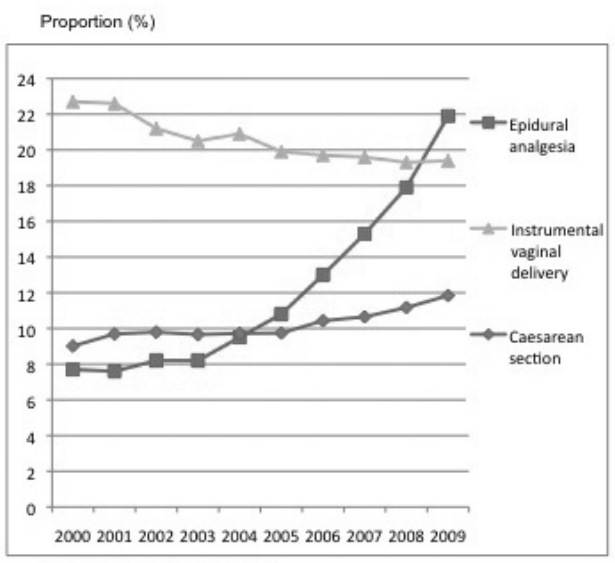

Figure 2a Nulliparous women

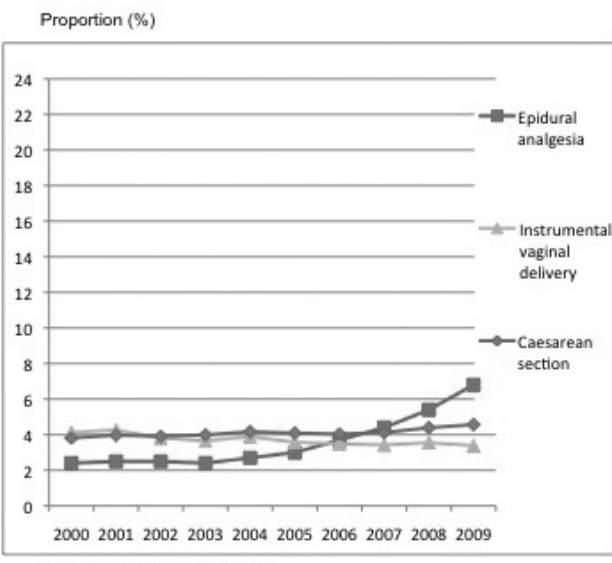

Figure $2 b$ Multiparous women 


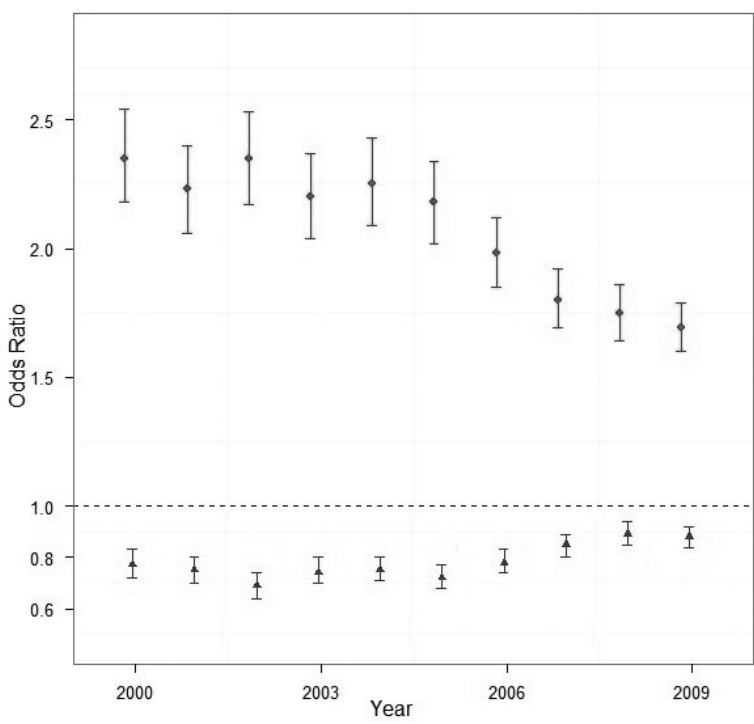

Figure 3. Association (adjusted odds ratio) of epidural analgesia during labour and operative deliveries in nulliparous women

Mode of delivery

$\rightarrow$ Caesarean

$\leftarrow$ Instrumental vaginal

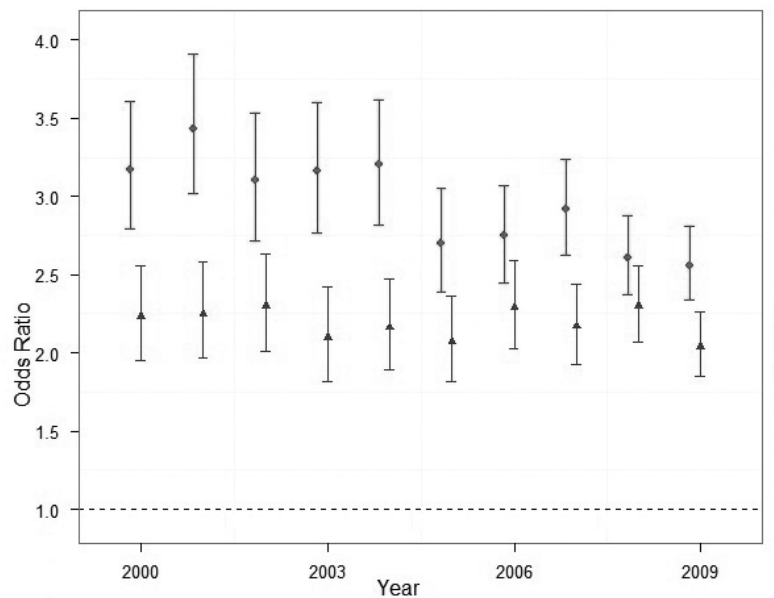

Figure 4. Association (adjusted odds ratio) of epidural analgesia during labour and operative deliveries in multiparous women

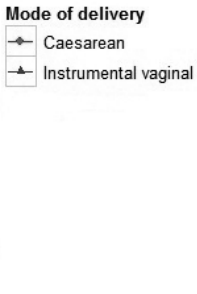

Data adjusted for socioeconomic status, conception by in-vitro-fertilisation techniques, parity, maternal age and ethnicity, gestational age at delivery, spontaneous vs. induced labour, referral during pregnancy or during labour from midwifery to obstetrical care, delivery under supervision of a midwife or obstetrician, prolonged rupture of membranes, time of day at the start of the second stage of labour, fetal head position, and birth weight. 


\section{Comment}

Main findings

In The Netherlands, the percentage of women who receive EA during labour nearly tripled in a 10 -year period in both nulliparous women (7.7\% to $21.9 \%)$ and multiparous women (2.4\% to $6.8 \%)$. Increasing EA use was not accompanied by increase in operative deliveries. The rate of operative deliveries remained relatively stable during this study period in nulliparous (CS rate increased 2.8\% and IVD rate decreased 3.3\%) and multiparous (CS rate increased $0.8 \%$ and IVD rate decreased $0.7 \%$ ) women. A positive association was found between EA and unplanned CS in nulliparous and multiparous women. Among nulliparous women a weak inverse association between EA and IVD was found. The association between EA and operative deliveries grew weaker with advancing years.

\section{Strengths and limitations}

The strength of this study is that it is the largest cohort with prospectively collected data in literature so far. This study has the scientific merit of a large collection of cases. The data are a good reflection of current obstetric practice in The Netherlands, being derived from a national database that includes around $96 \%$ of all deliveries over a recent 10 -year period. In addition, the present study reports data from both nulliparous and multiparous women; the majority of published studies on this topic only included nulliparous women. ${ }^{10}$ The present study has several limitations. First, the reliability of medical registry databases depends on accurate and correct data entry. However, the quality of the outcome measurement in this PRN database was published to be high. ${ }^{33}$ Another disadvantage of this dataset is that a possible previous CS in the group multiparous could not be used in the analysis because of severe underreporting, possibly creating a stronger association between EA and CS or IVD in multiparous women. The percentage of women with a prior CS who undergo a trial of labour in The Netherlands is approximately $72 \%$, and the average vaginal birth after caesarean rate is $54.4 \% .{ }^{34}$ In addition, patients' socioeconomic status was based on the mean household income level of the neighbourhood determined by the first four digits of each woman's postal code, causing some misclassification. Moreover, our analysis may be hampered by the fact that we could not adjust for possible confounding factors not registered in the PRN, such as duration of first stage of labour. 
Therefore, residual confounding cannot be excluded. We expect that adjusting for more factors, preferably factors influencing caregivers' judgment of progression and risks during labour may also result in a weaker association between EA and instrumental deliveries. In addition, the decision to perform an operative delivery is a subjective outcome measure made by the individual caregiver. Besides, in ten years EA analgesics and methods changed and this possibly also affected the association between EA and mode of delivery in our study. An important restriction of this study is the Dutch obstetrical care system, which is based on risk selection and not comparable with many other countries. Independent midwives (primary or midwifery care) attend low risk pregnancies and deliveries at home or in a birth clinic where EA use and CS or IVD are not available. Nevertheless, we chose to analyse the whole Dutch labouring population (including midwifery led low-risk pregnancies) to compare our results with international studies. During the study period, the number of midwifery-led births decreased from $36.2 \%$ in 2000 to $31.8 \%$ in $2009 .{ }^{17}$ We assume that this is merely the result of changing attitude of women and caregivers towards a request for pain relief. Consequently, with advancing years EA was offered to more women with uncomplicated deliveries. Therefore, we also analysed hospital births only, excluding deliveries in primary care (data not shown). Comparable results were found over the study period. Because of the same results when excluding the lowrisk population we assume that the type of surveillance in labour does not influence this results. Besides the reason to receive labour EA was not known. One can expect a difference in labour outcome between patients, which receive EA electively when active labour starts, or women where EA is requested during labour due to pain or anxiety or women where EA is clinically indicated by the obstetrician because of labour dystocia. Recently, this study group showed also an increased risk for an operative delivery in women with elective EA compared to women who receive analgesia on request. ${ }^{35}$

\section{Interpretation}

Our findings of a positive association between labour EA and unplanned CS in both nulliparous and multiparous women contradict those of the majority of published literature. ${ }^{7-10}$ Only Sidelnick et al. showed in a population-based study of 41488 grand multiparous women, EA to be an independent risk factor for CS (OR 2.9; 95\%-CI 2.4 to 
3.5) with a comparable low (2.1\%) EA use. ${ }^{36}$ This was comparable with the almost triple risk for CS we found in multiparous women with an EA rate of 2.4\% in 2000. However, the weakened association between labour EA and unplanned CS with advancing years may also confirm the literature. The most probable explanation is a change in indication for EA in The Netherlands. Traditionally EA during labour was used restrictively because of several reasons. Firstly, for long time the midwifery model of care in The Netherlands defined childbirth as a normal physiological process, accepting pain as an accompanying phenomenon. ${ }^{37}$ Secondly, women who deliver under supervision of an independent primary care midwife are not able to get EA unless they are referred to obstetrician care. Thirdly, the limited availability of labour EA in Dutch hospitals may also contribute to this restrictive use. A cross-sectional telephone survey in 2010 showed 24/7 availability in only $57 \%$ of Dutch hospitals. ${ }^{38}$ Restrictive EA use resulted in a selection of women with severe pain associated with labours of long duration, or for those with serious obstetrical pathology. An increased unplanned CS rate can surely be expected in this population with restrictive EA use. Nowadays, in The Netherlands the use of EA is rapidly becoming more liberal on request of the labouring woman, as represented in this study by the steep increase in EA the last few years. We assume that more women without obvious labour pathology deliver with EA resulting in a weaker association between EA and unplanned CS over time. Another factor that can affect the percentage of CS, also described by Caruselli et al., is a higher experience of the obstetricians in managing a delivery with EA. ${ }^{39}$ In the present study, EA was associated with a decreased risk of IVD in nulliparous women, a finding that is in contrast with the results of the Cochrane review (RR, 1.42; 95\%-Cl, 1.28 to 1.57$).{ }^{10}$ Leushuis also found a minor protective effect of EA for expulsive second stage arrest in nulliparous women. ${ }^{22}$ This may be the result of the Dutch policy of expectant pushing in order to achieve a spontaneous vaginal delivery. The Dutch guideline 'instrumental vaginal delivery' defines second stage arrest in nulliparous after 2 hours without EA and 3 hours with EA. ${ }^{40}$ This philosophy is in accordance with the results of the Pushing Early or Pushing Late with Epidural (PEOPLE) study, showing that delayed pushing in nulliparous women with EA reduces the risk of instrumental delivery. ${ }^{41}$ 


\section{Conclusion}

In summary, this large Dutch national cohort study showed a near triplication in the use of EA over a 10-year period, which was not accompanied by strong increases or decreases of either CS or IVD. This lack of co-variation is an argument against strong causality of EA for CS and IVD. Although we found significant associations between EA use and CS/ IVD, the strength of the associations weakened over the 10-year study period. This is probably a reflection of a trend towards a more liberal, less problem-driven use of EA in The Netherlands. Further studies are needed to document the further evolution of the trends in EA use and CS/IVD and to separate causality from confounding in the association between the two.

\section{Reference List}

1. Thorp JA, Hu DH, Albin RM, McNitt J, Meyer BA, Cohen GR, et al. The effect of intrapartum epidural analgesia on nulliparous labor: a randomized, controlled, prospective trial. Am J Obstet Gynecol 1993;169:851-858.

2. Ramin SM, Gambling DR, Lucas MJ, Sharma SK, Sidawi JE, Leveno KJ. Randomized trial of epidural versus intravenous analgesia during labor. Obstet Gynecol 1995;86:783-789.

3. Lieberman E, Lang JM, Cohen A, D'Agostino R Jr, Datta S, Frigoletto FD Jr. Association of epidural analgesia with cesarean delivery in nulliparas. Obstet Gynecol 1996;88:993-1000.

4. Howell C, Chalmers I. A review of prospective controlled comparisons of epidural with nonepidural forms of pain relief during labour. Int J Obstet Anesth 1992;1:93-110.

5. Sharma SK, Alexander JM, Messick G, Bloom SL, Mclntire D, Wiley J, et al. Cesarean delivery: a randomized trial of epidural analgesia versus intravenous meperidine analgesia during labor in nulliparous women. Anesthesiology 2002;96:546551.

6. Halpern SH, Muir H, Breen TW, Campbell DC, Barret J, Liston R, et al. A multicenter randomized controlled trial comparing patient-controlled epidural with intravenous analgesia for pain relief in labor. Anesth Analg 2004;99:1532-1538.
7. Leighton BL, Halpern SH. The effects of epidural analgesia on labor, maternal, and neonatal outcomes: a systematic review. Am J Obstet Gynecol 2002;186:S69-77.

8. Liu EH, Sia AT. Rates of caesarean section and instrumental vaginal delivery in nulliparous women after low concentration epidural infusions or opioid analgesia: systemic review. BMJ 2004;328:14101412.

9. Sharma SK, McIntire DD, Wiley J, Leveno KJ. Labor analgesia and cesarean delivery: an individual patient meta-analysis of nulliparous women. Anesthesiology 2004;100:142-148.

10. Anim-Somuah M, Smyth RM, Jones L. Epidural versus non-epidural or no analgesia in labour. Cochrane Database Syst Rev 2011;12:CD000331.

11. Wassen MMLH, Zuijlen J, Roumen FJME, Smits LJM, Marcus MA, Nijhuis JG. Early versus late epidural analgesia and risk on instrumental delivery in nulliparous women: a systematic review. BJOG 2011;118:655-661.

12. Blondel B, Supernant K, Du Mazaubrun C, Bréart G; pour la Coordination nationale des Enquêtes Nationales Périnatales. Trends in perinatal health in metropolitan France between 1995 and 2003: results from the National Perinatal Surveys. J Gynecol Obstet Biol Reprod 2006;35:373-387. 
13. Statistical Database. The Danish National Board of Health. Copenhagen, Denmark: 2011. Available at: http://www.sst.dk/Indberetning\%20og\%20 statistik/Sundhedsdata.aspx.

14. Osterman MKJ, Martin MPH. Epidural and spinal anesthesia use during labor: 27-state reporting area, 2008. Natl Vital Stat Rep 2011;59:1-16. Available at: http://www.cdc.gov/nchs/data/nvsr/nvsr59/ nvsr59_05.pdf.

15. Health \& Social Care Information Centre Service. NHS Maternity Statistics, England 2012-2013. London, England: Community Health Statistics, 2013. Available at: http://www.hscic.gov.uk/ catalogue/PUB12744/nhs-mate-eng-2012-13summ-repo-rep.pdf

16. Cammu H, Martens E, Martens G, Van Mol C, Jacquemyn $Y$. Perinatale activiteiten in Vlaanderen 2011 [in Dutch]. Brussel: Studiecentrum voor Perinatale Epidemiologie (SPE); 2011.

17. The Netherlands Perinatal Registry. Perinatal care in the Netherlands 2003-2012 [in Dutch]. Utrecht: The Netherlands Perinatal Registry.

18. Schuurhuis A, Roumen FJ, de Boer JB; Working Group Anaesthesiology. Practice guideline 'Pharmaceutical pain treatment during labour'; the woman's request is sufficient indication [in Dutch]. Dutch J Med 2009;153:A551.

19. on Elm E, Altman DG, Egger M, Pocock SJ, Gøtzsche PC, Vandenbroucke JP; STROBE Initiative. The Strengthening the Reporting of Observational Studies in Epidemiology (STROBE) statement: guidelines for reporting observational studies. J Clin Epidemiol 2008;61:344-349.

20. Källén $B$, Finnström $O$, Nygren $K G$, Otterblad Olausson $P$, Wennerholm UB. In vitro fertilisation in Sweden: obstetric characteristics, maternal morbidity and mortality. BJOG 2005;112:1529-1535.

21. Buckett WM, Chian RC, Holzer H, Dean N, Usher $\mathrm{R}$, Tan SL. Obstetric outcomes and congenital abnormalities after in vitro maturation, in vitro fertilization, and intracytoplasmic sperm injection. Obstet Gynecol 2007;110:885-891.

22. Leushuis E, Tromp M, Ravelli AC, van Huis AM, Mol BW, Visser GH, et al. Indicators for intervention during the expulsive second-stage arrest of labour. BJOG 2009;116:1773-1781.
23. Feinstein U, Sheiner E, Levy A, Hallak M, Mazor M. Risk factors for arrest of descent during the second stage of labor. Int J Gynaecol Obstet 2002;77:7-14.

24. Schuit E, Kwee A, Westerhuis ME, Van Dessel HJ, Graziosi GC, Van Lith JM, et al. A clinical prediction model to assess the risk of operative delivery. BJOG 2012;119:915-923.

25. Roberts CL, Algert CS, Carnegie M, Peat B. Operative delivery during labour: trends and predictive factors. Paediatr Perinat Epidemiol 2002;16:115-123.

26. Jiménez-Puente A, Benítez-Parejo N, Del DiegoSalas J, Rivas-Ruiz F, Maañón-Di Leo C. Ethnic differences in the use of intrapartum epidural analgesia. BMC Health Serv Res 2012;12:207.

27. Overgaard C, Fenger-Grøn M, Sandall J. Freestanding midwifery units versus obstetric units: does the effect of place of birth differ with level of social disadvantage? BMC Public Health 2012;12:478.

28. Ponkey SE, Cohen AP, Heffner LJ, Lieberman E. Persistent fetal occiput posterior position: obstetric outcomes. Obstet Gynecol 2003;101:915-920.

29. Donders AR, van der Heijden GJ, Stijnen T, Moons KG. Review: a gentle introduction to imputation of missing values. J Clin Epidemiol 2006;59:1087-1091.

30. Little RJA. Regression with missing X's: a review. J Am Stat Assoc 1992;87:1227-1237.

31. Moons KG, Donders RA, Stijnen T, Harrell FE Jr. Using the outcome for imputation of missing predictor values was preferred. J Clin Epidemiol 2006;59:1092-1101.

32. $\mathrm{R}$ Developmental Core Team. A language and environment for statistical computing. Vienna: $R$ project for statistical computing; 2006. [cited April 2009]. Available from: http://www.R-project.org/.

33. Anthony S, van der Pal-de Bruin KM, Graafmans WC, Dorrepaal CA, Borkent-Polet M, van Hemel $\mathrm{OJ}$, et al. The reliability of perinatal and neonatal mortality rates: differential under-reporting in linked professional registers vs Dutch civil registers. Paediatr Perinat Epidemiol 2001;15:306-314. 
34. Kwee A, Bots ML, Visser GH, Bruinse HW. Obstetric management and outcome of pregnancy in women with a history of caesarean section in the Netherlands. Eur J Obstet Gynecol Reprod Biol 2007;132:171-176.

35. Wassen MMLH, Smits LJM, Scheepers HCJ, Marcus MAE, Van Neer J, Nijhuis JG, Roumen FJME. Routine labour epidural analgesia versus labour analgesia on request: a randomised non-inferiority trial. BJOG 2014 [Epub ahead of print].

36. Sidelnick C, Karmon A, Levy A, Greemberg L, Shapira Y, Sheiner E. Intra-partum epidural analgesia in grandmultiparous women. J Matern Fetal Neonatal Med 2009;22:348-352.

37. Christiaens W, Verhaeghe M, Bracke P. Pain acceptance and personal control in pain relief in two maternity care models: a cross national comparison of Belgium and the Netherlands. BMC Health Serv Res 2010;10:268.

38. Wassen MMLH, Buijs C, Nijhuis JG. Availability of epidural analgesia during labour in The Netherlands in 2010 [in Dutch]. Dutch J Obstet Gynaecol 2010;123:397-400.

39. Caruselli M, Camilletti G, Torino G, Pizzi S, Amici M, Piattellini G, et al. Epidural analgesia during labor and incidence of cesarian section: prospective study. J Matern Fetal Neonatal Med 2011;24:250-252.

40. Dutch Society Obstetrics and Gynaecology. Guideline: instrumental vaginal delivery [in Dutch]. Utrecht.2005

41. Fraser WD, Marcoux S, Krause I, Douglas J, Goulet C, Boulvain M. Multicenter, randomized, controlled trial of delayed pushing for nulliparous women in the second stage of labor with continous epidural analgesia. The PEOPLE (Pushing Early or Pushing Late with Epidural) Study Group. Am J Obstet Gynecol 2000;182:1165-1172. 
4 Early versus late epidural analgesia and risk on

instrumental delivery in

nulliparous women:

a systematic review

MMLH WASSEN

J ZUIJLEN

FJME ROUMEN

LJM SMITS

MA MARCUS

JG NIJHUIS 


\section{Abstract}

\section{Background}

The optimal timing of epidural analgesia during labour and delivery has been a controversial issue.

\section{Objective}

Review of the literature regarding the relation between the timing of epidural analgesia and the rate of caesarean or instrumental vaginal deliveries.

\section{Search strategy}

Pubmed, Embase and the Cochrane Library were searched for articles published until 31 July 2010.

\section{Selection criteria}

Studies were selected in which the effects of early latent phase (defined as a cervical dilatation of $3 \mathrm{~cm}$ or less) epidural analgesia (including combined-spinal epidural) and late active phase epidural analgesia on the mode of delivery in nulliparous women at 36 weeks of gestation or more were evaluated.

\section{Data collection and analysis}

Data extraction was completed by using a data-extraction form. Risk ratio and its 95\% confidence intervals were calculated for caesarean delivery and instrumental vaginal delivery. Pooled data were calculated.

\section{Main results}

The search retrieved 20 relevant articles, of which six fulfilled the selection criteria of inclusion. These six studies reported on 15399 nulliparous women in spontaneous or induced labour with a request for analgesia. Risk of caesarean delivery (pooled risk ratio $1.02,95 \% \mathrm{Cl} 0.96-1.08$ ) or instrumental vaginal delivery (pooled risk ratio $0.96,95 \% \mathrm{Cl}$ 0.89-1.05) was not significantly different between groups.

\section{Authors' conclusions}

This systematic review showed no increased risk of caesarean delivery or instrumental vaginal delivery for women receiving early epidural analgesia at cervical dilatation of $3 \mathrm{~cm}$ or less in comparison with late epidural analgesia. 


\section{Introduction}

Epidural analgesia (EA) is the most effective treatment for pain control during labour and delivery. ${ }^{1,2}$ The effect of regional analgesia on progress of labour and mode of delivery has often been debated. Results of randomised controlled trials (RCTs) and systematic reviews published between 2002 and 2004 did not demonstrate any difference in the rate of caesarean deliveries between women who had received EA and women who only received intravenous analgesia. ${ }^{1,3-6}$ A Cochrane review, published, in 2005, showed that EA was associated with an increased risk of instrumental vaginal birth (pooled risk ratio [RR] 1.38, 95\% Cl 1.24-1.53) compared with deliveries with nonepidural analgesia or no analgesia. ${ }^{2}$

A landmark study by Wong et al., ${ }^{7}$ published in 2005, provided evidence that early epidurals in comparison with late epidurals do not cause an increased rate of caesarean deliveries and instrumental vaginal deliveries in nulliparous women with spontaneous labour. Recently, more studies have been performed on the timing effect of EA related to the mode of delivery. A systematic review in 2007 by Marucci et al. ${ }^{8}$ reported on the timing effects of neuraxial analgesia on the mode of delivery. That review included five RCTs, one impact cohort study and three retrospective cohort studies, of which one contains only data from an abstract. A similar rate for caesarean delivery (odds ratio [OR] 1.00, 95\%-Cl 0.82 to 1.23 ) and instrumental vaginal delivery in the early neuraxial analgesia and control group (OR 1.00, 95\%-Cl 0.83 to 1.21) was shown. However, these latter results may not be convincing because of the use of a too broad definition of the early group (before 4-5 $\mathrm{cm}$ dilatation) and the use of an incomparable control group (including parenteral opioid and/or late EA). ${ }^{8}$

Friedman ${ }^{9}$ analysed 500 nulliparous women in 1955 and divided the first stage into an early latent phase and an ensuing active phase. He described the start of the active phase of labour at 3-4 cm cervical dilatation. The introduction of a national guideline in the Netherlands in 2008 on the management of labour pain resulted not only in an increase in EA requests, but also those requests being made at an earlier stage in the course of labour. ${ }^{10}$ Therefore we are interested in the effect of early EA strictly defined as $3 \mathrm{~cm}$ or less in the latent phase on the mode of delivery. 
The main objective of this report was to review recent literature on the influence of this stricter definition of early EA (including combined-spinal epidural) compared with late EA in nulliparous women at 36 weeks or more of gestation, on the rate of caesarean deliveries or instrumental vaginal deliveries.

\section{Methods}

\section{Searching and selection}

A search was made for RCTs, prospective cohort studies and retrospective cohort studies in which the effects of early EA (defined as cervical dilatation $<4 \mathrm{~cm}$ ) on the mode of delivery in nulliparous women have been studied.

We performed a search in the electronic databases Pubmed (Medline), EMBASE and the Cochrane Library until 31 July 2010. The following terms were used: 'Analgesia, epidural' [Mesh] AND ['caesarean section' [Mesh] OR 'instrumental vaginal delivery' OR 'Vacuum Extraction, Obstetrical' [Mesh]] AND [early OR timing OR 'Labor Stage, First' [Mesh]] Publication year or language restrictions on publication data were not applied. Cross-references of the selected studies were checked to identify other studies. Two authors (MW and JZ) independently performed the search and screened the abstracts of identified studies. Relevant abstracts were selected and full text articles were studied. Any disagreement was resolved with a third reviewer (FR) if necessary.

\section{Study population and eligibility criteria}

Women with a gestational age of at least 36 weeks, spontaneous or induced labour, with a singleton in vertex presentation were included in this review. Studies were included according to the following defined criteria:

1. RCTs and prospective and retrospective cohort studies.

2. Nulliparous women, 36 weeks or more of gestation with spontaneous or induced labour.

3. Comparison of early EA, defined as $3 \mathrm{~cm}$ or less, versus late $E A$ (at least $4 \mathrm{~cm}$ ).

4. Primary outcome was the rate of caesarean deliveries or instrumental vaginal deliveries.

Reviews and meta-analyses were excluded from analysis for this review. Only trials with a 
clear description of the type of analgesia used were included in the analysis. No publicly accessible protocol for this current systematic review is available. Primary outcome measure was the effect of early EA on the mode of delivery: instrumental vaginal delivery or caesarean delivery.

\section{Assessment of methodological quality and data extraction}

The systematic review was written in accordance with the PRISMA statement. ${ }^{11}$

The methodological quality of the RCTs was assessed by the Jadad criteria. ${ }^{12} \mathrm{~A}$ numerical score between zero and five is assigned as a rough measure of study reporting quality (zero being weakest and five being strongest).

Blinding of participants and caregiver as well as blinding of the outcome assessment was not possible because of the type of intervention. Therefore, the maximum score that could be given to these studies was three, according to the Jadad criteria.

Data extraction was independently completed by MW and JZ by using a data-extraction form. The following data were extracted from the selected RCTs: publication year, inclusion period, inclusion criteria, exclusion criteria, parity, gestational age, length, weight, randomisation procedure, description of cross-over, dropouts, withdrawals, power analysis, mode of delivery, indication for instrumental delivery and cervical dilatation at EA. No original or unpublished data were obtained from the investigators of the included studies.

\section{Data analysis}

Primary outcome measure was the effect of early EA on the mode of delivery: instrumental vaginal delivery or caesarean delivery. For each study separately, risk ratio and its 95\% confidence interval were calculated for dichotomous variables. Subsequently, data of all studies were pooled using the Mantel-Haenszel method. The presence of statistical heterogeneity was determined using $R^{2}$ statistics. This $R^{2}$ describes the percentage of variation across studies that are the result of heterogeneity rather than chance. Heterogeneity was considered substantial when $l^{2}$ was above $50 \% .^{13,14}$ Confidence intervals around $l^{2}$ were calculated using the statistical package $\mathrm{R} \cdot{ }^{15} \mathrm{After}$ exclusion of the heterogeneous studies, the pooled results were recalculated. Analysis was performed 
using Review Manager (RevMan) (Computer program, Version 5.0. Copenhagen: The Nordic Cochrane Centre, The Cochrane Collaboration, 2008).

\section{Results}

\section{Selected studies}

The search identified a total of 327 studies including 124 duplicates. Of the remaining 203, we excluded 183 after reviewing the abstracts. The full text of the remaining 20 articles was examined in more detail. This resulted in the exclusion of another 14 articles for the reasons explained in Figure 1. Finally, six studies; five RCTs and one retrospective cohort study appeared to be appropriate for review and fulfilled the inclusion criteria.

\section{Description of studies and characteristics}

The six selected studies involved a total of 15399 (range 60-12 793 women per study) nulliparous women with a gestational age of at least 36 weeks and a singleton in vertex presentation. Of the selected studies, five concerned nulliparous women only., ${ }^{716-19}$ The retrospective cohort study of Ohel and Harats ${ }^{20}$ presented results for both nulliparous and multiparous women. Only nulliparity-related results were included in this review, however. Description of the characteristics and interventions of the separate studies are presented in Table 1. Three RCTs included women in spontaneous labour, ${ }^{7,16,19}$ one RCT included women with induced labour, ${ }^{18}$ and one included both spontaneous and induced labour. ${ }^{17}$ The retrospective cohort study of Ohel did not report the start of labour. ${ }^{20}$ In the study of Luxman et al. ${ }^{16}$ early and late EA were compared. Women who were randomised to late EA received no other form of analgesia before EA administration. Continuous EA was achieved by using bupivacaïne $0.25 \%, 8 \mathrm{ml} /$ hour. $^{16}$ 


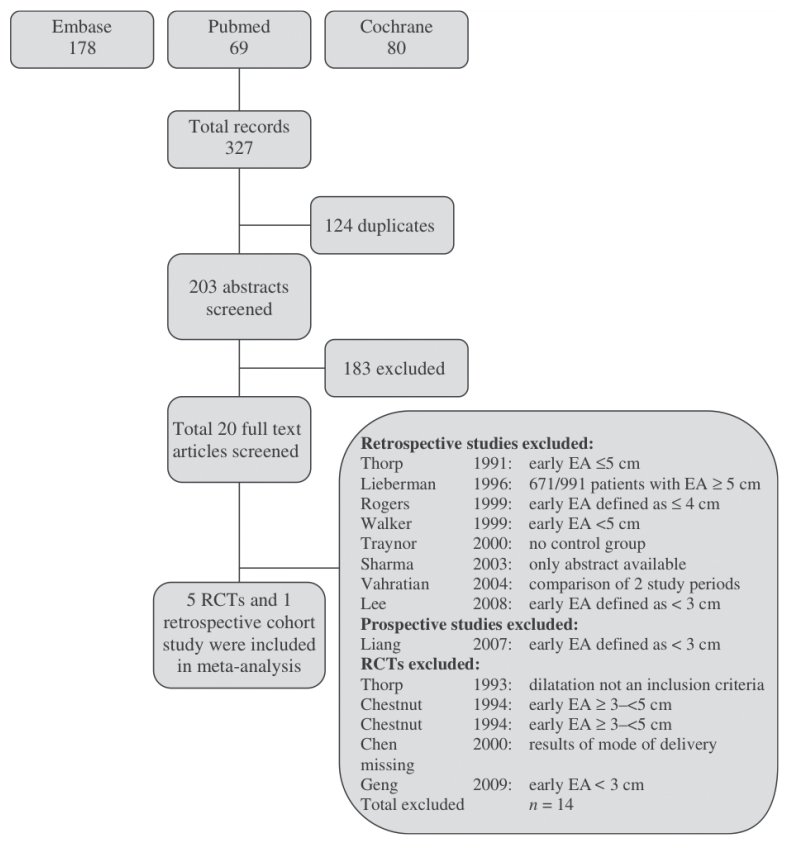

Figure 1. Flow diagram of literature search; EA, epidural analgesia.

Wong et al. ${ }^{7,18}$ randomised women after the first request for analgesia to receive intrathecal fentanyl or systemic hydromorphone. Subsequently patient-controlled epidural analgesia was initiated in the intrathecal group at the second request and in the systemic group at a cervical dilatation of at least $4 \mathrm{~cm}$ or at the third request for analgesia.

In the late intervention group of the RCT from Wong et al. ${ }^{7}$ in 2005 , protocol violations occurred in 11 women at the second request for analgesia and with a cervical dilatation of $<4 \mathrm{~cm}$. They refused the study drug and received EA. In the RCT from Wong et al. in 2009, ${ }^{18}$ 35 women in the late group received EA at second request when cervical dilatation was $<4 \mathrm{~cm}$.

The study by Ohel et al. ${ }^{17}$ compared early EA with early opioid (pethidine and promethazine iv) and late EA (at least 4-5 cm dilatation). The EA was maintained by a continuous infusion of ropivacaïne $0.1 \%$ with fentanyl $2 \mathrm{lg} / \mathrm{ml}$ at a rate of $10 \mathrm{ml} /$ hour. Boluses of 5-10 $\mathrm{ml}$ ropivacaïne $0.2 \%$ were given upon request. Significantly more women in the late group did not receive EA (13.6\%) in comparison with the early group (4.5\%; $P=0.0008)$. Wang et al. ${ }^{19}$ randomised between early EA versus early opioid (25 mg meperidine 
intramuscularly) and late EA when the cervix was at least $4 \mathrm{~cm}$ dilated. A patient- controlled EA pump was given with a $10-\mathrm{ml}$ bolus of $0.125 \%$ ropivacaïne and $0.3 \mu \mathrm{g} / \mathrm{ml}$ sufentanil without background infusion. In the late group protocol violation occurred in 41 of the 6399 women and they received EA when the cervix was <4 cm dilated; 102 women were randomly assigned to the early group whose cervix was $>4 \mathrm{~cm}$ dilated.

In the retrospective cohort study of Ohel and Harats ${ }^{20}$ early EA versus late EA was studied. Continuous EA was achieved by using bupivacaïne $0.5 \%$. No further details about the epidural administration were given. A similar prevalence of administration of opioids was described in the early and late EA groups.

\section{Methodological quality and statistical heterogeneity}

In three of the five RCTs women were randomised using a computer-generated random number list and an adequate description of withdrawals and dropouts was given. ${ }^{7,18,19}$ The methodological quality of the RCTs was assessed by the Jadad criteria and is summarised in Table 2. Because of slow study enrolment, the RCT by Wong et al. ${ }^{18}$ in 2009 stopped before the initial 1600 women were included; 806 participants were included in the analysis. In the RCT of Luxman et al. ${ }^{16}$ an inappropriate method of randomisation was used because participants were divided according to their sequence of arrival into two groups.

In the RCT of Ohel et al., ${ }^{17}$ randomisation was stratified according to the cause of labour onset (either spontaneous or induced). The RCTs of Luxman and Ohel did not report the rate of withdrawals, cross-over or dropouts. ${ }^{16,17}$

No statistical heterogeneity among the selected studies was detected for the overall rate of caesarean delivery $\left(R^{2}=0.0 \%, 95 \%-\mathrm{Cl} 0.0\right.$ to 89.2$)$, caesarean delivery for dystocia $\left({ }^{2}=\right.$ $0.0 \%, 95 \%-\mathrm{Cl} 0.0$ to 88.7 ), caesarean delivery for other fetal status ( $12=35.3 \%, 95 \%-\mathrm{Cl} 0.0$ to 96.0$)$, spontaneous vaginal delivery $\left({ }^{2}=0.0 \%, 95 \%-\mathrm{Cl} 0.0\right.$ to 95.8$)$. However, confidence intervals around the $l^{2}$ estimates were wide because of the low number of studies included. Statistical heterogeneity was found for instrumental vaginal delivery $\left(R^{2}=57.8 \%, 95 \%-\mathrm{Cl} 0.0\right.$ to 92.2). Because of the het- erogeneity, the pooled result was recalculated after excluding the heterogeneous trial ${ }^{20}\left(I^{2}=0.0 \%, 95 \%-\mathrm{Cl} 0.0\right.$ to 86.9$)$. Again, the precision of these estimates of $l^{2}$ was low. 


\section{Mode of delivery}

The rate of caesarean delivery (RR $1.02,95 \%-\mathrm{Cl} 0.96$ to 1.08 ), Figure 2, instrumental vaginal delivery (RR 0.96, 95\%-Cl 0.89 to 1.05 ) and spontaneous delivery (RR 1.01, 95\%-Cl 0.98 to 1.03 ) was not significantly different between the early EA and the control groups (Table 3) and no significant difference was found in the indication for caesarean delivery in both groups. Because of significant heterogeneity of instrumental vaginal delivery, the pooled result was recalculated after excluding the heterogeneous trial. ${ }^{20} \mathrm{After}$ this, still no significant difference was observed in the two groups in the rate of instrumental vaginal delivery (RR $0.94,95 \%-C l 0.87$ to 1.02 ).

\begin{tabular}{|c|c|c|c|c|c|c|c|c|c|}
\hline \multirow[b]{2}{*}{ Study or subgroup } & \multicolumn{2}{|c|}{ Favours early EA } & \multicolumn{2}{|c|}{ Control } & \multicolumn{3}{|c|}{ Risk ratio } & \multirow{2}{*}{$\begin{array}{c}\text { Risk ratio } \\
\text { M-H, Fixed, } 95 \% \mathrm{Cl} \\
\end{array}$} & \\
\hline & Events & Total & Events & Total & Weight & $\mathrm{M}-\mathrm{H}$, Fixed, $95 \% \mathrm{Cl}$ & Year & & \\
\hline Luxman 1998 & 2 & 30 & 3 & 30 & $0.2 \%$ & $0.67[0.12,3.71]$ & 1998 & & \\
\hline Wong 2005 & 65 & 366 & 75 & 362 & $4.5 \%$ & $0.86[0.64,1.16]$ & 2005 & - & \\
\hline Ohel 2006 & 28 & 221 & 25 & 228 & $1.5 \%$ & $1.16[0.70,1.92]$ & 2006 & & \\
\hline Wang 2009 & 1486 & 6394 & 1456 & 6399 & $86.4 \%$ & $1.02[0.96,1.09]$ & 2009 & & \\
\hline Wong 2009 & 134 & 406 & 126 & 400 & $7.5 \%$ & $1.05[0.86,1.28]$ & 2009 & - & \\
\hline Total $(95 \% \mathrm{Cl})$ & & 7417 & & 7419 & $100.0 \%$ & $1.02[0.96,1.08]$ & & 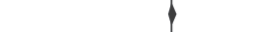 & \\
\hline Total events & 1715 & & 1685 & & & & & & \\
\hline $\begin{array}{l}\text { Heterogeneity: } \mathrm{Chi}^{2}= \\
\text { Test for overall effect }\end{array}$ & $\begin{array}{l}84, \mathrm{df}=4( \\
=0.57(P=\end{array}$ & $\begin{array}{l}0.77) ; \\
57)\end{array}$ & $2=0 \%$ & & & & & 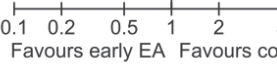 & $\begin{array}{ll}5 & 10 \\
\text { control }\end{array}$ \\
\hline
\end{tabular}

Figure 2. Forest plot, indiviudal and pooled risk ratio (RR) with 95\% confidence intervals $(\mathrm{CI})$ rate of caesarean delivery. 
Table 1. Intervention details of RCTs

\begin{tabular}{|c|c|c|c|c|c|}
\hline \multirow[t]{2}{*}{ Author, year, design } & \multirow[t]{2}{*}{ Inclusion } & \multirow{2}{*}{$\begin{array}{l}\text { No. of } \\
\text { participants }\end{array}$} & \multirow[t]{2}{*}{ Inclusion criteria } & \multicolumn{2}{|l|}{ Intervention } \\
\hline & & & & Early & Late \\
\hline $\begin{array}{l}\text { Luxman et al., 1998, }{ }^{16} \\
\text { RCT }\end{array}$ & Yes & 60 & $\begin{array}{l}\text { Nulliparity, term, vertex position, } \\
\text { spontaneous labour }\end{array}$ & $\begin{array}{l}<4 \mathrm{~cm} \\
3 \mathrm{ml} 2 \% \text { lidocaine with epinephrine via epidural } \\
\text { catheter test dose } \\
8 \mathrm{ml} 0.25 \% \text { bupivacaine } \\
\text { when pain, top-up dose } 8 \mathrm{ml} 0.25 \% \text { bupivacaine }\end{array}$ & $\begin{array}{l}\geq 4 \mathrm{~cm} \\
\mathrm{no} \text { analgesia }<4 \mathrm{~cm} \\
3 \mathrm{ml} 2 \% \text { lidocaine with epinephrine } \\
\text { via epidural catheter test dose } \\
8 \mathrm{ml} 0.25 \% \text { bupivacaine } \\
\text { when pain, top-up dose } 8 \mathrm{ml} 0.25 \% \\
\text { bupivacaine }\end{array}$ \\
\hline \multirow[t]{2}{*}{$\begin{array}{l}\text { Wong et al., 2005. } \\
\text { RCT }\end{array}$} & Yes & 728 & $\begin{array}{l}\text { Nulliparity, } \geq 36 \text { weeks of gestation, } \\
\text { singleton, vertex, spontaneous } \\
\text { labour or spontaneous rupture of } \\
\text { membranes, analgesia request at } \\
<4 \mathrm{~cm}\end{array}$ & $\begin{array}{l}\text { First analgesia request }(<4 \mathrm{~cm} \text { ) } \\
\text { combined-spinal epidural (intrathecal fentanyl } 25 \mu \mathrm{g} \\
\text { plus epidural test dose: lidocaine } 15 \mathrm{mg} / \mathrm{ml} \text { and } \\
\text { epinephrine } 5 \mu \mathrm{g} / \mathrm{ml}: 3 \mathrm{ml} \text { ) } \\
\text { Second analgesia request }\end{array}$ & $\begin{array}{l}\text { hydromorphone } 1 \mathrm{mg} \\
\text { intramuscularly and } 1 \mathrm{mg} \\
\text { intravenously }\end{array}$ \\
\hline & & & & $\begin{array}{l}<4 \mathrm{~cm} \text { :EA bolus } 15 \mathrm{ml} \text { (bupivacaine, } 0.625 \mathrm{mg} / \mathrm{ml} \text { PER } \\
\text { fentanyl, } 2 \mu \mathrm{g} / \mathrm{ml} \text { ); PCA } \\
\geq 4 \mathrm{~cm} \text { or no cervical dilatation: PCA bolus: } 15 \mathrm{ml} \\
\text { (bupivacaine } 1.25 \mathrm{mg} / \mathrm{mll} \text { ); PCA }\end{array}$ & $\begin{array}{l}<4 \mathrm{~cm} \text { : hydromorphone } 1 \mathrm{mg} \\
\text { intramuscularly and } 1 \mathrm{mg} \\
\text { intravenously } \\
\geq 4 \mathrm{~cm} \text { : EA test dose; bolus } 15 \mathrm{ml} \\
\text { (bupivacaine } 1.25 \mathrm{mg} / \mathrm{mll} ; \text { PCA }\end{array}$ \\
\hline $\begin{array}{l}\text { Ohel et al., 2006, }{ }^{17} \\
\text { RCT }\end{array}$ & Yes & 449 & $\begin{array}{l}\text { Nulliparity, } \geq 36 \text { weeks of gestation, } \\
\text { spontaneous or induced labour, } \\
\text { analgesia request } \leq 3 \mathrm{~cm} \text { dilatation }\end{array}$ & $\begin{array}{l}\text { EA after first request: } 3 \mathrm{ml} \text { lidocaine } 2 \% \text { test dose, } \\
\text { followed by bolus of } 10 \mathrm{ml} \text { of ropivacaine } 0.2 \% \text { plus } \\
50 \mu \mathrm{g} \text { fentanyl, continuous infusion of ropivacaine } \\
0.1 \% \text { with fentanyl } 2 \mu \mathrm{g} / \mathrm{ml} \text { at } 10 \mathrm{~m} / \text { hour rate. } \\
\text { Boluses of } 5-10 \mathrm{ml} \text { ropivacaine } 0.2 \% \text { upon request }\end{array}$ & $\begin{array}{l}<4 \mathrm{~cm} \text { : intravenous pethidine and } \\
\text { promethazine as required } \\
\geq 4 \mathrm{~cm} \text { EA, identical protocol }\end{array}$ \\
\hline $\begin{array}{l}\text { Wong et al., } 2009{ }^{18} \\
\text { RCT }\end{array}$ & Yes & 806 & $\begin{array}{l}\text { Nulliparity, } \geq 36 \text { weeks of gestation, } \\
\text { singleton, vertex, induction of } \\
\text { labour, analgesia request }<4 \mathrm{~cm}\end{array}$ & Protocol identical to Wong, ${ }^{5} 2005$ & $\begin{array}{l}\text { Protocol identical to Wong et al., } \\
2005^{7}\end{array}$ \\
\hline $\begin{array}{l}\text { Wang et al., } 2009,{ }^{19} \\
\text { RCT }\end{array}$ & Yes & 12793 & $\begin{array}{l}\text { Nulliparity, term, singleton, vertex, } \\
\text { spontaneous labour, request for } \\
\text { analgesia and at least } 1.0 \mathrm{~cm} \\
\text { cervical dilatation }\end{array}$ & $\begin{array}{l}\text { EA: } 3 \mathrm{ml} \text { test dose lidocaine } 1.5 \% \text { plus } 5 \mu \mathrm{g} / \mathrm{ml} \\
\text { epinephrine, } 15 \mathrm{ml} \text { single bolus } 0.125 \% \text { ropivacaine } \\
\text { with } 0.3 \mu \mathrm{g} / \mathrm{ml} \text { sufentanil, followed by PCA with } \\
10 \mathrm{ml} \text { bolus }\end{array}$ & $\begin{array}{l}\text { cervix }<4 \mathrm{~cm} \text { : meperidine } 25 \mathrm{mg} \\
\text { intramuscularly, repeatable } \\
\text { cervix } \geq 4 \mathrm{~cm} \text { : EA. Identical protocol } \\
\text { as latent phase analgesia }\end{array}$ \\
\hline
\end{tabular}

Table 2. Methodological quality of RCTs

\begin{tabular}{|c|c|c|c|c|c|}
\hline Methodological quality criteria & Luxman et al. ${ }^{16}$ & Wong et al. ${ }^{7}$ & Ohel et al. ${ }^{17}$ & Wong et al. ${ }^{18}$ & Wang et al. ${ }^{19}$ \\
\hline Jadad criteria & 0 & 3 & 2 & 3 & 3 \\
\hline Randomisation procedure mentioned & + & + & + & + & + \\
\hline Description cross-over & - & + & - & + & + \\
\hline Description power analysis & - & + & + & + & + \\
\hline
\end{tabular}

Table 3. Mode of delivery

\begin{tabular}{lclrrrrr} 
Outcome measure & $\begin{array}{c}\text { No. of } \\
\text { studies }\end{array}$ & Study references & $\begin{array}{c}\text { No. of } \\
\text { women }\end{array}$ & Early NA $\boldsymbol{n} / \mathbf{N}$ & Control $\mathbf{n} / \mathbf{N}$ & $\mathbf{R R}$ & $\mathbf{9 5 \%} \mathbf{C l}$ \\
\hline Caesarean delivery & 5 & $7,16,17,19,19$ & 14836 & $1715 / 7417$ & $1685 / 7419$ & 1.02 & $0.96-1.08$ \\
Caesarean delivery for dystocia & 4 & $7,17-19$ & 14776 & $1356 / 7387$ & $1317 / 7389$ & 1.03 & $0.96-1.10$ \\
Caesarean delivery for other fetal status & 4 & $7,17-19$ & 14776 & $357 / 7387$ & $365 / 7389$ & 0.98 & $0.85-1.13$ \\
Instrumental vaginal delivery & 6 & $7,16-20$ & 15399 & $950 / 7501$ & $1123 / 7898$ & 0.96 & $0.89-1.05$ \\
& 5 & Excluded reference 20 & 14836 & $911 / 7417$ & $968 / 7419$ & 0.94 & $0.87-1.02$ \\
Spontaneous delivery & 6 & $7,16-20$ & 15399 & $4819 / 7501$ & $4884 / 7898$ & 1.01 & $0.98-1.03$ \\
& 5 & Excluded reference 20 & 14836 & $4791 / 7417$ & $4766 / 7419$ & 1.01 & $0.98-1.03$ \\
\hline
\end{tabular}




\section{Discussion}

During the last few years, many studies have been published about the effects of the timing of EA on the outcome of labour. This review shows no increased pooled risk of caesarean (RR $1.02,95 \%-\mathrm{Cl} 0.96$ to 1.08 ) or instrumental vaginal ( $\mathrm{RR} 0.96,95 \%-\mathrm{Cl} 0.89$ to 1.05 ) deliveries in nulliparous women at 36 weeks or more of gestation receiving early EA at $<4 \mathrm{~cm}$ dilatation in comparison with EA given to women admitted when at least $4 \mathrm{~cm}$ dilated. The pooled risk ratio of caesarean delivery is based on the results of RCTs only.

These results are comparable with those of a systematic review about the effects of EA timing on the mode of delivery, published by Marucci et al. in 2007..$^{8}$ There are, however, several differences between both studies. Marucci et al. defined early EA as a cervical dilatation $<4-5 \mathrm{~cm}$, whereas we used the stricter lower limit of $<4 \mathrm{~cm}$. These are the women suffering from severe pain in the latent first stage of labour, whose desire for regional analgesia should not be denied. ${ }^{21}$

Marucci et al. ${ }^{8}$ included five RCTs, three retrospective studies, and one impact cohort study. We excluded the data of two of these studies: one because only an abstract was available, and the second because it was an impact cohort study in which two separate time periods of labour pain management were compared, the early period (before the use of EA) with mainly usage of early parenteral opioid, and the late period with use of early EA. ${ }^{22,23}$ In the current review, we included two recent randomised trials resulting in the data including far more nulliparous women (15 399 versus 3320). ${ }^{24}$ Moreover, Marucci et al. compared early EA with early parenteral opioid, or late EA, or both early parenteral opioid in combination with late EA. We only compared early EA with late EA.

The most important limitation of this systematic review is the lack of methodological uniformity in the different studies. Different interventions in the early EA group as well as in the control group, different dose of anaesthetics and spontaneous as well as induced labours were included. However, all women allocated to the 'late intervention' group of the included trials, except one, ${ }^{16}$ received systemic opioid analgesia. Besides, statistical heterogeneity was not significant for the overall rate of caesarean delivery, caesarean delivery for dystocia, caesarean delivery for other fetal status and rate of spontaneous delivery. However, the

broad range of $95 \%$ confidence intervals of the $P^{2}$ cannot exclude statistical heterogeneity. This is because of the small number of studies included in the meta-analysis. Individual 
results of all RCTs showed no increased risk for caesarean delivery or instrumental vaginal delivery in the early EA group. These results suggest that it is unlikely that specific analgesia techniques are associated with an increased risk of caesarean or instrumental vaginal delivery. Only the retrospective cohort study of Ohel and Harats ${ }^{20}$ showed an increased risk of instrumental vaginal delivery (RR $1.43,95 \%-\mathrm{Cl} 1.10$ to 1.87 ; data not shown in this review). However, in this study, traditional epidural with $0.5 \%$ bupivacaïne was used. The Comparative Obstetric Mobile Epidural Trial (COMET) Study Group reported a significant increase of the rate of normal vaginal deliveries in the low-dose combined-spinal group and the low-dose infusion group compared with the traditional epidural group..$^{25}$ The use of lowdose epidural techniques for labour analgesia has benefits for delivery outcome. ${ }^{25}$ In two of the included studies combined-spinal epidural was used. ${ }^{7,18}$ There is little difference between combined- spinal epidural and EA in labour despite a slightly faster onset of pain relief with combined-spinal epidural and fewer complaints of pruritus with EA. No difference in obstetric or neonatal outcome was observed. ${ }^{26}$

According to the results of this meta-analysis and the individual included studies, there is compelling evidence that earlier EA is not accompanied by an increased rate of caesarean or instrumental vaginal deliveries. Obviously, it is important to realise that the results of this review are not applicable to women who are not in labour or who have an undilated unfavourable cervix. Although all reviewed studies mentioned that they included women in (early) labour, this was only specified in the study of Wang et al., ${ }^{19}$ who used a lower limit of cervical dilatation of $1 \mathrm{~cm}$ as an exclusion criterion. According to the National Institute for Clinical Excellence guidelines, early labour or the latent stage of labour is described as a period of time, not necessarily continuous, when there are painful contractions, and there is some cervical change, including cervical effacement and dilatation up to $4 \mathrm{~cm} .^{21}$

\section{Conclusions}

This systematic review of the literature showed no increased risk of caesarean delivery or instrumental vaginal delivery for women receiving early EA compared with late EA. Therefore, a woman's request for EA early in labour cannot be rejected on the grounds of its presumed adverse influence on the mode of delivery. Consequently, the preference of the labouring women should be leading. 


\section{Reference List}

1. Leighton BL, Halpern SH. The effects of epidural analgesia on labor, maternal, and neonatal outcomes: a systemic review. Am J Obstet Gynecol 2002;186:S69-77.

2. Anim-Somuah M, Smyth R, Howell C. Epidural versus non-epidural or no analgesia in labour. Cochrane Database Syst Rev 2005;4:CD000331.

3. Liu EH, Sia AT. Rates of caesarean section and instrumental vaginal delivery in nulliparous women after low concentration epidural infusion or opioid analgesia: systemic review. BMJ 2004;328:14101420.

4. Sharma SK, McIntire DD, Wiley J, Leveno KJ. Labor analgesia and cesarean delivery: an individual patient meta-analysis of nulliparous women. Anesthesiology 2004;100:142-148.

5. Sharma SK, Alexander JM, Messick G, Bloom $\mathrm{SL}$, McIntire DD, Wiley J, et al. Cesarean delivery: a randomized trial of epidural analgesia versus intravenous meperidine analgesia during labor in nulliparous women. Anesthesiology 2002;96:546551.

6. Halpern SH, Muir H, Breen TW, Campbell DC, Barrett J, Liston R, et al. A multicenter randomized controlled trial comparing patient- controlled epidural with intravenous analgesia for pain relief in labor. Anesth Analg 2004;99:1532-1538.

7. Wong CA, Scavone BM, Peaceman AM, McCarthy RJ, Sullivan JT, Diaz NT, et al. The risk of cesarean delivery with neuraxial analgesia given early versus late in labor. N Engl J Med 2005;352:655-665.

8. Marucci M, Cinnella G, Perchiazzi G, Brienza N, Fiore T. Patient- requested neuraxial analgesia for labor: impact on rates of cesarean and instrumental vaginal delivery. Anesthesiology 2007;106:10351045.

9. Friedman EA. Primigravid labor; a graphicostatistical analysis. Obstet Gynecol 1955;6:567-589.

10. CBO-Richtlijn. Medicamenteuze pijnbehandeling tijdens de bevalling. Utrecht: CBO-Richtlijn, 2008.
11. Moher D, Liberati A, Tetzlaff J, Altman DG; for the PRISMA Group. Preferred reporting items for systematic reviews and meta-analysis: the PRISMA statement. BMJ 2009;339:b2535.

12. Jadad AR, Moore RA, Carroll D, Jenkinson C, Reynolds DJ, Gavaghan DJ, et al. Assessing the quality of reports of randomized clinical trials: is blinding necessary? Control Clin Trials 1996;17:1-12.

13. Higgins JPT, Thompson SG. Quantifying heterogeneity in a meta- analysis. Stat Med 2002;21:1539-1558.

14. Higgins JP, Thompson SG, Deeks JJ, Altman DG. Measuring inconsis- tency in meta-analysis. BMJ 2003;327:557-560.

15. Viechtbauer W. Conducting meta-analysis in $R$ with the metaphor package. J Stat Softw 2010;36:148.

16. Luxman D, Wolman I, Groutz A, Cohen JR, Lottan $M$, Pauzner $D$, et al. The effect of early epidural block administration on the progression and outcome of labor. Int J Obstet Anesth 1998;7:161-164.

17. Ohel G, Gonen R, Vaida S, Barak S, Gaitini L. Early versus late initiation of epidural analgesia in labor: does it increase the risk of cesarean section? A randomized trial. Am J Obstet Gynecol 2006;194:600-605.

18. Wong CA, McCarthy RJ, Sullivan JT, Scavone BM, Gerber SE, Yaghmour EA. Early compared with late neuraxial analgesia in nulliparous labor induction. A randomized controlled trial. Obstet Gynecol 2009;113:1066-1074.

19. Wang F, Shen X, Guo X, Peng Y, Gu X. Epidural analgesia in the latent phase of labor and the risk of cesarean delivery: a five-year randomized controlled trial. Anesthesiology 2009;111:871-880.

20. Ohel G, Harats H. Epidural anesthesia in early compared with advanced labor. Int J Gynaecol Obstet 1994;45:217-219.

21. National Collaborating Centre for Women and Children's Health: induction of labour. NICE Clinical guideline 70. London: Royal College of Obstetricians and Gynaecologists Press, 2008. pp. 72-75. 
22. Sharma SK, Alexander JM, Wiley J, Mclntire $\mathrm{DD}$, Leveno KJ. Effects of epidural analgesia in early labor on caesarean delivery. Anesthesiology 2003;1:34.

23. Vahratian A, Zhang J, Hasling J, Troendle JF, Klebanoff JF, Thorp JM Jr. The effect of early epidural versus early intravenous analgesia use on labor progression: a natural experiment. Am J Obstet Gynecol 2004;191:259-265.

24. Peisner DB, Rosen MG. Transition from latent to active labor. Obstet Gynecol 1986;68:448-451.

25. Comparative Obstetric Mobile Epidural Trial (COMET) Study Group UK. Effect of low-dose mobile versus traditional epidural techniques on mode of delivery: a randomised controlled trial. Lancet 2001;358:19-23.

26. Simmons SW, Cyna AM, Dennis AT, Hughes D. Combined spinal- epidural versus epidural analgesia in labour. Cochrane Database Syst Rev 2007;3:CD003401. 



\title{
5 Routine labour epidural analgesia versus labour analgesia on request: a randomised non-inferiority trial
}

\author{
MMLH WASSEN \\ LJM SMITS \\ HCJ SCHEEPERS \\ MAE MARCUS \\ J VAN NEER \\ JG NIJHUIS \\ FJME ROUMEN
}




\section{Abstract}

\section{Objective}

To assess the effect on mode of delivery of the routine use of labour epidural analgesia (EA) compared with analgesia on request.

\section{Design}

Randomised non-inferiority trial.

\section{Setting}

One university and one non-university teaching hospital in The Netherlands.

\section{Population}

Women with a singleton pregnancy in cephalic presentation beyond $36+0$ weeks' gestation.

\section{Methods}

Participants were randomly allocated to receive either routine EA or analgesia on request. Intention-to-treat (ITT) and per-protocol (PP) analyses were performed, with confidence intervals $(\mathrm{Cl})$ calculated for the differences in percentages or means.

\section{Main outcome measure}

Rate of operative delivery (instrumental vaginal or caesarean), labour characteristics, and adverse labour and neonatal outcomes.

\section{Results}

A total of 488 women were randomly allocated to the routine EA $(n=233)$ or analgesia on request group $(n=255)$. In the routine EA group, 89.3\% (208/233) received EA. According to ITT analysis, 34.8\% (81/233) women in the routine EA group had an operative delivery, compared with $26.7 \%$ (68/255) in the analgesia on request group (difference $8.1 \%, 95 \% \mathrm{Cl}$ -0.1 to $16.3 \%)$. The difference in rate of operative deliveries according to the PP analysis was statistically significant (difference $8.9 \%, 95 \%-\mathrm{Cl} 0.4 \%$ to $17.4 \%$ ). Inferiority of EA could not be rejected as in both analyses the upper bound of the confidence interval exceeded the pre-specified inferiority criterion of $+10 \%$. Women in the routine EA group had more adverse effects, including hypotension (difference $9.5,95 \%-\mathrm{Cl} 4.2$ to 14.9 ), and motor blockade (difference $6.8,95 \%-\mathrm{Cl} 1.1$ to 12.5 ). 


\section{Conclusion}

Non-inferiority of routine EA could not be demonstrated in this trial. Routine EA use is likely to lead to more operative deliveries and more maternal adverse effects. The results of our study do not justify routine use of EA.

\section{Introduction}

Epidural analgesia (EA) is the most effective method of pain relief, but also has unintended adverse effects on mode of delivery and labour outcome. ${ }^{1,2}$ Labour EA is associated with an increased risk of an instrumental vaginal delivery (IVD), but not with an increased risk of a caesarean section (CS). ${ }^{1}$ The question remains whether these adverse effects are caused by EA itself or whether they are confounded by indication. In the absence of a medical contraindication, maternal request is a sufficient medical indication for pain relief during labour. ${ }^{3}$ All studies published to date have been conducted in women who had a strong need for pain relief. ${ }^{1,2}$ In general, there is a correlation between women with a strong need for pain relief and failure of progress in labour, for example, in the case of labour dystocia. ${ }^{4}$ Thus, a request for EA for pain relief may be an indication of obstructed labour. At present, there is a lack of randomised controlled trials investigating the effect of EA on labour outcome in women without a strong need for pain relief.

In The Netherlands, and throughout the world, maternal request for EA during labour is increasing. ${ }^{5-8}$ Recently, a systematic review showed no increased risk of an IVD or CS in women receiving early EA at a cervical dilatation of $3 \mathrm{~cm}$ or less compared to late $E A$ at a cervical dilatation of at least $4 \mathrm{~cm} .^{9}$

The objective of the present study was to assess the effect of routine use of EA compared to analgesia on maternal request on operative delivery and labour and neonatal outcomes. This non-inferiority trial was designed to test the hypothesis that routine EA is not unacceptably inferior to analgesia on request regarding the risk of an IVD or unplanned CS. 


\section{Methods}

We performed a bicentre, open-label, randomised, non-inferiority trial. The institutional review boards of the participating centres approved the study. Participants were recruited from the Atrium Medical Centre Parkstad (Atrium MCP), a non-university teaching hospital, and the Maastricht University Medical Centre+ (MUMC+), The Netherlands. The recruitment period was from September 2008 until May 2012. The trial was reported in concordance with the CONSORT statement. ${ }^{10}$

\section{Participants}

Women were eligible to participate in the study if they were 18 years or older, pregnant with a singleton in vertex presentation and a gestational age of 36 weeks or more, had the intention to deliver vaginally, and did not have a contraindication for EA. For this study, a contraindication for EA was defined as: use of coumarin derivatives, use of low molecular weight heparin (LMWH) in therapeutic doses, use of LMWH in prophylactic doses less than 10 hours before, low platelet count $<80 \times 109$ /L, use of blood platelet aggregation inhibitors, a history of increased bleeding tendency, history of blood clotting disorders, an allergy for anaesthetics used, or history of spine disorders or spinal infection.

From 32 weeks' gestation on, eligible pregnant women were given oral and written information about the aims, methods, reasonably anticipated benefits, and potential hazards of the study. Advantages and disadvantages of epidural analgesia as described in the Cochrane review, ${ }^{1}$ were explained to them by the research coordinator and/or the staff of the participating hospital. The rationale of the study was discussed, as was the hypothesis that routine epidural analgesia was not unacceptably inferior to analgesia on request regarding the risk of an operative delivery. Subjects were informed that their participation was voluntary and that they might withdraw consent to participate at any time during the study without any consequences for their obstetrical care. This was merely done on the outpatient clinic, but also a number of women were informed in the labour room before induction of labour was started. After a period of consideration, both oral and written informed consent was obtained. 


\section{Randomisation}

Participating women were randomised before labour started. Women were randomly allocated to either routine EA or analgesia on request in a 1:1 ratio with stratification for centre and parity (nulliparous or parous women). Randomisation was performed using sequentially numbered opaque envelopes that were opened by study personnel after obtaining written informed consent. Although allocation of group was concealed, the participants, obstetricians, and outcome assessors were not blinded to the eventual treatment (open-label). Data-analysing members were blinded to group assignment.

\section{Interventions}

Participants allocated to the routine EA group immediately received EA when they were in labour, as determined by the attending obstetrician. Labour was defined as having an effaced cervix with at least $2 \mathrm{~cm}$ dilatation in combination with regular contractions.

At Atrium MCP, EA was maintained by a continuous background infusion of ropivacaïne $(0.125 \%)$ with sufentanil $(1 \mu \mathrm{g} / \mathrm{ml}$ ) (from 01-09-2008 to 12-05-2011) and bupivacaïne $(0.125 \%)$ with sufentanil $(1 \mu \mathrm{g} / \mathrm{ml}$ ) (from $12-05-2011$ to $31-05-2012)$ at a rate of $7-10 \mathrm{ml}$ per hour. At MUMC+, EA was initiated with an $8 \mathrm{ml}$ bolus of ropivacaïne $0.180 \%$ ) and sufentanil $(0.5 \mu \mathrm{g} / \mathrm{ml})$ and subsequently was patient-controlled with a $4 \mathrm{ml}$ bolus of ropivacaïne $(0.180 \%)$ and sufentanil $(0.5 \mu \mathrm{g} / \mathrm{ml})$ without background infusion. In the analgesia on request group, labouring women received pain relief only on request. According to local hospital protocol and patient preference, the women were given opiates intramuscularly or EA (at first or second pain relief request after opiates) for labour pain control.

\section{Outcomes}

The primary non-inferiority outcome was the rate of operative deliveries (defined as either IVD or unplanned CS). Secondary outcomes were maternal and labour characteristics, including interval between rupture of membranes and birth, use of oxytocin augmentation, maternal fever during labour (defined as temperature $\geq 38.0^{\circ} \mathrm{C}$ ), maternal labour antibiotic use (excluding prophylactic use), length of second stage of labour, and adverse labour outcome (e.g., shoulder dystocia, postpartum haemorrhage, manual removal of the placenta, and third or fourth degree perineal rupture). Neonatal data were also analysed: birth weight, one- and five-minute Apgar scores, umbilical artery $\mathrm{pH}$, umbilical artery base 
excess, neonatal fever (defined as temperature $\geq 38.0^{\circ} \mathrm{C}$ ), and neonatal admission. EArelated complications were also recorded, including maternal hypotension, postpartum urinary retention (need for bladder catheterization), and motor blockade. The degree of motor block was assessed using the Bromage scale, with 0 indicating free movement of legs and feet; I, just able to flex knees with free movement of feet; II, unable to flex knees, but with free movement of feet; and III, unable to move legs or feet.

\section{Study design, sample size and statistical analysis}

This non-inferiority trial was designed to test the hypothesis that routine EA is not inferior to analgesia on request to an acceptable extent regarding the risk of having an operative delivery. The largest clinically acceptable difference (degree of inferiority, $\Delta$ ) was set at $10 \%$. The statistical null hypothesis was that the risk of an operative delivery in the routine EA group would exceed that in the analgesia on request group by more than $10 \%$. If the noninferiority margin $(+\Delta=10 \%)$ is exceeded, routine $E A$ is defined to be unequivocally inferior in comparison with analgesia on request. To reject the null hypothesis, the upper limit of the $\mathrm{Cl}$ around the observed difference should be less than the non-inferiority margin.

For sample size calculation, we used the following input values: chance that delivery is non-instrumental, 72.9\%11; power 0.8; alpha 0.05; delta (maximally acceptable difference) $10 \%$. We calculated that 244 women were required in each of the study arms. Based on a preliminary study in 2008 in the Atrium Medical Centre, which showed that 6 of 50 eligible women (12\%) would participate in this randomised trial, it was estimated that more than 4000 women had to be approached. The primary analysis was according to intentionto-treat (ITT). Although intention-to-treat-analysis is the preferred type of analysis in superiority trials, in a non-inferiority trial it may unjustifiedly lead to the conclusion of noninferiority. Therefore, a per-protocol analysis is needed to cross-validate the results of the ITT analysis. ${ }^{10,12}$ In our per-protocol analysis we excluded all women who did not receive EA from the EA group. Continuous variables were summarised as medians with interquartile ranges (IQR). Treatment effects were presented as differences in means or percentages with 95\% confidence intervals $(\mathrm{Cl})$. The chi-square test was used for categorical variables. The Student's t-test or the non-parametric Mann-Whitney $U$ test was used to analyse continuous variables. Non-inferiority was evaluated by comparing the upper bound of 
the $\mathrm{Cl}$ around the difference between the number of operative deliveries in the routine EA group and the analgesia on request group, with $\Delta(10 \%)$. Statistical significance of any

differences between the two study arms was evaluated by checking whether the $95 \% \mathrm{Cl}$ included 0 (for differences). Three variables had more than 5\% missing data: neonatal fever (17\%), ethnicity (17.8\%), and education (18.4\%). Missing data were imputed using single imputation. Statistical analysis was performed using SPSS ${ }^{\circledR}$ software (version 18.0, SPSS Inc., Chicago, IL, USA).

\section{Results}

A total of 493 women were randomised, and five women were excluded after randomisation. Figure 1 shows the 488 participants assigned to either receive routine $E A(n=233)$ or analgesia on request $(n=255)$. EA was initiated at a median cervical dilatation of $3 \mathrm{~cm}($ IQR $2-4)$ in the routine EA group and at $4 \mathrm{~cm}$ (IQR 3 - 5) in the analgesia on request group (difference in mean $-1.0 ; 95 \% \mathrm{Cl}-1.3$ to -0.7 ). Median duration of EA until birth was 448 (IQR 300 - 648) minutes and 441 (IQR 275 - 602) minutes in the routine EA group and analgesia on request group respectively. In the routine EA group, 70/208 (33.7\%) women received patient-controlled EA, and 44/120 (36.7\%) women in the analgesia on request group received it (difference in percentage $-3.0 ; 95 \%-\mathrm{Cl}-13.8$ to 7.7$)$. 
Figure 1. Flowchart Study population

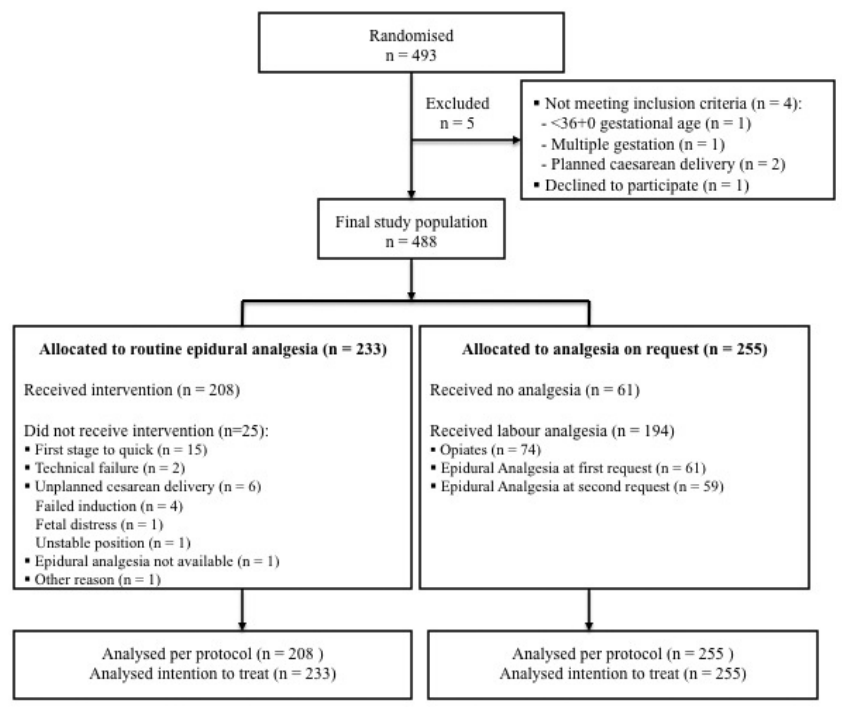

Table 1. Baseline characteristics of the study groups

\begin{tabular}{|c|c|c|c|}
\hline & $\begin{array}{c}\text { Routine } \\
\text { Epidural Analgesia }\end{array}$ & $\begin{array}{c}\text { Routine } \\
\text { Epidural Analgesia }\end{array}$ & $\begin{array}{l}\text { Analgesia } \\
\text { on request }\end{array}$ \\
\hline & $\begin{array}{l}\text { Per-protocol } \\
\qquad(n=208)\end{array}$ & $\begin{array}{l}\text { Intention-to-treat } \\
\qquad(n=233)\end{array}$ & $(n=255)$ \\
\hline Maternal age (y) & $30.0(26.0-33.0)$ & $30.0(27.0-34.0)$ & $30.0(26.0-33.0)$ \\
\hline BMI at start pregnancy (QI) & $24.2(21.6-29.4)$ & $24.0(21.6-29.0)$ & $24.6(21.7-28.6)$ \\
\hline \multicolumn{4}{|l|}{ Parity } \\
\hline • Nulliparous & $106(51.0)$ & $115(49.4)$ & $122(47.8)$ \\
\hline - Multiparous, history: & $102(49.0)$ & $118(50.6)$ & $135(52.9)$ \\
\hline Vaginal delivery & $69(67.6)$ & $82(69.5)$ & $93(68.9)$ \\
\hline Planned caesarean section & $9(8.8)$ & $10(8.5)$ & $16(11.9)$ \\
\hline Unplanned caesarean section & $19(18.6)$ & $21(17.8)$ & $14(10.4)$ \\
\hline Vaginal and caesarean section & $5(4.9)$ & $5(4.2)$ & $1(0.7)$ \\
\hline Caucasian* & $143(86.1)$ & $161(86.6)$ & $191(88.8)$ \\
\hline \multicolumn{4}{|l|}{ Education $^{\star *}$} \\
\hline •Primary & $1(0.5)$ & $1(0.5)$ & $3(1.4)$ \\
\hline - Secondary & $107(64.1)$ & $118(63.1)$ & $140(66.4)$ \\
\hline - Tertiary & $59(35.3)$ & $68(36.4)$ & 68 (32.2) \\
\hline
\end{tabular}

Data presented as median and interquartile range (25 - 75) or $\mathrm{n}(\%)$.

${ }^{*} \mathrm{n}=166$ routine epidural analgesia group according to per-protocol analysis, $n=186$ routine epidural analgesia group according to intention-to-treat analysis, $n=215$ analgesia on request group.

${ }^{\star \star} n=167$ routine epidural analgesia group according to per-protocol analysis, $n=187$ routine epidural analgesia group according to intention-to-treat analysis, $n=211$ analgesia on request group.

Highest completed education level was divided into primary (elementary school), secondary (high school, vocational school and preparatory school), and tertiary education (higher professional education or Master/Bachelor level). 
Table 2. Maternal and labour characteristics

\begin{tabular}{|c|c|c|c|}
\hline & $\begin{array}{c}\text { Routine } \\
\text { Epidural Analgesia }\end{array}$ & $\begin{array}{l}\text { Analgesia } \\
\text { on request }\end{array}$ & $\begin{array}{l}\text { Difference in } \\
\text { percentage or } \\
\text { mean }(95 \%-\mathrm{Cl})\end{array}$ \\
\hline & $\begin{array}{l}\text { Intention-to-treat } \\
\qquad(\mathrm{n}=233)\end{array}$ & $(n=255)$ & \\
\hline Spontaneous onset of labor & $83(35.6)$ & $104(40.8)$ & $-5.2(-13.8$ to 3.5$)$ \\
\hline Gestational age at birth (days) & $280(273-287)$ & $280(272-288)$ & $0.2(-1.5$ to 1.9$)$ \\
\hline Interval between rupture of membranes and birth (h) & $7.9(4.3-14.4)$ & $7.7(2.7-14.1)$ & $1.5(-5.1$ to 8.2$)$ \\
\hline Oxytocin augmentation & $125(53.6)$ & $116(45.5)$ & $8.2(-0.7$ to 17.0$)$ \\
\hline Maternal fever $(\geq 38.0 \circ \mathrm{C})$ & $49(21.0)$ & $40(15.7)$ & $5.3(-1.5$ to 12.2$)$ \\
\hline Maternal labour antibiotic use & $15(6.4)$ & $17(6.7)$ & $-0.2(-4.6$ to 4.2$)$ \\
\hline Number digital vaginal examination & $6(5-9)$ & $6(4-8)$ & $0.2(-3.5-0.8)$ \\
\hline Length of second stage ( $\mathrm{min}$ ) & $20.0(10.0-49.5)$ & $19.0(8.0-45.0)$ & $2.0(-3.2$ to 7.1$)$ \\
\hline \multicolumn{4}{|l|}{ Mode of delivery } \\
\hline Operative & $81(34.8)$ & $68(26.7)$ & $8.1(-0.1$ to 16.3$)$ \\
\hline - Vaginal instrumental & $37(15.9)$ & $29(11.4)$ & $4.5(-1.6$ to 10.6$)$ \\
\hline - Unplanned caesarean section & $44(18.9)$ & $39(15.3)$ & $3.6(-3.1$ to 10.3$)$ \\
\hline \multicolumn{4}{|l|}{ Indications for instrumental delivery* } \\
\hline - Suspected fetal distress & $22(27.2)$ & $13(19.1)$ & $8.0(-5.4$ to 21.5$)$ \\
\hline - Arrest of labor & $45(55.6)$ & $47(69.1)$ & $-13.6(-29.0$ to 1.9$)$ \\
\hline - Suspected fetal distress and arrest of labor & $11(13.6)$ & $7(10.3)$ & $3.3(-7.1$ to 13.7$)$ \\
\hline - Other & $3(3.7)$ & $1(1.5)$ & $2.2(-2.8$ to 7.2$)$ \\
\hline \multicolumn{4}{|l|}{ Adverse labour outcome } \\
\hline - No & $203(87.1)$ & $215(84.3)$ & $2.8(-3.4$ to 9.0$)$ \\
\hline - Shoulder dystocia & $5(2.1)$ & $8(3.1)$ & $-1.0(-3.8$ to 1.8$)$ \\
\hline $\begin{array}{l}\text { - Postpartum haemorrhage } \\
\text { ( } \geq 1000 \mathrm{ml} \text { blood loss) }\end{array}$ & $14(6.0)$ & $11(4.3)$ & $1.7(-2.2$ to 5.6$)$ \\
\hline $\begin{array}{l}\text { - Postpartum haemorrhage and manual } \\
\text { removal placenta }\end{array}$ & $6(2.6)$ & $8(3.1)$ & $-0.6(-3.5$ to 2.4$)$ \\
\hline • Manual removal placenta & $3(1.3)$ & $1(0.4)$ & $0.9(-0.7$ to 2.5$)$ \\
\hline - Third/fourth degree perineal rupture & $2(0.9)$ & $4(1.6)$ & $-0.7(-2.6$ to 1.2$)$ \\
\hline \multicolumn{4}{|l|}{ Adverse events epidural analgesia } \\
\hline • Maternal hypotension & $35(15.0)$ & $14(5.5)$ & 9.5 (4.2 to 14.9$)$ \\
\hline - Motor blockade & $35(15.0)$ & $21(8.2)$ & 6.8 (1.1 to 12.5$)$ \\
\hline - Postpartum urinary retention & $2(0.9)$ & $2(0.8)$ & $0.1(-1.5$ to 1.7$)$ \\
\hline
\end{tabular}

Data presented as median and interquartile range (25 - 75) or $\mathrm{n}(\%)$.

$\mathrm{Cl}$, confidence interval.

${ }^{*} \mathrm{n}=81$ for routine epidural analgesia group, $\mathrm{n}=68$ for analgesia on request group.

As shown in Table 1, baseline characteristics of the participants in both groups were comparable. In the ITT analysis 81/233 (34.8\%) women in the routine EA group experienced an operative delivery, compared with $68 / 255$ (26.7\%) in the analgesia on request group (difference $8.1 \%, 95 \%-\mathrm{Cl}-0.1 \%$ to $16.3 \%$, Table 2, Figure 2). According to the PP analysis, $74 / 208$ (35.6\%) women in the routine EA group and 68/255 (26.7\%) in the analgesia on 
request group had an operative delivery (difference $8.9 \%, 95 \%-\mathrm{Cl} 0.4 \%$ to $17.4 \%$ ). The difference in rate of operative deliveries according to the PP analysis was statistically significant. However in both the ITT and PP the upper bound of the $\mathrm{Cl}$ exceeded the prespecified inferiority criterion of $+10 \%$ as also is shown in Figure 2 , therefore, non-inferiority could be rejected. However, the result is inconclusive regarding possible inferiority of magnitude of delta. Mode of operative delivery (IVD or CS) and the indication to perform an operative delivery was not significantly different between both groups. There was also no important difference between the groups in continuing EA during the second stage of labour (73.8\% vs. $71.3 \%$; difference $2.6 \%, 95 \%-\mathrm{Cl}-8.7 \%$ to $13.8 \%$ ). ITT analysis showed no significant differences in labour characteristics (Table 2). In the PP analysis, the routine EA group used significantly more oxytocin augmentation (59.1\% vs. $45.5 \%$; difference $13.6 \%$, 95\%-Cl $4.6 \%$ to $22.7 \%$ ) and experienced significantly more maternal fever ( $23.1 \%$ vs. $15.7 \%$; difference $7.4 \%, 95 \%-\mathrm{Cl} 0.1 \%$ to $14.7 \%$ ). In the routine EA group, significantly more women experienced EA-related adverse events, such as maternal hypotension (15.0\% vs. 5.5\%; difference $9.5,95 \%-\mathrm{Cl} 4.2$ to 14.9$)$ and motor blockade (15.0\% vs. $8.2 \%$; difference $6.8,95 \%$ $\mathrm{Cl} 1.1$ to 12.5$)$. When analysing these EA-related adverse effects only in women who actually received EA in both groups, there was no significant difference between the groups. Other epidural related adverse events like bleeding, infection or postpunction headache did not occur.

The incidence of adverse labour outcome (Table 2) and neonatal outcome (Table 3) was comparable between groups in ITT analysis and PP analysis.

Figure 2. Difference in percentage of operative delivery according to the per-protocol and the intention-to-treat analysis

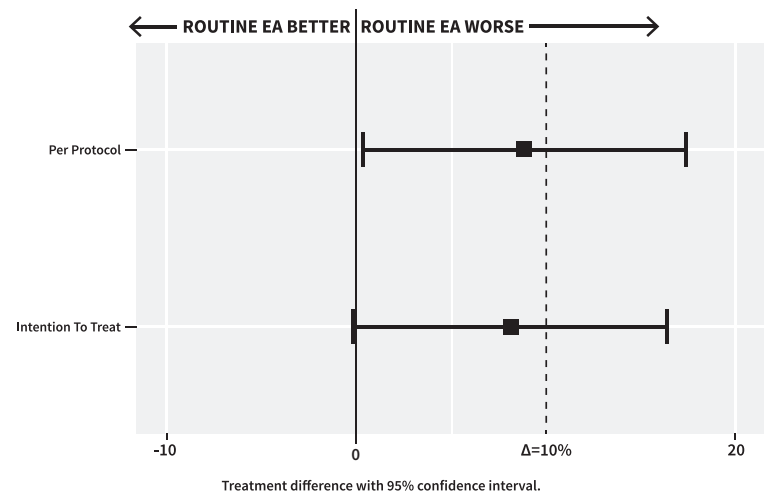

The black dashed line at $\Delta=10 \%$ indicates the non-inferiority margin. The black dots and the error bars indicate the mean difference and 2 -sided $95 \%$ confidence intervals $(\mathrm{Cl})$ in percentage of operative delivery between routine $\mathrm{EA}$ and analgesia on request. If the $\mathrm{Cl}$ includes the non-inferiority margin and zero, as id the case in the ITT analysis, the difference is non-significant, and the result regarding non-inferiority is inconclusive. If the $\mathrm{Cl}$ includes the non-inferiority margin and is wholly to the right of zero, as is the case in the PP analysis, the difference is statistically significant, but the result regarding non-inferiority is still inconclusive in that it is still plausible that the true treatment difference is less than $\Delta=10 \%$. 


\begin{tabular}{|c|c|c|c|}
\hline & $\begin{array}{l}\text { Routine } \\
\text { Epidural Analgesia } \\
\text { Intention-to-treat } \\
\qquad(\mathrm{n}=233)\end{array}$ & $\begin{array}{l}\text { Analgesia on } \\
\text { request } \\
(n=255)\end{array}$ & $\begin{array}{c}\text { Difference in } \\
\text { percentage or } \\
\text { mean }(95 \% \mathrm{Cl})^{*}\end{array}$ \\
\hline Birth weight (grams) & $3540(3148-3873)$ & $3450(3130-3800)$ & 39 (-53 to 132$)$ \\
\hline \multicolumn{4}{|l|}{ Apgar score* } \\
\hline - ' 1 min $<7$ & $14(6.0)$ & $17(6.7)$ & $-0.6(-5.0$ to 3.7$)$ \\
\hline - ‘ $5 \min <7$ & $4(1.7)$ & $5(2.0)$ & $-0.2(-2.6$ to 2.2$)$ \\
\hline \multicolumn{4}{|l|}{ Arterial $\mathrm{pH}^{*}$} \\
\hline$\cdot<7.05$ & $1(0.4)$ & $5(2.0)$ & $-1.5(-3.4$ to 0.4$)$ \\
\hline$\cdot 7.05-7.15$ & 30 (12.9) & $39(15.3)$ & $-2.4(-8.5$ to 3.8$)$ \\
\hline$\cdot>7.15$ & $201(86.6)$ & $211(82.7)$ & $3.9(-2.5$ to 10.3$)$ \\
\hline Arterial Base Excess $<-10^{\star}$ & 30 (12.9) & $40(15.7)$ & $-2.8(-9.0$ to 3.5$)$ \\
\hline Neonatal fever $(\geq 38.0 \mathrm{oC})^{\star}$ & 30 (12.9) & $24(9.4)$ & $3.5(-2.1$ to 9.1$)$ \\
\hline Neonatal admission* & $49(21.1)$ & $63(24.7)$ & $-3.6(-11.0$ to 3.9$)$ \\
\hline
\end{tabular}

\section{Discussion}

\section{Main Findings}

Non-inferiority of routine EA could not be demonstrated in this trial, but routine labour EA may result in an increased rate of operative deliveries. Routine use of EA results in significantly more EA-related adverse events like maternal hypotension, and motor blockade. No differences in adverse labour and neonatal outcomes were found between routine use of EA and analgesia on request.

\section{Strengths and limitations}

This study is the first randomised controlled trial investigating the effect on labour outcome of routine use of EA in women without a request for pain relief vs. pain relief with opiates or EA only on the woman's request. All studies published until now have been performed in women with a request for pain relief, which may have provided a bias in the study results. ${ }^{1,2}$ The study also has some limitations. First, the techniques used for EA varied by institution, 
which may influence the outcome of labour. However, despite this difference, a metaanalysis of patient-controlled EA versus continuous infusion found no difference in the rate of IVD or CS. ${ }^{13}$ A recent systematic review and meta-analysis also found no statistical difference in the rate of CS between intermittent EA bolus and continuous epidural infusion. ${ }^{14}$ Second, different local anaesthetics (bupivacaine and ropivacaine) were used in this study. However, a double-blinded multicentre study by Gogarten showed both local anaesthetics provided equally effective analgesia at equal doses without a difference in side effects. ${ }^{15}$

Thirdly, some selection bias occurred. The estimation is that around $10-15 \%$ of all eligible women were included. This was based on both the data of the preliminary results as the total number of women delivering in the study period. Furthermore, the use of EA in the analgesia on request group was higher than in the normal population in The Netherlands $\left(47.1 \%\right.$ versus $\left.26 \%{ }^{16}\right)$, suggesting that women who already favoured EA for pain treatment were more likely to participate. If EA resulted in an increased risk of operative deliveries, the rate of operative deliveries should have been higher in this analgesia on request group because of the selection of women favouring EA. However, the rate of operative deliveries in the analgesia on request group was $26.7 \%$ and comparable with national data. ${ }^{11}$

Finally, study enrolment was slow and the inclusion period took almost four years. Based on the hospital birth registers, the exact number of eligible women in both hospitals was estimated to be around 8000 . Around 4000 of them were asked to participate in the study.

\section{Interpretation}

To the best of our knowledge, this study is the first randomised trial on routine use of EA during labour in women without request for pain relief. When compared with the EA group of a Cochrane systematic review ${ }^{1}$, which compared EA with non-epidural or no pain relief during labour, the IVD rate was comparable to this study's routine EA group (15.9\% (37/233) vs. $17.0 \%$ (675/3981)). The CS rate, however, was substantially higher in the early EA group in our study (18.9\% (44/233) vs. 10.8\% (455/4223)), respectively. ${ }^{1}$ The Cochrane review found no significant increased risk for CS delivery in women receiving labour EA. Significantly more often maternal hypotension and motor blockade were recorded in the routine EA group. These results are in agreement with earlier results. ${ }^{1}$ These adverse effects were comparable between groups when only analysing women receiving EA. 


\section{Conclusion}

In this study, with the regimens for analgesia used, non-inferiority of routine EA could not be demonstrated. Routine labour EA is likely to increase the rate of operative deliveries and is also associated with more adverse maternal effects such as maternal hypotension and motor blockade. On the basis of these results, we conclude that routine use of EA should not be advised. 


\section{Reference List}

1. Anim-Somuah M, Smyth RMD, Jones L. Epidural versus non-epidural or no analgesia in labour. Cochrane Database Syst Rev 2011;12:CD000331.

2. Leighton $\mathrm{BL}$, Halpern $\mathrm{SH}$. The effects of epidural analgesia on labor, maternal, and neonatal outcomes: a systematic review. Am J Obstet Gynecol 2002;186:S69-S77.

3. ACOG committee opinion \# 295: pain relief during labor. Obstet Gynecol 2004;104:213.

4. Alexander JM, Sharma SK, McIntire DD, Wiley J, Leveno KJ. Intensity of labor pain and cesarean delivery. Anesth Analg 2001;92:1524-1528.

5. The Netherlands Perinatal Registry. Perinatal care in the Netherlands 2003-2009 [in Ducth]. Utrecht: The Netherlands Perinatal Registry;2013.

6. Blondel B, Supernant K, Du Mazaubrun C, Breart $G$. Trends in perinatal health in metropolitan France between 1995 and 2003: Results from the National Perinatal Surveys. J Gynecol Obstet Biol Reprod (Paris) 2006;354:373-387. French.

7. Vuori E, Gissler M. Perinatal statistics: parturients, deliveries and newborns 2011. [http://www.thl. fi/en_us/web/en/statitics/topics/reproductive_ health/deliveries].

8. Cammu H, Martens E, Martens G, Van Mol C, Jacquemyn Y. Perinatal activities in Flanders 2011. Studycentre Perinatal Epidemiology, Brussel, SPE 2011. Dutch. Perinatale activiteiten in Vlaanderen 2011. Studiecentrum voor Perinatale Epidemiologie, Brussel, SPE 2011.

9. Wassen MM, Zuijlen J, Roumen FJ, Smits LJ, Marcus MA, Nijhuis JG. Early versus late epidural analgesia and risk on instrumental delivery in nulliparous women: a systematic review. BJOG 2011;118:655-661.

10. Piaggio G, Elbourne DR, Pocock SJ, Evans SJW, Altman DG; CONSORT group. Reporting of noninferiority and equivalence randomized trials: an extension of the CONSORT 2010 statement. JAMA 2012;308:2594-2604.
11. The Netherlands Perinatal Registry. Landelijke verloskunde registratie tweede lijn (LVR-2) 2008 [in Dutch]. Utrecht: The Netherlands Perinatal Registry; 2008.

12. Scott IA. Non-inferiority trials: determining whether alternative treatments are good enough. Med J Aust 2009;190:326-330.

13. Van der Vyver M, Halpern S, Joseph G. Patientcontrolled epidural analgesia versus continuous infusion for labour analgesia: a meta-analysis. $\mathrm{Br} \mathrm{J}$ Anaesth 2002;89:459-465.

14. George RB, Allen TK, Habib AS. Intermittent epidural bolus compared with continuous epidural infusions for labor analgesia: a systematic review and meta-analysis. Anesth Analg 2013;116:133-144.

15. Gogarten W, Van de Velde M, Soetens F, Van Aken H, Brodner G, Gramke HF et al. A multicentre trial comparing different concentrations of ropivacaine plus sufentanil with bupivacaine plus sufentanil for patient-controlled epidural analgesia in labour. Eur J Anaesthesiol 2004;21:38-45.

16. Neef de T. Figures and trends of pain relief in the Netherlands. In Slager, E, editor: Reproductieve geneeskunde, gynaecologie en obstetrie anno 2013 [in Dutch]. Haarlem: DCHG, medische communicatie, 2013:882-886. 



\title{
6 Neonatal sepsis is mediated by maternal fever in labour epidural analgesia
}

\author{
MMLH WASSEN \\ B WINKENS \\ EMI DORSSERS \\ MAE MARCUS \\ RM J MOONEN \\ FJME ROUMEN
}




\section{Summary}

The association between neonatal sepsis and labour epidural analgesia (EA) was evaluated. In a retrospective matched case-control study, 453 women delivering with EA (EA group) were matched on parity with 453 women with deliveries without EA (non-EA group). Significantly more neonates born in the EA-group had fever $\geq 38.0^{\circ} \mathrm{C}(11.6 \%$ vs. $1.8 \%, p<$ 0.001 ) at birth. The overall incidence of neonatal sepsis, based on clinical symptoms and defined as proven (by a positive blood culture) or suspected (no positive blood culture), was significantly higher in the EA group ( $6.0 \%$ vs. $2.2 \% ; p=0.002)$, but the incidence of proven neonatal sepsis alone was not $(0.4 \%$ vs. $0 \% ; p=0.250)$. EA turned out to be an independent risk factor for neonatal sepsis (adjusted OR 2.43, 95\%-Cl 1.15 to 5.13; $p=0.020$ ). However, in the EA group as well as the non-EA group, the incidence of neonatal sepsis was significantly higher in mothers with intra-partum fever compared with afebrile mothers (11.0\% vs. $2.9 \%$ in EA group, $p=0.004 ; 8.2 \%$ vs. $1.3 \%$ in Non-EA group, $p=0.006$ ). Therefore we conclude, that the positive association between neonatal sepsis and labour EA is possibly mediated by maternal intra-partum fever. 


\section{Introduction}

For many years, epidural analgesia (EA) during labour has been associated with an increased risk of intrapartum maternal fever. ${ }^{1,2}$ Retrospective studies ${ }^{3-5}$ and randomized controlled trials $^{6-8}$ have suggested a causal relationship between EA and the occurrence of maternal fever during labour. Maternal fever may result in adverse fetal and neonatal outcome. ${ }^{9-11}$ However, the association between neonatal sepsis and labour epidural analgesia (EA) is the subject of continuous debate. Increased rates of evaluation for neonatal sepsis have been associated with labour EA in the majority of published studies, ${ }^{4,5,12,-15}$ According to some investigators, however, there is no increased need for sepsis screening in neonates born after labour EA. ${ }^{16,17}$ Others advise sepsis evaluation only in neonates born to women with EA-related intra-partum fever. ${ }^{7}$ No difference in documented neonatal sepsis was found in neonates whose mothers received EA independent of maternal intrapartum fever. ${ }^{4,5,7,12,14}$ However, in daily practice, the diagnosis of neonatal sepsis is difficult and mostly made in retrospect and not at birth. ${ }^{18}$ First, signs of neonatal sepsis are nonspecific and noninfectious syndromes can mimic the signs of neonatal sepsis. ${ }^{19}$ Second, diagnostic tests for neonatal sepsis have a poor positive predictive accuracy. ${ }^{18}$ Diagnostic tests for early-onset sepsis (other than blood or cerebrospinal fluid cultures) are useful for identifying infants with a low probability of sepsis, but not to identify infants who are likely to be infected. At least one $\mathrm{ml}$ of blood is needed to adequately detect bacteremia if a pediatric blood culture bottle is used. Drawing this volume of blood is often not feasible. ${ }^{19}$ Most infants with earlyonset sepsis develop signs in the first 24 hours of life. Approximately $1 \%$ of the infants will appear healthy at birth and then develop signs of infection after a variable time period. ${ }^{19} \mathrm{In}$ daily practice, antimicrobial treatment should be started in neonates who are suspected of sepsis based on clinical signs, before blood culture results are known..$^{18,19}$

Neonatal sepsis in several studies regarding the association between EA and neonatal sepsis was described as a "positive" neonatal blood culture 5,7,12 $^{5}$ wereas in other studies the criteria for diagnosing neonatal sepsis were not described at all. ${ }^{4,14}$ This variety of definitions of neonatal sepsis reflects the problem in daily practice. Only Kaul et al. subdivided between definite sepsis proven by a positive blood, urine, or cerebrospinal fluid culture vs. presumed sepsis, shown only by indirect evidence (including immature polymorphonuclear white 
cells, cardiovascular instability requiring inotropic support, or pneumonia) with no direct positive culture. ${ }^{17}$

In The Netherlands but also worldwide, the percentage of EA during labour is still increasing; it is relevant to investigate possible consequences of EA on the neonate. The aim of this study was to evaluate the association between neonatal sepsis, based on diagnostic and clinical criteria according to a strict definition, and labour EA in a time period of restricted EA use in The Netherlands, and to identify possible influencing factors.

\section{Materials and Methods}

For the present retrospective matched case-control study, data were collected on women who delivered and received labour EA (EA group) between January 1, 2005 and January 1, 2008 at the Atrium Medical Center Parkstad, a non-university teaching hospital in Heerlen, The Netherlands. The Medical Ethical Committee of the Atrium Medical Center Parkstad approved the study. Deliveries under supervision of an obstetrician of a term $\left(37^{+0}-41^{+6}\right.$ weeks of gestation), singleton, liveborn and cephalic presentation were included (EA group). Maternal temperature $\geq 37.5^{\circ} \mathrm{C}$ at admission before delivery, prophylactic antibiotic use during labour, and an elective caesarean section were excluded, but chronic medical disorders like diabetes or growth restriction were not. Using the hospital delivery register, the included deliveries were matched on parity (nulliparous, multiparous but no prior vaginal births - only caesarean section - and multiparous with at least one previous vaginal birth in obstetrical history) with subsequent delivery without the administration of EA (nonEA group).

EA was maintained by a continuous background infusion of sufentanil $(1 \mu \mathrm{g} / \mathrm{ml})$ with ropivacaïne $(1.25 \mathrm{mg} / \mathrm{ml})$. After a test dose of $2 \mathrm{ml}$ and a therapeutic dose of $8 \mathrm{ml}$, a continuous infusion of $7-10 \mathrm{ml} /$ hour was administered. In both groups, nalbuphine 10 or $20 \mathrm{mg}$ intramuscularly was offered at the first request for pain relief.

Maternal temperature during labour was measured tympanically with the Genius ${ }^{\mathrm{TM}} 2$ (Covidien, error $\pm 0.1^{\circ} \mathrm{C} / 32.2^{\circ} \mathrm{F}$ ) or rectally with the thermoval classic (Hartmann, error $\pm 0.1^{\circ} \mathrm{C} / 32.2^{\circ} \mathrm{F}$ ). Temperature was taken at admission and on indications including: clinical signs of hyperthermia, in case of a tachycardic ( $\geq 160$ beats/min) cardiotocogram (CTG), or 
clinical signs of an intrauterine infection. The following neonatal outcomes were recorded: birth weight, Apgar score at 5 minutes $(<7)$, umbilical artery $\mathrm{pH}(<7.00)$, umbilical artery base excess $(\leq-15 \mathrm{mmol} / \mathrm{L})$, and fever at birth $\left(\geq 38.0^{\circ} \mathrm{Cor} \geq 100.4^{\circ} \mathrm{F}\right)$ measured rectally within one hour postpartum. Results of blood or surface cultures of ear, mouth or stomach, and serum C-Reactive Protein (CRP, mg/l) were obtained from institutional laboratory databases. Clinical symptoms of possible neonatal infection like apnea, hypothermia defined as a rectal temperature below $36.4^{\circ} \mathrm{C}$ or $\leq 97.5^{\circ} \mathrm{F}$, fever defined as a rectal temperature above $\geq 38.0^{\circ} \mathrm{C}$ or $\geq 100.4^{\circ} \mathrm{F}$, lethargy, vomiting, increasing residuals, respiratory distress, and hemodynamic instability occurring within $72 \mathrm{~h}$ after birth were evaluated. Maternal and labour characteristics were abstracted from maternal and infant medical records: age, gestational age at delivery, start of labour, duration of rupture of membranes, use of systemic analgesia or antibiotics intra-partum, duration of EA, maternal fever $\left(\geq 38.0^{\circ} \mathrm{C}\right.$ or $\geq 100.4^{\circ} \mathrm{F}$ ), duration of second stage of labour, and mode of delivery. The primary outcome measure was neonatal sepsis. Neonatal sepsis was defined as having two or more clinical symptoms of infection (apnea, hypothermia defined as rectal temperature below 36.4 degrees Celsius, fever defined as rectal temperature above 38 degrees Celsius, lethargy, vomiting, increasing residuals, respiratory distress, hemodynamic instability) diagnosed and persistent within $72 \mathrm{~h}$ after birth, plus a positive blood culture for bacteria (excluding Staphylococcus epidermidis) or, in the case of a negative blood culture for neonatal sepsis, a rise in C-reactive protein (CRP) > $10 \mathrm{mg} / \mathrm{l}$, or a positive surface (ear, mouth or stomach) culture of a known virulent pathogen (Van der Ham et al., 2012). Based on these criteria, every single neonatal case was judged by an independent pediatrician-neonatologist (R.M.), who adjudicated between sepsis or no sepsis.

\section{Statistical analysis}

First, the association of neonatal sepsis with EA use was evaluated. Second, a subgroup analysis was performed where this association was studied separately for mothers with intra-partum fever and for afebrile mothers.

Differences in numerical and categorical variables between the EA group and the non-EA group were compared using linear and logistic regression, accounting for the matching variable (vaginal parity). The effects of EA on numerical and binary outcome variables 
were analyzed using multivariable linear and logistic regression analysis, respectively, with correction for the matching variable (parity) and literature-based preselected, potential confounders for neonatal sepsis ( $\geq 18 \mathrm{~h}$ duration of ruptured membranes and mode of delivery). ${ }^{18}$ Confounding factors were assessed using the $10 \%$ of OR rule. The number of potential confounders was restricted to make sure that the number of events per variable in the regression model were large enough to obtain reliable parameter estimates. ${ }^{20}$ Odds ratios (ORs) and their 95\% confidence intervals (Cls) were computed. A two-sided probability value of $\leq 0.05$ was considered statistically significant. No a priori sample size calculation was performed due to the retrospective design of the study. Statistical analysis was performed using SPSS ${ }^{\circledR}$ software (version 18.0, SPSS Inc., Chicago, IL, USA).

\section{Results}

Among 4310 deliveries during the three-year study period, 453 (10.5\%) were performed under EA for pain relief during labour (EA group) and fulfilled the inclusion criteria. These deliveries were matched on vaginal parity with 453 deliveries without EA (non-EA group). Both groups consisted of 327 nulliparous women (72.2\%). Of the multiparous women, 48 $(10.6 \%)$ had undergone only one caesarean section in the past, and $78(17.2 \%)$ had at least one previous vaginal delivery. Less than $1.5 \%$ of the data were missing for each variable. Neonatal outcomes at birth according to EA use are shown in Table I.

Table I. Neonatal outcome at birth according to epidural analgesia use

\begin{tabular}{|c|c|c|c|}
\hline & $\begin{array}{l}\text { EA group } \\
(n=453)\end{array}$ & $\begin{array}{l}\text { non-EA group } \\
\qquad(n=453)\end{array}$ & P-value* \\
\hline Birth weight (g) & $3538 \pm 486$ & $3393 \pm 529$ & $<0.001$ \\
\hline Apgar score at 5 minutes $<7$ & $14(3.1 \%)$ & $12(2.6 \%)$ & 0.691 \\
\hline Umbilical artery $\mathrm{pH}<7.00$ & $4(0.9 \%)$ & $4(0.9 \%)$ & 1.000 \\
\hline Umbilical artery base excess $\leq-15(\mathrm{mmol} / \mathrm{l})$ & $5(1.1 \%)$ & $6(1.3 \%)$ & 0.762 \\
\hline Neonatal temperature at birth $\geq 38.00 \mathrm{C}$ & $52(11.6 \%)$ & $8(1.8 \%)$ & $<0.001$ \\
\hline
\end{tabular}


In the EA group, mean birth weight was significantly higher than in the non-EA group, whereas Apgar scores at five minutes and umbilical artery $\mathrm{pH}$ and $\mathrm{BE}$ were not significantly different between the two groups. Significantly more neonates born in the EA-group had fever $\geq 38.0^{\circ} \mathrm{C}(11.6 \%$ vs. $1.8 \%, p<0.001)$ at birth. EA was an independent risk factor for neonatal fever with an adjusted OR of 7.17 (95\%-Cl 3.36 to 15.29; $\mathrm{p}<0.001)$.

As shown in Table II, maternal age was not significantly different between the two groups, but women in the EA group had a significantly more advanced gestational age at delivery and were more frequently induced. Women in the EA group also had a significantly longer duration of ruptured membranes and received systemic analgesia and intra-partum antibiotics more frequently. Although the mean duration of the second stage of labour was not significantly different between the two groups, fewer women in the EA-group experienced a spontaneous vaginal delivery. The incidence of maternal intra-partum fever was significantly higher in the EA group than in the non-EA group ( $38.1 \%$ vs. $13.5 \%$; adjusted OR 3.80, 95\%-Cl 2.71 to $5.33 ; \mathrm{p}<0.001)$.

Table II. Maternal and labour characteristics according to epidural analgesia use

\begin{tabular}{|c|c|c|c|}
\hline & $\begin{array}{l}\text { EA group } \\
(n=453)\end{array}$ & $\begin{array}{l}\text { non-EA group } \\
\qquad(n=453)\end{array}$ & P-value* \\
\hline Maternal age (years) & $29.7 \pm 5.5$ & $29.0 \pm 5.5$ & 0.051 \\
\hline Gestational age (days) & $282.6 \pm 8.9$ & $280.1 \pm 8.9$ & $<0.001$ \\
\hline Induction of labor & $126(27.8 \%)$ & $69(15.2 \%)$ & $<0.001$ \\
\hline Duration of ruptured membranes (hours) & $19.9 \pm 28.9$ & $11.1 \pm 18.6$ & $<0.001$ \\
\hline Systemic analgesia use intra-partum & $329(72.6 \%)$ & $222(49.0 \%)$ & $<0.001$ \\
\hline Maternal fever intra-partum & $172(38.1 \%)$ & $61(13.5 \%)$ & $<0.001$ \\
\hline Antibiotic use intra-partum & $48(10.6 \%)$ & $6(1.3 \%)$ & $<0.001$ \\
\hline Duration of second stage (minutes) ** & $33.2 \pm 23.7$ & $32.7 \pm 27.2$ & 0.610 \\
\hline Mode of delivery & & & $<0.001$ \\
\hline • spontaneous vaginal & $258(57.0 \%)$ & $337(74.4 \%)$ & \\
\hline - instrumental vaginal & $81(17.9 \%)$ & $64(14.1 \%)$ & \\
\hline • caesarean section & $114(25.2 \%)$ & $52(11.5 \%)$ & \\
\hline
\end{tabular}


Figure 1. Evaluation of neonates born in the EA group and the non-EA group

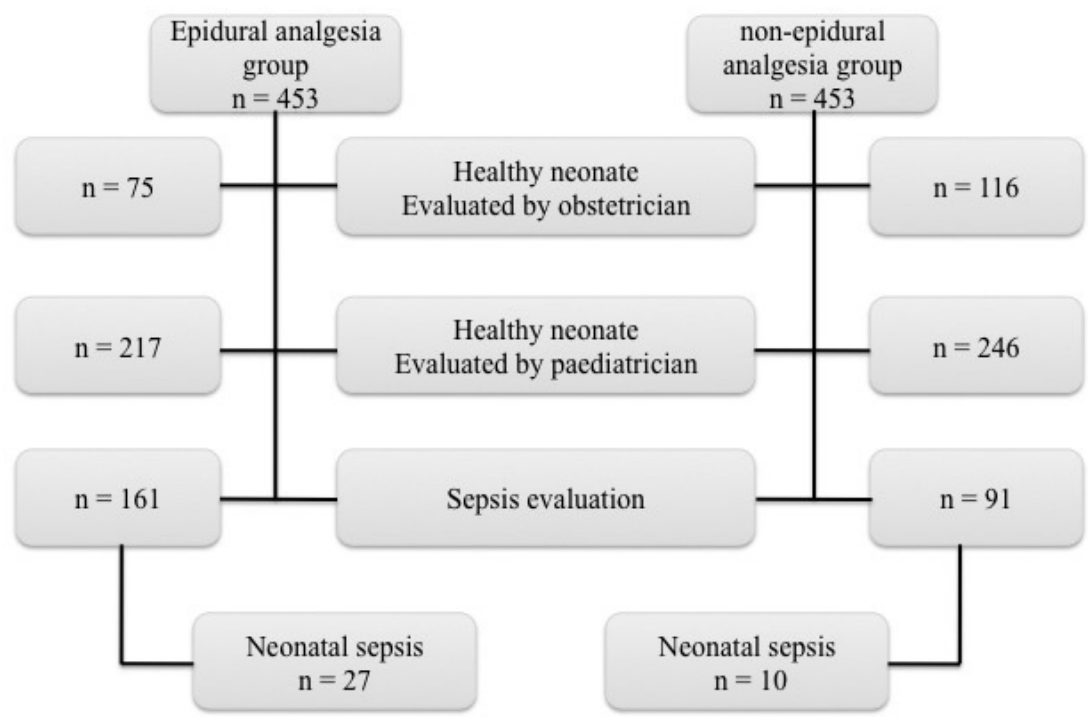

Figure 1 shows the evaluation of the neonates after birth. According to the local protocol, neonates born after an uneventful first period followed by a spontaneous vaginal delivery and judged by the obstetrician to be healthy and in good clinical condition at birth were not evaluated by a pediatrician (EA group, $n=75$; non-EA group, $n=116$ ). A pediatrician evaluated all other neonates at birth, including those born after an instrumental vaginal delivery or a caesarean section. In cases where they were judged to be healthy and in good clinical condition, with a normal temperature and without clinical symptoms of infection, the neonates were allowed to stay with the mother under supervision of the obstetrician (EA group, $n=217$; non-EA group, $n=246$ ). All other neonates underwent sepsis evaluation in the neonatal medium care unit by a pediatrician (EA group, $n=161$; non-EA group, $n=91$ ). As shown in Table III, the incidence of neonatal sepsis was significantly higher in the EAgroup $(6.0 \%$ vs. $2.2 \%, p=0.020)$. Logistic regression analysis with correction for only the matching variable parity showed that EA was significantly associated with an increased risk of neonatal sepsis (OR 2.81, 95\%-Cl 1.34 to $5.87 ; \mathrm{p}=0.006$ ). Mode of delivery and duration of ruptured membranes were selected as potential confounders. In the analysis, only duration of $\geq 18$ hours of ruptured membranes was shown to be a confounder and an independent risk 
factor for neonatal sepsis $(p=0.003)$. Multivariable logistic regression analysis, controlling for matching variable parity and $\geq 18$ hours of ruptured membranes, demonstrated that EA remained significantly associated with an increased risk of neonatal sepsis, with an OR of $2.43(95 \%-\mathrm{Cl} 1.15$ to $5.13 ; \mathrm{p}=0.020)$.

Sepsis was proven with a positive blood culture in only two neonates in the EA group and in none of the neonates in the non-EA group ( $0.4 \%$ vs. $0 \%, p=0.250)$. In the EA group, $16 / 25$ (64 $\%)$ neonates were classified as being suspected of sepsis because of clinical symptoms and increased CRP, whereas 9/25 (36\%) neonates had clinical symptoms, increased CRP and positive surface cultures. In the non-EA group, 9/10 (90\%) neonates had clinical symptoms and increased CRP, whereas one (10\%) neonate had clinical symptoms, increased CRP and a positive surface culture. A second analysis was performed to evaluate the association of EA with neonatal sepsis according to the occurrence of maternal intra-partum fever. In mothers with intra-partum fever, the incidence of neonatal sepsis was not significantly different between the EA group and the non-EA group (11.0\% vs. 8.2\%; Adjusted OR 1.19, 95\%-CI 0.42 to $3.40 ; p=0.744$ ), as it was in afebrile mothers ( $2.9 \%$ vs. $1.3 \%$; Adjusted OR $2.17,95 \%-\mathrm{Cl} 0.70$ to 6.72; $p=0.180$ ). In the EA group as well as the non-EA group, however, the incidence of neonatal sepsis was significantly higher in mothers with intra-partum fever than in afebrile mothers ( $11.0 \%$ vs. $2.9 \%$ in EA-group, $p=0.004 ; 8.2 \%$ vs. $1.3 \%$ in Non-EA-group, $p=0.006$ ).

Table III. Neonatal sepsis according to epidural analgesia use

\begin{tabular}{|c|c|c|c|c|}
\hline & $\begin{array}{l}\text { EA group } \\
(n=453)\end{array}$ & $\begin{array}{c}\text { non-EA group } \\
(n=453)\end{array}$ & OR (95\%-Cl) & P-value* \\
\hline Neonatal sepsis (\%) & $27(6.0)$ & $10(2.2)$ & $2.43(1.15-5.13)$ & 0.020 \\
\hline $\begin{array}{l}\text { - Neonatal sepsis in case of maternal } \\
\text { intra-partum fever }\end{array}$ & $19(11.0)$ & $5(8.2)$ & $1.19(0.42-3.40)^{*}$ & 0.744 \\
\hline - Neonatal sepsis in afebrile mothers & $8(2.9)$ & $5(1.3)$ & $2.17(0.70-6.72)^{*}$ & 0.180 \\
\hline
\end{tabular}




\section{Discussion}

In this retrospective, single-center, matched case-control study, EA was associated with an increased risk of neonatal sepsis. This is not in agreement with earlier published reports, and the discrepancy is because of differences in the definition of sepsis. When only the incidence of neonatal sepsis defined as a positive blood culture was considered, we found no association between the two, as published earlier. ${ }^{4,7,12,14}$ However, drawing a sufficient volume of neonatal blood is often not feasible as well as unreliable for detecting low-level bacteremia. ${ }^{19}$ Data suggest that $1.0 \mathrm{ml}$ of blood should be the minimum volume drawn for culture. ${ }^{19}$ Connell et al indicated that blood cultures of sufficient volume were twice as likely to yield a positive result. ${ }^{21} \mathrm{Neal}$ et al demonstrated $>50 \%$ of blood specimens were less than $0.5 \mathrm{ml.}{ }^{22}$ This results in a false negative blood culture.

Because of this problem of false negative blood cultures and the difficulty in diagnosing neonatal sepsis, we used a definition of sepsis recently suggested by others. ${ }^{23}$

Of the preselected confounders, only the duration of ruptured membranes $\geq 18$ hours proved to be a significant independent risk factor for neonatal sepsis. This finding supposes infection plays a role in the association between EA and neonatal sepsis. However, although chorioamnionitis was not documented in our study, we judged this factor as non-significant, as EA remained associated with neonatal sepsis in the multivariable analysis after correcting for parity and prolonged rupture of membranes.

EA was also an independent risk factor for maternal fever and neonatal fever, as demonstrated by many other investigators, ${ }^{1,4,5,7,9,12,19}$ Moreover, maternal intra-partum fever has been shown to result in adverse fetal and neonatal outcome. ${ }^{10,11,24-26}$ In our study, the incidence of neonatal sepsis was increased in mothers with intra-partum fever independent of labour EA use. This suggests maternal intra-partum fever is a mediator in the relationship between EA and neonatal sepsis. Various theories have been proposed to explain the causal mechanism between EA and maternal fever but the exact etiology is still debated..$^{27,28}$ The first published reports about labour EA and hyperthermia found no relation to clinical evidence of infection. ${ }^{1,2}$ Recently, additional evidence supports that EArelated fever is associated with a non-infectious inflammatory state, as demonstrated by elevated interleukin (IL)-6 levels. ${ }^{8,29-31}$ The strength of the present study is that it is the first study to report the incidence of neonatal sepsis based on these particular diagnostic and 
clinical criteria in association with labour EA. It was performed in a single non-university teaching hospital regarding individual case analysis of neonatal sepsis parameters and treatment of maternal and neonatal fever.

This study also has several limitations. Firstly, it concerns a retrospective study design. Secondly, determining the mechanism for maternal fever with EA is made difficult by the characteristics of women in labour who receive them. ${ }^{27}$ It is not clear whether a cause-andeffect relationship between EA and maternal fever exists, or whether EA is a marker for other factors that place a woman at risk. ${ }^{3,4,6}$ In agreement with the latter idea are several possible biases in our study, due to the restrictive use of EA in The Netherlands during the study period: the higher rate of labour induction in the EA-group suggesting more pathological conditions; the low EA rate, suggesting other indications than pain for EA, for example dystocic labour; and the higher caesarean section rate, also suggesting more labour dystocia. In addition, because of the $10 \%$ of OR rule we could only correct for 2 confounders in the statistical analysis. ${ }^{20}$ Thirdly, reliable results were only available for the duration of ruptured membranes and not for the total duration of labour, or the number of vaginal examinations in labour, which might be confounders for neonatal sepsis. Finally, neonatal sepsis was assessed only when indicated, as judged by the obstetrician or paediatrician, which might result in selection bias because of a higher rate of neonatal sepsis suspicion in the EA-group regarding the potential pathological condition leading to the EA. Moreover, we were not able to specify the amount of neonatal blood drawn for culture, possibly resulting in a volume too small for a reliable blood culture test result. In conclusion, our data showed an association between EA and neonatal sepsis, possibly mediated by maternal intra-partum fever. Because the etiology of EA fever still remains controversial and increasing evidence shows adverse fetal and neonatal outcome in cases of maternal intra-partum fever, it is necessary to evaluate and treat all neonates with clinical suspicion of sepsis or with a "high-likelihood" of early-onset neonatal sepsis. 


\section{Reference List}

1. Fusi L, Steer PJ, Maresh MJ, Beard RW. Maternal pyrexia associated with the use of epidural analgesia in labor. Lancet 1989;1:1250-1252.

2. Camann WR, Hortvet LA, Hughes $N$, Bader AM, Datta $S$. Maternal temperature regulation during extradural analgesia for labor. $\mathrm{Br} \mathrm{J}$ Anaesth 1991;67:565-568.

3. Herbst A, Wølner-Hanssen $\mathrm{P}$, Ingemarsson I. Risk factors for fever in labor. Obstet Gynecol 1995;86:790-794.

4. Lieberman E, Lang JM, Frigoletto F, Jr., Richardson DK, Ringer SA, Cohen A. Epidural analgesia, intrapartum fever, and neonatal sepsis evaluation. Pediatrics 1997;99:415-419.

5. Yancey MK, Zhang J, Schwars J, Dietrich CS 3rd, Klebanoff M. Labor epidural analgesia and intrapartum maternal hyperthermia. Obstet Gynecol 2001;98:763-770.

6. Ramin SM, Gambling DR, Lucas MJ, Sharma SK, Sidawi JE, Leveno KJ. Randomized

trial of epidural versus intravenous analgesia during labor. Obstet Gynecol 1995;86:783-789.

7. Philip J, Alexander JM, Sharma SK, Leveno KJ, McIntire DD, Wiley J. Epidural analgesia during labor and maternal fever. Anesthesiology 1999;90:12711275.

8. Riley LE, Celi AC, Onderdonk AB, et al. Association of epidural-related fever and non-infectious inflammation in term labor. Obstet Gynecol 2011;117:588-595.

9. Segal S. Labor epidural analgesia and maternal fever. Anesth Analg 2010;111:1467-1475.

10. Lieberman E, Lang J, Richardson DK, Frigoletto FD, Heffer LJ, Cohen A. Intrapartum maternal fever and neonatal outcome. Pediatrics 2000;105:8-13.

11. Impey L, Greenwood C, MacQuillan K, Reynolds M, Sheil O. Fever in labor and neonatal encephalopathy: a prospective cohort study. BJOG 2001;108:594-597.
12. Agakidis C, Agakidou E, Philip Thomas S, Murthy P, John Lloyd D. Labor Epidural analgesia is independent risk factor for neonatal pyrexia. J Matern Fetal Neonatal Med 2011;24:1128-1132.

13. Goetzl L, Cohen A, Frigoletto F Jr, Ringer SA, Lang JM, Lieberman E. Maternal epidural use and neonatal sepsis evaluation in afebrile mothers. Pediatrics 2001;108:1099-1102.

14. Gonen R, Korobochka R, Degani S, Gaitini L. Association between epidural analgesia and intrapartum fever. Am J Perinatol 2000;17:127-130.

15. Heesen M, Klöhr S, Rossaint R, Straube S, Van de Velde M. Labour epidural analgesia and antiinfectious management of the neonate: a metaanalysis. J Perinat Med 2012;40:625-630.

16. Haque KN, Radford P. Epidural analgesia and fever. Pediatrics 2002;110:196-197.

17. Kaul B, Vallejo M, Ramanathan S, Mandell G. Epidural labor analgesia and neonatal sepsis evaluation rate: a quality improvement study. Anesth Analg 2001;93:986-990.

18. Andres Camacho-Gonzalez A, Spearman PW, Stoll BJ. Neonatal Infectious Diseases. Evaluation of Neonatal Sepsis. Pediatr Clin North Am 2013;60:367389.

19. Polin RA, Committee on Fetus and Newborn. Management of neonates with suspected or proven early-onset bacterial sepsis. Pediatrics 2012;129:1006-1015.

20. Peduzzi P, Concato J, Kemper E, Holford TR, Feinstein AR. A simulation study of the number of events per variable in logistic regression analysis. J Clin Epidemiol 1996;49:1373-1379.

21. Connell TG, Rele M, Cowley D, Buttery JP, Curtis N. How reliable is a negative blood culture result? Volume of blood submitted for culture in routine practice in a children's hospital. Pediatrics 2007;119:891-896.

22. Neal PR, Kleiman MB, Reynolds JK, Allen SD, Lemons JA, Yu PL. Volume of

blood submitted for culture from neonates. J Clin Microbiol 1986;24:353-356. 
23. Van der Ham DP, van der Heyden JL, Opmeer $\mathrm{BC}$, et al. Management of late preterm premature rupture of membranes: the PPROMEXIL-2 trial. Am J Obstet Gynecol 2012;207:276.e1-10.

24. Lieberman E, Eichenwald E, Mathur G, Richardson D, Heffner L, Cohen A. Intrapartum fever and unexplained seizures in term infants. Pediatrics 2000;106:983-988.

25. Greenwell EA, Wyshak G, Ringer SA, Johnson LC, Rivkin MJ, Lieberman E. Intrapartum temperature elevation, epidural use, and adverse outcome in term infants. Pediatrics 2012;129:e447-e454.

26. Petrova A Demissie K, Rhoadss GG, Smulian JC, Marcella S, Ananth CV.

Association of maternal fever during labor with neonatal and infant morbidity and mortality. Obstet Gynecol 2001;98:20-27.

27. Viscomi CM, Manullang T. Maternal fever, neonatal sepsis evaluation, and epidural labor analgesia. Reg Anesth Pain Med 2000;25:549-553.

28. Alexander JM. Epidural analgesia for labor pain and its relationship to fever. Clin Perinatol 2005;32:777-787.

29. De Jongh RF, Bosmans EP, Puylaert MJ, Ombelet WU, Vandeput HJ, Berghmans RA. The influence of anaesthetic techniques and type of delivery on peripartum serum interleukin-6 concentrations. Acta Anaesthesiol Scand 1997;41:853-860.

30. Smulian JC, Bhandari V, Vintzileos AM, ShenSchwarz S, Quashie C, Lai-Lin YL, et al. Intrapartum fever at term: serum and histologic markers of inflammation. Am J Obstet Gynecol 2003;188:269274.

31. Goetzl L, Cohen A, Frigoletto F Jr, Ringer SA, Lang JM, Lieberman E. Maternal epidural use and neonatal sepsis evaluation in afebrile mothers. Pediatrics 2001;108:1099-1102. 


\title{
7 Prevalence and predictors of chronic pain after labour and delivery
}

\author{
JMFW VERMELIS \\ MMLH WASSEN \\ AAA FIDDELERS \\ JG NIJHUIS \\ MAE MARCUS
}




\section{Abstract}

\section{Purpose of review}

Labour pain is a complex phenomenon with sensory, emotional, and perceptive components and can be regarded as one of the most serious kinds of pain. Different strategies to approach acute labour pain have been developed. Chronic pain after labour and delivery has not been studied so extensively. In this review recent findings about chronic pain after labour and delivery will be discussed.

\section{Recent findings}

Prevalence rates of chronic pain after caesarean section are between 6 and $18 \%$ and after vaginal delivery they are between 4 and 10\%. Predictors for chronic pain after caesarean section and delivery are previous chronic pain, general anaesthesia and higher postdelivery pain. As labour pain is rated as one of the most serious kinds of acute pain one could make a prediction about chronic pain after labour and delivery. We speculate that effective treatment of this pain with epidural analgesia could prevent the development of chronic pain.

\section{Summary}

Treatment of acute pain during labour and delivery is necessary to prevent chronic pain. Future studies should focus on the long-term effects of different analgesic regimens on the development of chronic pain after labour and delivery. 


\section{Introduction}

Pain is defined as 'an unpleasant sensory and emotional experience associated with actual or potential tissue damage, or described in terms of such damage' by the International Association for the Study of Pain. ${ }^{1}$ This definition recognizes the interplay between the objective, physiological sensory aspects of pain and its subjective, emotional, and psychological aspects. Chronic pain often occurs as a complication of surgery, which can be associated with significant morbidity and socio-economic impact. It is recognized that persistent pain after surgery is a common problem. ${ }^{2}$ Chronic pain after surgical procedures

such as groin hernia repair, breast and thoracic surgery, leg amputation, and coronary artery repair leads to chronic pain complaints in $10-50 \%$ of patients $s^{3-7}$, whereas $2-10 \%$ have moderate to severe pain. ${ }^{2}$

That acute postoperative pain is a predictor for chronic pain is known. ${ }^{8}$ Therefore, it is expected that acute pain during labour and delivery would also generate chronic pain. Until now only a few data have been generated about the occurrence of chronic pain after delivery, showing the incidence of chronic pain after caesarean section to be at least $6 \%{ }^{9}$, whereas it is $4 \%$ after vaginal birth. ${ }^{10}$

In this review, we summarize the recent literature on acute pain in relation to obstetrics and the development of chronic pain in general. Furthermore, predictors and the prevalence of chronic pain after labour and delivery will be discussed.

\section{Acute pain and obstetrics}

The amount of pain experienced during labor is the result of complex processing of multiple physiologic and psycho-social factors on a woman's individual interpretation of nociceptive labor stimuli. ${ }^{11}$ In the 1980 s, Melzack et al. ${ }^{12}$ determined that about $65-68 \%$ of primiparas and multiparas rated their labour pain as 'severe' or 'very severe'; moreover, $23 \%$ of primiparas and $11 \%$ of multiparas rated their pain as 'horrible'. Labour pain scores are found to be higher than average pain scores reported by patients with chronic low-back pain, pain in nonterminal cancer patients, arthritic pain and other forms of chronic and acute pain that are universally acknowledged to be severe. ${ }^{13}$ 

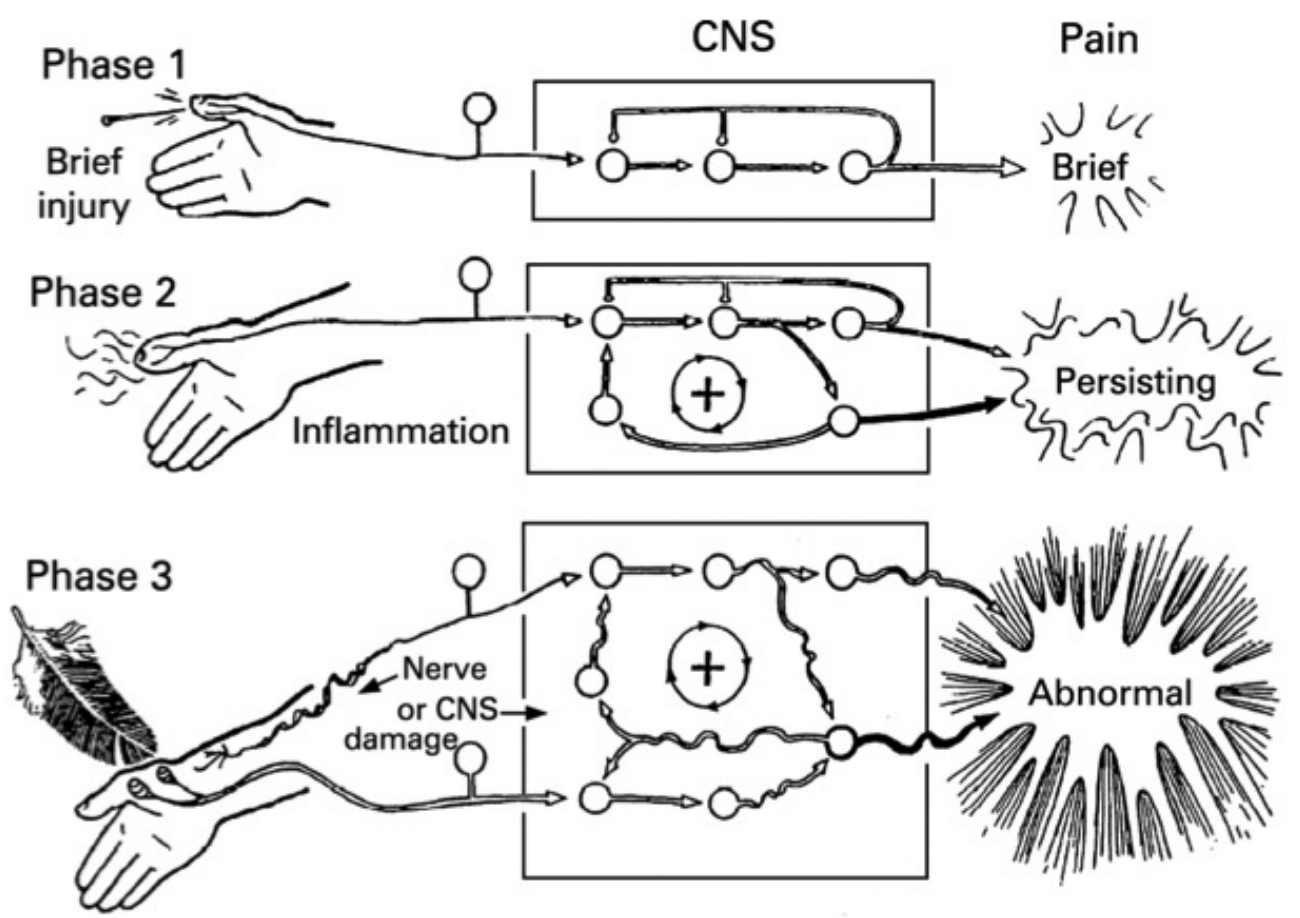

Labour pain arises from contraction of the myometrium against the resistance of the cervix and perineum, progressive dilatation of the cervix and lower uterine segment, as well as stretching and compression of pelvic and perineal structures. ${ }^{14}$ Pain during the first stage of labour is mostly visceral pain resulting from uterine contractions and cervical dilatation. During this phase, T10 - L1 dermatomes are involved. The visceral afferent fibers responsible for labor pain travel with sympathic nerve fibers to the uterine and cervical plexuses, through the hypogastric and aortic plexuses, before entering the spinal cord with the T10 L1 nerve roots ${ }^{14}$ (see Fig. $2^{15}$ ).

The onset of perineal pain at the end of the first stage signals the beginning of fetal descent and the second stage of labor. Stretching and compression of pelvic and perineal structures intensifies the pain. Sensory innervation of the perineum is provided by the pudendal nerve $(\mathrm{S} 2-4)$, so pain during the second stage of labor involves the T10-S4 dermatomes ${ }^{14}$ (see Fig. $2^{15}$ ). The duration and severity of experienced pain could be of importance in the long- 
term psychological well-being and the development of chronic pain in the mother. However, data are lacking in this regard.

\section{Development of chronic pain}

Chronic pain is defined as pain that persists beyond the usual course of an acute disease or after a reasonable time for healing to occur. This period can vary from 2 to 6 months. ${ }^{1}$ After surgery, the pathogenic mechanisms of pain are complex. Some main risk factors for developing chronic pain are acute postoperative pain and the intensity of preoperative pain. Also type of surgery and the patient's genetic and psychosocial profile is of importance. ${ }^{2}$

Acute pain is useful, as it indicates actual or potential tissue damage and motivates a response that removes the organism from that threat. Activation of these peripheral nociceptors signals the presence, location, intensity and duration of a noxious stimulus and fades when the stimulus is removed. Nociceptors, also called primary afferents, are either lightly myelinated Ad or unmyelinated C fibers. The Ad fibers are associated with cold and pressure and the $\mathrm{C}$ fibers can respond to thermal, mechanical and chemical stimuli. ${ }^{16}$

Another kind of pain that occurs to tissue injury and inflammation is inflammatory pain. In a surgical wound, inflammation is induced as a result of direct trauma with release of inflammatory mediators from tissues and cells. It results in a local higher sensitivity (peripheral sensitization). As a consequence of an increase in the excitability of neurons in the central nervous system (central sensitization), inflammatory pain is also associated with exaggerated responses to normal sensory inputs. In many chronic pain conditions, pain persists in the absence of continued tissue damage. There is a combination of sensory loss and paradoxical hypersensitivity. Damage of the afferent transmission system causes partial or complete loss of input to the nervous system, leading to a negative sensory phenomenon such as loss of touch or temperature or pressure sensations. Repeated or prolonged noxious stimuli are able to upregulate the nervous system at a number of sites (peripheral nerves, spinal cord and the brain/brainstem) resulting in the phenomenon that painful sensations become more painful (hyperalgesia) or previously nonpainful sensations are perceived as painful (allodynia)2 (see Fig. $1^{17}$ ).

In the case of chronic pain after labour, the states of chronic pain that could already exist 
in this population, such as pelvic pain, back pain and pelvic girdle pain, should first be described. Chronic pelvic pain is a major public health problem in the developed world. Chronic pelvic pain is a symptom, not a diagnosis, and is defined as intermittent or constant pain in the lower abdomen or pelvis of at least 6 months' duration, not occurring exclusively with menstruation or intercourse and not associated with pregnancy. ${ }^{18} \mathrm{~A}$ multidisciplinary approach is often required in the treatment of chronic pelvic pain. Back pain and pelvic girdle pain are very common in pregnancy. Prevalence rates of $42-70 \%$ have been found in previous prospective and retrospective studies. ${ }^{19-21}$ It is obvious that this pain can interfere with many activities of daily living.

Figure 2. Schematic depiction of the peripheral nociceptive pathways involved in the pain of childbirth

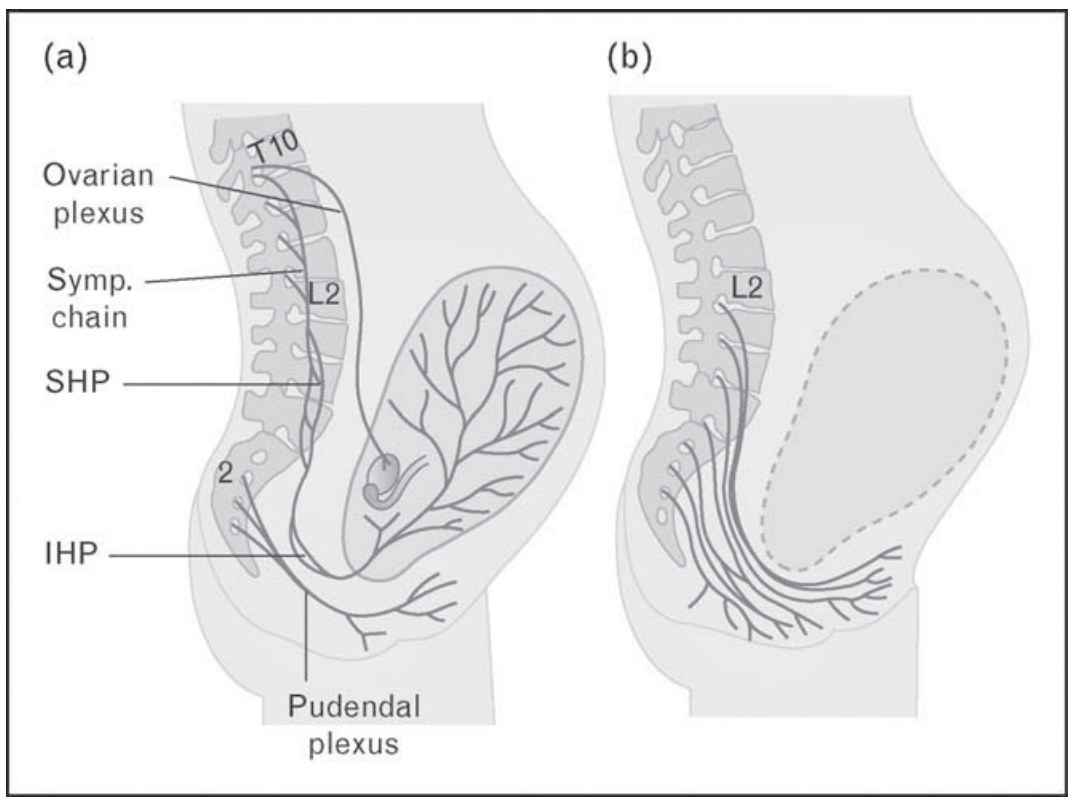

(a) The uterus, including the lower uterine segment and cervix, is supplied by afferents that pass from the uterus to the spinal cord by accompanying sympathetic nerves through the cervical plexus, the superior and inferior hypogastric plexuses (SHP, IHP), the lumbar and lower thoracic sympathetic chain, and to the $T 11, T 12$, and $L 1$ nerve roots. The vagina and perineum are supplied by afferents that travel to the spinal cord via the pudendal nerve to the S2-4 nerve roots. (b) The nerve involved in the transmission of nociceptive impulses is provoked by noxius stimulation of pelvic structures. 


\section{Chronic pain and caesarean section}

Post-caesarean patients differ from the general surgical population because of concerns of exposure to analgesic drugs to the newborns and because of a need for early physical request to care for their baby. Pain treatment after childbirth may even be less adequate than after surgery. This is because of the restraint to use non- steroidal anti-inflammatory drugs or adequate doses of opioids during breastfeeding. ${ }^{25}$

Few studies have focused on chronic pain after cesarean section. Almeida et al. ${ }^{26}$ found that $67 \%$ of women with chronic pelvic pain had a history of caesarean section. A positive association was observed between a history of caesarean section and chronic pelvic pain, independent of the association with other findings detected by diagnostic laparoscopy. ${ }^{26}$ Another study with a total of 220 patients showed that $18.6 \%$ of patients still experienced pain more than 3 months after caesarean section, whereas in $12.3 \%$ of patients pain remained after a mean observation time of 10 months after surgery. Daily pain was reported in $5.9 \%$ of the patients. The type of anesthesia was found to be a predictor of chronic pain, showing that patients undergoing caesarean section under general anaesthesia had a higher frequency of pain than patients receiving spinal anaesthesia. ${ }^{9}$ In this study patients also had a higher recall of postoperative pain as well as previous pain problems. ${ }^{9}$ In an Asian study, the incidence of chronic pain after 3 months was $9.2 \%$ after elective caesarean section under spinal anaesthesia. Higher recalled pain scores postoperatively, the presence of pain elsewhere and nonprivate insurance status were found to be independent risk factors. ${ }^{27}$

Tissue trauma from surgery represents a common cause of chronic pain and disability ${ }^{3,28}$ Women are at increased risk compared with men concerning developing chronic pain after surgery ${ }^{7,22}$, and exhibithigherchronic pain severity. ${ }^{2}$ On the basis of this knowledge, caesarean section might certainly induce chronic pain. Possible causes of chronic pain after caesarean section are anatomic distortion of pelvic structures or adhesions involving bladder, round ligaments and adjacent structures, after suture and abnormal healing. Another possible cause is the occurrence of myofascial pain due to nerve bundle injury and formation of neuromas at the site of incision. Effective strategies for the relief of postoperative pain after caesarean section are summarized in a review by Lavand'homme. ${ }^{25}$ This review concludes that current studies agree that drugs combinations multimodal or balanced analgesia are mandatory to achieve satisfactory and effective pain relief with reduced side effects. 
Effective perioperative block of nociceptive input from the wound by means of regional anaesthesia and the administration of analgesic drugs may prevent central sensitization and reduce development of chronic pain.

\section{Chronic pain and delivery}

Eisenach et al..$^{29}$ recently compared the occurrence of chronic pain after caesarean section and after vaginal delivery. For this prospective, longitudinal cohort study 1288 women were enrolled. The prevalence of severe acute pain within $36 \mathrm{~h}$ postpartum was found to be $10.9 \%$ and persistent pain after 8 weeks was found to be $9.8 \%$. Severity of acute postpartum pain was independently related to the risk of persistent postpartum pain, whereas no relation was observed concerning mode of delivery. Women with severe acute postpartum pain had a 2.5 -fold increased risk of persistent pain. Interestingly this study also showed that patients with severe acute postpartum pain had a three-fold increased risk of postpartum depression compared with those with mild postpartum pain. ${ }^{29}$

In an American study, chronic pain after caesarean section and vaginal delivery were compared and no difference was found. The incidence of pain at 8 weeks was nearly $10 \%$, regardless of mode of delivery, with half of those having activities of daily living affected by pain..$^{30}$ Independent predictive variables for chronic pain at 8 weeks post delivery were age, cigarette smoking and rate of treatment of postdelivery pain after vaginal delivery. And after caesarean section the independent predictive variables were somatization score, pain with menstruation, state of health, caesarean section for dystocia and spinal anaesthesia versus epidural anaesthesia. ${ }^{31}$

A study from Finland found a significant difference in persistent pain 1 year after delivery between caesarean section (44/229, 18\%) and vaginal delivery (20/209, 10\%). The persistent pain was mild in 55\% of the women in both groups, and intense or unbearable in four women after caesarean sections and in six women after vaginal births. Persistent pain was significantly more common in women with previous pain, previous back pain and any chronic disease. The women with persistent pain recalled significantly more pain on the day after caesarean section and vaginal birth than those who did not report persistent pain. ${ }^{32}$ Genital and pelvic pain are common and well documented problems in the early postpartum 
period but little is known about their course. The reported prevalence rates of perineal pain at 12-24 months postpartum range from 5 to $33 \% .^{33}$

In a recent small study, almost half of the 114 participants reported a current (18\%) or resolved (26\%) episode of genital or pelvic pain lasting 3 or more months. Nine percent of the mothers continued to experience pain that started after they last gave birth. ${ }^{34}$

In an Australian study, the prevalence and persistence of health problems were assessed 6 months after childbirth. They concluded that health problems commonly occurred after childbirth, with some resolution over the 6 months postpartum. Some important differences in prevalence of health problems were evident when parity and method of birth were considered. Primiparas were more likely than multiparas to report perineal pain and sexual problems. Compared with unassisted vaginal births, women who had caesarean sections reported more exhaustion, lack of sleep, and bowel problems and reported less perineal pain and urinary incontinence. Women with forceps or vacuum extraction reported more perineal pain and sexual problems. ${ }^{10}$

\section{Conclusion}

Chronic pain after surgery is a common finding and has been studied extensively. Strong predictors of chronic pain after surgery are preoperative pain and acute postoperative pain. Prevalence rates of chronic pain after caesarean section are between 6 and $18 \%$ and after vaginal delivery they are between 4 and 10\%. Predictors for chronic pain after caesarean section are a history of previous chronic pain, general anaesthesia and higher postoperative pain. After vaginal delivery the main predictors for developing chronic pain are also a history of previous chronic pain and higher pain scores postdelivery.

As labour pain is rated as one of the most serious kinds of acute pain one could make a prediction about chronic pain after labour and delivery. We speculate that effective treatment of this pain with epidural analgesia could prevent the development of chronic pain. The scarcity of data about the occurrence of chronic pain after labour and delivery warrants more extensive research. 


\section{Reference List}

1. Merskey H, Bogduk N. Classification of chronic pain: description of chronic pain syndromes and definitions of pain terms. Seattle: IASP Press; 1994.

2. Kehlet H, Jensen TS, Woolf CJ. Persistent postsurgical pain: risk factors and prevention. Lancet 2006;367:1618-1625.

3. Chahine L, Kanazi G. Phantom limb syndrome: a review. Middle East J Anesthesiol 2007;19:345-355.

4. Gärtner R, Jensen MB, Nielsen J, et al. Prevalence of and factors associated with persistent pain following breast cancer surgery. JAMA 2009;302:1985-1992.

5. Aasvang E, Kehlet $\mathrm{H}$. Chronic postoperative pain: the case of inguinal herniorrhaphy. $\mathrm{Br} \mathrm{J}$ Anaesth 2005;95:69-76.

6. Gottschalk A, Cohen SP, Yang S, Ochroch EA. Preventing and treating pain after thoracic surgery. Anaesthesiology 2006;104:594-600.

7. Wildgaard K, Ravn J, Kehlet H. Chronic postthoracotomy pain: a critical review of pathogenic mechanisms and strategies for prevention. Eur J Cardiothorac Surg 2009;36:170180.

8. Gramke HF, de Rijke JM, van Kleef $M$, et al. Predictive factors of postoperative pain after daycase surgery. Clin J Pain 2009;25:455-460.

9. Nikolajsen L, Sorensen HC, Jensen TS, Kehlet $\mathrm{H}$. Chronic pain following caesarean section. Acta Anaesthesiol Scand 2004;48:111-116.

10. Thompson JF, Roberts CL, Currie M, Ellwood DA. Prevalence and persistence of health problems after childbirth: association with parity and method of birth. Birth 2002;29: 83-94.

11. Lowe NK. The nature of labor pain. Am J Obstet Gynecol 2002;186:S16-S24.

12. Melzack R, Kinch RA, Dobkin P, et al. Severity of labor pain: influence of physical as well as psychologic variables. Can Med Assoc J 1984;130:579-584.

13. Melzack R. The myth of painless childbirth (the John J. Bonica lecture). Pain 1984;19:321-337.
14. McMahon S, Koltzenburg M., Wall and Melzack's textbook of pain. 5th ed. 2006. Philadelphia: Elsevier/Churchill Livingstone. pp. 794-795.

15. Loeser JD, Butler SH, Chapman CR, Turk DC. Bonica's management of pain. 3rd ed. New York: Lippincott Williams and Wilkins; 2001.

16. Marchand F, Perretti M, McMahon SB. Role of immune system in chronic pain. Nature 2005;6:521532.

17. Cervero F, Laird JMA. One pain or many pains? News Physiol Sci 1991;6:268-273.

18. Kennedy SH, Moore J. The initial management of chronic pelvic pain. Green top guidelines. London: Royal College of Obstetricians and Gynaecologists; 2005.

19. Nore 'n L, Ostgaard S, Johansson G, et al. Lumbar back pain and posterior pelvic pain during pregnancy: a 3-year follow-up. Eur Spine J 2002;11:267-271.

20. Wang SM, Dezinno P, Maranets I, et al. Low back pain during pregnancy: prevalence, risk factors, and outcomes. Obstet Gynaecol 2004;104:65-70.

21. Mogren IM, Pohjanen Al. Low back pain and pelvic pain during pregnancy. Spine 2005;30:983991.

22. Gutke A, Östgaard HC, Öberg B. Predicting persistent pregnancy-related low back pain. Spine 2008; 33: E386-E393.

23. Mogren IM. Physical activity and persistent low back pain and pelvic pain post partum. BMC Public Health 2008;8:417.

24. Wijnhoven $\mathrm{HAH}$, Vet de HCW, Smit HA, Picavet HSJ. Hormonal and reproductive factors are associated with chronic low back pain and chronic upper extremity pain in women: The MORGEN study. Spine 2006;31:1496-1502.

25. Lavand'homme P. Postcesarean analgesia: effective strategies and association with chronic pain. Curr Opin Anaesthesiol 2006;19:244-248. 
26. Almeida ECS, Nogueira FJ, Candido dos Reis FJ, Rosa e Silva JC. Cesarean section as a cause of chronic pelvic pain. Int J Gynaecol Obstet 2002;79:101-104.

27. Sng BL, Sia ATH, Quek K, et al. Incidence and risk factors for chronic pain after caesarean section under spinal anaesthesia. Anaesth Intensive Care 2009;37:748-752.

28. CBO guideline of medical treatment of pain during labor and delivery. Dutch society of anaesthesiology and Dutch society of obstetrics and gynaecology; 2008.

29. Eisenach JC, Pan PH, Smiley R, et al. Severity of acute pain after childbirth, but not type of delivery, predicts persistent pain and postpartum depression. Pain 2008;140:87-94.

30. Pan PH, Smiley R, Lavand'homme P, et al. Chronic pain after delivery: is it different between vaginal and operative deliveries? Anaesthesiology 2007;107:A767.

31. Pan PH, Smiley R, Lavand'homme P, et al. Predictive factors for chronic pain at 8 weeks after vaginal or cesarean deliveries. Anaesthesiology 2007;107:A1203.

32. Kainu JP, Sarvela J, Tiippana E, et al. Persistent pain after caesarean section and vaginal birth: a cohort study. Int J Obstet Anesth 2010;19:4-9.

33. Williams A, Herron-Marx S, Hicks C. The prevalence and enduring postnatal perineal morbidity and its relationship to perineal trauma. Midwifery 2007;23:392-403.

34. Paterson LQP, Davis SNP, Khalife $S$, et al. Persistent genital and pelvic pain after childbirth. J Sex Med 2009;6:215-221. 
In The Netherlands, labour analgesia was approached conservatively until very recently. The increased availability and effectiveness of epidural analgesia (EA) have altered the expectations of many women regarding intrapartum pain control. Nowadays, a significant number of women are requesting EA for relief of labour pain. The risks and benefits of EA, as well as other options for pain control, should be objectively presented to each woman before the onset of labour. This thesis contributes to the knowledge about the effect of EA on labour outcome. The general discussion summarizes the main results of this thesis, and answers the research questions as mentioned in the outline of this thesis (chapter 1 ). Furthermore, conclusions and implications for clinical practice are discussed, and topics for further research are proposed.

\section{Factors associated with prelabour epidural preference}

Involvement in decision-making regarding pregnancy, labour and delivery is a very important factor in satisfaction and childbirth experience, ${ }^{1,2}$ and women are increasingly encouraged to take an active role in this process. ${ }^{2,3} \mathrm{~A}$ study of Rijnders et al. showed, that more than $16 \%$ of Dutch women looked back negatively three years after their delivery. ${ }^{4}$ Women who had not been given a choice of pain relief were three times more likely to recall their birth experience negatively. As the demand for EA during delivery has been increasing over the years, and the choice of pain relief has been associated with a negative recall, it is worthwhile considering the factors which influence preferences and decisionmaking regarding EA. The first point of interest was to understand women's expectations and birth experience to reduce factors associated with a negative labour experience in future. We explored the prelabour EA preferences and independent factors influencing this choice in pain relief and decision-making in The Netherlands and Belgium. The Netherlands and Belgium are neighbouring countries and quite comparable in terms of, for example, language, geographic position and cultural habits, but characterized by differences in EA use (low rate in The Netherlands and high rate in Belgium) and organisation of maternity care. In The Netherlands, maternal age of 35 years or older, a positive attitude of the caregiver towards EA, and a lower degree of labour pain coping were independently associated with prelabour EA preference. In Belgium, only a lower 
degree of labour pain coping was associated with prelabour EA preference (chapter 2). Especially labour pain coping seems to be an important factor in the decision process to choose for EA. In addition, women can be encouraged to attend childbirth classes to help them prepare for stresses that may arise during labour and delivery. Care level in The Netherlands (first line midwifery care versus obstetrical hospital care), remarkably, did not contribute to this decision. As expected, a difference in EA preference was found between The Netherlands and Belgium. Schytt et al. showed in a population-based cohort study of 2529 women, that the woman and her background, as well as the local cultural practice in the delivery unit, matter with regard to the use of EA. ${ }^{5}$

\section{Trends in epidural analgesia use, rate of operative delivery and association of epidural analgesia with operative deliveries in The Netherlands}

In The Netherlands, EA use increased from 5.4\% in 2003 to $17.9 \%$ in $2012 .{ }^{6}$ This increase in EA rate in The Netherlands in the past ten years allowed us to study the effect of a more liberal use on the rate of operative deliveries. Remarkably, we found relatively stable rates of operative deliveries in a Dutch cohort with a nearly triplication of EA use in ten years (chapter 3). The positive association with the risk of unplanned caesarean section (CS) weakened in this study period, and EA was not associated with an increased risk of instrumental vaginal delivery (IVD) in nulliparous women (chapter 3 ). This supports the idea, that EA is not an important causal factor for operative deliveries. Our findings contradict those of previous studies. Results of randomised controlled trials and systematic reviews published between 2002 and 2004 did not demonstrate any difference in the rate of CS between women who had received EA and women who only received intravenous analgesia. ${ }^{7-11}$ However, earlier studies generating concern that EA was associated with an increase in the risk of CS, were comparable with our results. ${ }^{12,13}$ This implies and confirms, that the traditional Dutch approach of restrictive labour pain treatment is accompanied by an increased risk of CS. Restrictive EA use resulted in a selection of women with severe pain associated with labours of long duration, or for those with serious obstetrical pathology. An increased unplanned CS rate can surely 
be expected in this population with restrictive EA use. The use of EA in The Netherlands is rapidly becoming more liberal, represented in this study by the steep increase in EA during the last few years. We suggest, this has resulted in more women without obvious labour pathology to deliver with EA, as a weaker association was seen between labour EA and unplanned CS over time. Perhaps most illuminating are studies in institutions where the use of EA has increased abruptly over a short period of time. These studies also refute the hypothesis, that increased utilization of EA is responsible for an increased caesarean section rate. ${ }^{14,15}$ The results of our cohort study can be used to counsel women in The Netherlands about the effect of labour EA on the probability of an operative delivery.

\section{Timing of epidural analgesia and the rate operative deliveries}

The effect of timing of EA is very important. Because EA is the most effective labour analgesia, and, if the timing of its administration is not associated with any adverse consequences, then a request for EA should not be rejected to women in early labour. Women with EA have an increased risk of an instrumental vaginal delivery (IVD) (pooled risk ratio [RR] 1.38, 95\% Cl 1.24-1.53) compared to women who received non-EA or no analgesia.16 No association with caesarean section (CS) was found. Despite this risk, an increasing percentage of women request for EA during labour, and the challenge has been to find out a management strategy to reduce the risk of an operative delivery, for example by delaying the administration of EA in labour. In 2005, Wong et al. provided evidence that early EA, in comparison with late EA, does not cause an increased rate of CS and IVD in nulliparous women with spontaneous labour. ${ }^{17} \mathrm{~A}$ systematic review in 2007 by Marucci et al. reported on the timing effects of EA on the mode of delivery..$^{18} \mathrm{~A}$ similar rate for CS (odds ratio [OR] 1.00, 95\%-CI 0.82 to 1.23 ) and IVD in the early EA group and control group (OR 1.00, 95\%-Cl 0.83 to 1.21) was shown. However, these latter results are not convincing because of the use of a too broad definition of 'early labour' $(<4-5 \mathrm{~cm}$ cervical dilatation) and the use of an incomparable control group (including parenteral opioid and/or late EA). Therefore, we conducted a systematic review of studies in which the effects of early latent phase (defined as a cervical dilatation of $3 \mathrm{~cm}$ or less) EA (including combined-spinal epidural) and late EA (defined as at least $4 \mathrm{~cm}$ ) on the mode of delivery in nulliparous 
women at 36 weeks of gestation or more, were evaluated (chapter 4). In our review, we found no increased risk of CS or IVD for women receiving early EA in comparison with women receiving late EA. Therefore, a woman's request for EA early in labour cannot be rejected on the grounds of its presumed adverse influence on the mode of delivery. The findings of this review have important implications for practice.

\section{Routine epidural analgesia use and effect on operative deliveries}

All studies published until very recently about the effect of EA on mode of delivery had been conducted in women who had a strong need for pain relief. ${ }^{7,16}$ In general, there is a correlation between women with a strong need for pain relief and failure of progress in labour, for example, in the case of labour dystocia. ${ }^{19}$ Thus, a request for EA for pain relief may be an indication of obstructed labour. The question remains, whether these adverse effects are caused by EA itself or whether they are confounded by indication. Because there was a lack of randomised controlled trials investigating the effect of EA on labour outcome in women without a strong need for pain relief, the TREAT trial was conducted (chapter 5). The TREAT trial, a non-inferiority trial, was designed to test the hypothesis that routine EA is not unacceptably inferior to analgesia on request regarding the risk of an operative delivery (defined as an instrumental vaginal delivery or unplanned caesarean section). A total of 488 women were randomly allocated to the routine EA ( $n=233$ ) or analgesia on request group $(n=255)$. According to ITT analysis, 34.8\% (81/233) women in the routine EA group had an operative delivery, compared with $26.7 \%$ (68/255) in the analgesia on request group (difference $8.1 \%, 95 \% \mathrm{Cl}-0.1$ to $16.3 \%$ ). The difference in rate of operative deliveries according to the PP analysis was statistically significant (difference $8.9 \%, 95 \% \mathrm{Cl} 0.4 \%$ to $17.4 \%)$. Inferiority of EA could not be rejected, as in both analyses the upper bound of the confidence interval exceeded the pre-specified inferiority criterion of $+10 \%$. Non-inferiority of routine EA could not be demonstrated in this trial, but routine labour EA may result in an increased rate of operative deliveries, and is also associated with more adverse EA related maternal effects such as hypotension and motor blockade. On the basis of these results, we conclude that routine use of EA should not be advised (chapter 5). 


\section{Neonatal sepsis and epidural analgesia}

The TREAT trial showed no significant differences in neonatal outcomes between routine use of EA and analgesia on request (chapter 5). In the routine EA group $12.9 \%$ of the neonates developed fever $\left(\geq 38.0^{\circ} \mathrm{C}\right)$, compared to $9.4 \%$ neonates of the analgesia on request group (difference in percentage 3.5; 95\% Cl -2.1 tot 9.1) (chapter 5). However, although not statistically significant, more neonates from the analgesia on request group were admitted to the neonatal ward, compared to neonates from the routine EA group (difference in percentage 3.6; 95\% Cl -3.9 tot 11.0) (chapter 5). We cannot explain this difference on the basis of differences in neonatal outcome. Based on the (nonsignificantly) increased risk of neonatal fever in the routine EA group, we should have expected more admissions of neonates in this group. Increased rates of evaluation for neonatal sepsis have been associated with labour EA in the majority of published studies. ${ }^{20-25}$ The association between neonatal sepsis and labour EA is a complicated topic of research. In daily practice, the diagnosis of neonatal sepsis is difficult and mostly made in retrospect, and not at birth. ${ }^{26}$ In the literature, different definitions of neonatal sepsis are used and therefore the results of different studies are not comparable. We evaluated the association between labour EA and neonatal sepsis, based on diagnostic and clinical criteria according to a strict definition (chapter 6$).{ }^{27}$ We found significantly more neonates born in the EA-group with fever $\geq 38.0^{\circ} \mathrm{C}(11.6 \%$ vs. $1.8 \%, p<0.001)$ at birth compared to neonates from mothers who delivered without EA. This incidence of neonatal fever is comparable to the routine EA group (12.9\%) in the TREAT trial (chapter 5). We found significantly more neonates with neonatal sepsis according to the strict definition in the EA group (6.0\% vs. 2.2\%; OR 2.81, 95\%-CI 1.34 to 5.87). EA was an independent risk factor for neonatal sepsis (adjusted OR 2.43, 95\%-CI 1.15 to 5.13). If neonatal sepsis was only defined as a positive blood culture, no differences were found between the EA and non-EA group ( $0.4 \%$ vs. $0 \% ; p=0.250)$. In this study, the incidence of neonatal sepsis was increased in mothers with intra-partum fever, independent of labour EA use (chapter 6). This suggests, maternal intra-partum fever is a mediator in the relationship between EA and neonatal sepsis. EA is known to be an independent risk factor for maternal fever as well as neonatal fever. ${ }^{20-22,28-31}$ Besides, maternal intra-partum fever has been shown to result in adverse foetal and neonatal outcome. ${ }^{32-36}$ When regarding the results of the 
TREAT trial (chapter 5), no difference in maternal fever intrapartum was found. This might explain the comparable results in neonatal outcome between both groups.

\section{Chronic pain after labour and delivery}

Does chronic pain secondary to childbirth exist? Why should this question be answered? Because studies assume that severe pain can have neuropsychological consequences, and labour pain has been associated with postnatal depression and the development of posttraumatic stress disorder. ${ }^{37,38}$ Patients with severe acute postpartum pain had a three-fold increased risk of postpartum depression compared with women who experienced mild postpartum pain..$^{39}$ It is important to know the incidence of chronic pain after labour. In a literature review we found that the incidence of chronic pain ranged from 4-10\% after a vaginal delivery and 6-18\% after caesarean section (CS) (chapter 7). Predictors for chronic pain after CS and delivery are: previous chronic pain, general anaesthesia, and more postdelivery pain (chapter 7 ). Others showed, that women with severe acute postpartum pain had a 2.5 fold increased risk of chronic persistent pain. ${ }^{39}$ We speculate, that effective labour pain treatment with EA could reduce the onset of chronic pain after labour and delivery. In a separate study, we explored the effect of routine EA on chronic pain. These findings have not been analysed yet.

\section{Conclusions of this thesis and implications for clinical practice}

EA is a highly effective method of pain relief and a useful intervention in certain circumstances. In The Netherlands, among women of 35 years and older, a positive attitude of the caregiver towards EA, and a lower degree of labour pain coping were independently associated with prelabour EA preference. Over a recent period of 10 years, EA use in The Netherlands nearly tripled, representing a more liberal labour analgesia policy, without any important increase in the percentage of operative deliveries during the same period. In coming years, request for EA is expected to further increase. The association between EA and operative deliveries is becoming weaker - a possible reflection of a less problem driven policy towards the use of EA. The timing of the administration of EA is not associated with any excess adverse consequences. So, if women decide to choose for EA during labour, it 
should not be rejected to women in early labour $(<3 \mathrm{~cm}$ cervical dilatation). The evidence from the TREAT trial suggests, that EA should not be used routinely, as it is currently the case in many hospitals in the U.S. Routine use of EA likely increases operative delivery rates, and causes more EA-related adverse effects like maternal hypotension and motor blockade, as compared to analgesia on maternal request.

Women need to be adequately informed about the risks associated with labour EA, after which they should have the opportunity to request EA.

\section{Future perspectives}

Data of The Netherlands are not generally applicable to other countries, because EA policy was very restrictive in our country until very recently. It will be of great value to repeat the cohort study on the association between EA and instrumental deliveries in The Netherlands in coming years, as we expect a gradual but persistent increase in EA use in the future. Because of the ongoing increase in EA request in The Netherlands and also worldwide, it is necessary to inform and counsel patients about the benefits and risks of EA.

Besides the effect of routine EA on mode of delivery and labour outcome as described in this thesis, also maternal preferences and long term health of the mother is important and contribute to decision-making. The TREAT trial also assessed patients' beliefs about EA antepartum, ${ }^{40}$ and pain catastrophizing ${ }^{41}$. The Short Form (SF-36) evaluated ante partum and six weeks postpartum quality of life. Six weeks postpartum in the routine EA group as well as the analgesia on request group also childbirth experience ${ }^{40}$ was evaluated.

The debate about the aetiology of maternal fever accompanied with epidural analgesia is still going on and a very intriguing discussion. To evaluate the association between maternal fever in women with EA and neonatal sepsis, a study has to randomize between antibiotic treatment during labour or not. However, it is expected that medical ethical committees will not agree to perform this study because of ethical reasons.

We speculate that effective labour pain treatment with EA could reduce the onset of chronic pain after labour and delivery. In a separate study we explored the effect of routine EA on chronic pain. 
The TREAT trial also evaluates the economic impact and costs of routine EA. The ongoing increase in The Netherlands of maternal request for EA during labour may result in increased health care costs. Of course a change in pain treatment surrounding birth will have an impact for the women in labour, as well as for the society. On the one hand the costs of care are likely to increase due to EA, as EA is more expensive and might lead to an increased risk of an operative delivery and EA-related side effects as shown in this thesis. On the other hand, women in the routine EA-group will have less pain while in labour and therefore possibly recover more quickly postpartum as compared to women in the analgesia on request group. It is interesting to evaluate the economic impact and costeffectiveness or routine EA. 


\section{Reference List}

1. Hodnett ED. Pain and women's satisfaction with the experience of childbirth: a systematic review. Am J Obstet Gynecol 2002;186:S160-172.

2. Lally JE, Murtagh MJ, Macphail S, Thomson R. More in hope than expectation: a systematic review of women's expectations and experience of pain relief in labour. BMC Med 2008;6:7.

3. Brown JB, Carroll J, Boon H, Marmoreo J. Women's decision-making about their health care: views over the life cycle. Patient Educ Couns 2002;48:225-231.

4. Rijnders $M$, Baston $H$, Schönbeck $Y$, van der Pal K, Prins M, Green J, Buitendijk S. Perinatal factors related to negative or positive recall of birth experience in women 3 years postpartum in the Netherlands. Birth 2008;35:107-116.

5. Schytt E, Waldenström U. Epidural analgesia for labor pain: whose choice? Acta Obstet Gynecol Scand 2010;89:238-242.

6. The Netherlands Perinatal Registry. Perinatal care in the Netherlands 2003-2012 [in Dutch]. Utrecht: The Netherlands Perinatal Registry.

7. Leighton BL, Halpern SH. The effects of epidural analgesia on labor, maternal, and neonatal outcomes: a systemic review. Am J Obstet Gynecol 2002;186:S69-77.

8. Liu EH, Sia AT. Rates of caesarean section and instrumental vaginal delivery in nulliparous women after low concentration epidural infusion or opioid analgesia: systemic review. BMJ 2004; 328:14101420.

9. Sharma SK, McIntire DD, Wiley J, Leveno KJ. Labor analgesia and cesarean delivery: an individual patient meta-analysis of nulliparous women. Anesthesiology 2004;100:142-148.

10. Sharma SK, Alexander JM, Messick G, Bloom SL, McIntire DD,Wiley J, et al. Cesarean delivery: a randomized trial of epidural analgesia versus intravenous meperidine analgesia during labor in nulliparous women. Anesthesiology 2002;96:546551.
11. Halpern SH, Muir H, Breen TW, Campbell DC, Barrett J, Liston R, et al. A multicenter randomized controlled trial comparing patient-controlled epidural with intravenous analgesia for pain relief in labor. Anesth Analg 2004;99:1532-1538.

12. Thorp JA, Hu DH, Albin RM, McNitt J, Meyer BA, Cohen GR, et al. The effect of intrapartum epidural analgesia on nulliparous labor: a randomized, controlled, prospective trial. Am J Obstet Gynecol 1993;169:851-858.

13. Ramin SM, Gambling DR, Lucas MJ, Sharma SK, Sidawi JE, Leveno KJ. Randomized trial of epidural versus intravenous analgesia during labor. Obstet Gynecol 1995;86:783-789.

14. Gribble RK, Meier PR. Effect of epidural analgesia on the primary cesarean rate. Obstet Gynecol 1991;78:231-234.

15. Lyon DS, Knuckles G, Whitaker E, Salgado S. The effect of instituting an elective labor epidural program on the operative delivery rate. Obstet Gynecol 1997;90:135-141.

16. Anim-Somuah M, Smyth RMD, Jones L. Epidural versus non-epidural or no analgesia in labour. Cochrane Database Syst Rev 2011;12:CD000331.

17. Wong CA, Scavone BM, Peaceman AM, McCarthy RJ, Sullivan JT, Diaz NT, et al. The risk of cesarean delivery with neuraxial analgesia given early versus late in labor. N Engl J Med 2005;352:655-665.

18. Marucci M, Cinnella G, Perchiazzi G, Brienza N, Fiore T. Patient- requested neuraxial analgesia for labor: impact on rates of cesarean and instrumental vaginal delivery. Anesthesiology 2007;106:10351045.

19. Alexander JM, Sharma SK, McIntire DD, Wiley J, Leveno KJ. Intensity of labor pain and cesarean delivery. Anesth Analg 2001;92:1524-1528.

20. Lieberman E, Lang JM, Frigoletto F, Jr., Richardson DK, Ringer SA, Cohen A. Epidural analgesia, intrapartum fever, and neonatal sepsis evaluation. Pediatrics 1997;99:415-419. 
26. Camacho-Gonzalez A, Spearman PW, Stoll BJ. Neonatal Infectious Diseases. Evaluation of Neonatal Sepsis. Pediatr Clin North Am 2013;60:367389.

27. Van der Ham DP, van der Heyden JL, Opmeer BC, et al. 2012. Management of late preterm premature rupture of membranes: the PPROMEXIL-2 trial. Am J Obstet gynecol 2012;207:276.e1-10.

28. Philip J, Alexander JM, Sharma SK, Leveno KJ, McIntire DD, Wiley J. Epidural analgesia during labor and maternal fever. Anesthesiology 1999;90:12711275.

29. Polin RA, Committee on Fetus and Newborn. 2012. Management of neonates with suspected or proven early-onset bacterial sepsis. Pediatrics 2012;129:1006-1015.

30. Fusi L, Steer PJ, Maresh MJ, Beard RW. Maternal pyrexia associated with the use of epidural analgesia in labor. Lancet 1989;1:1250-1252.

31. Segal S. Labor epidural analgesia and maternal fever. Anesthesia and Analgesia 2010; 111:14671475.

32. Lieberman E, Lang J, Richardson DK, Frigoletto FD, Heffer LJ, Cohen A. Intrapartum maternal fever and neonatal outcome. Pediatrics 2000;105:8-13.

33. Lieberman E, Eichenwald E, Mathur G, Richardson D, Heffner L, Cohen A. Intrapartum fever and unexplained seizures in term infants. Pediatrics 2000;106:983-988.

34. Impey L, Greenwood C, MacQuillan K, Reynolds M, Sheil O. Fever in labor and neonatal encephalopathy: a prospective cohort study. BJOG 2001;108:594-597.

35. Petrova A Demissie K, Rhoadss GG, Smulian JC, Marcella S, Ananth CV. Association of maternal fever during labor with neonatal and infant morbidity and mortality. Obstet Gynecol 2001;98:20-27.

36. Greenwell EA, Wyshak G, Ringer SA, Johnson LC, Rivkin MJ, Lieberman E. Intrapartum temperature elevation, epidural use, and adverse outcome in term infants. Pediatrics 2012;129 e447-e454.
37. Soet JE, Brack GA, Dilorio C. Prevalence and predictors of women's experience of psychological trauma during childbirth. Birth 2003;30:36-46.

38. Eidelman Al, Hoffmann NW, Kaitz M. Cognitive deficits in women after childbirth. Obstet Gynecol 1993;81:764-767.

39. Eisenach JC, Pan PH, Smiley R, et al. Severity of acute pain after childbirth, but not type of delivery, predicts persistent pain and postpartum depression. Pain 2008;140:87-94.

40. Van den Bussche E, Crombez G, Eccleston C, Sullivan MJ. Why women prefer epidural analgesia during childbirth: the role of beliefs about epidural analgesia and pain catastrophizing. Eur J Pain 2007;11:275-282.

41. Sullivan MJL, Bishop SR, Pivik J. The Pain Catastrophizing Scale: development and validation. Psychol Assess 1995;7:524-532. 


\section{Valorization \\ 9

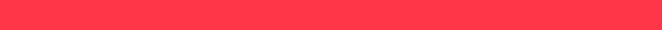 \\ gValorization \\ ent \\ (a) \\ (x)}

zation

(1) 
Knowledge valorization refers to the "process of creating value from knowledge, by making knowledge suitable and/or available for social (and/or economic) use, and by making knowledge suitable for translation into competitive products, services, processes and new commercial activities" (adapted definition based on the National Valorization Committee 2011:8)

\section{Background}

Every year, around 175.000 women deliver a child in The Netherlands. In 2008, an evidencebased Dutch guideline was published about labour pain treatment. Epidural analgesia (EA) is the best labour analgesia method. With EA, a catheter is directed into the epidural space, and the patient receives a continuous infusion or intermittent administration of local anaesthetics. The injection can result in a loss of sensation including the sensation of pain by blocking the transmission of signals through nerve fibers in or near the spinal cord. In The Netherlands, the use of EA increased from $8.2 \%$ in 2006 to $17.9 \%$ in 2012.

Although EA is the most effective method of pain relief, its use is associated with an increased risk of maternal hypotension, motor-blockade, maternal fever, urinary retention, a longer 2nd stage of labour, neonatal complications and instrumental vaginal delivery. However, there is no information about the effect of proactive offering routine EA before maternal request for pain relief on labour outcome. To assess the effect of a proactive policy of offering routine EA before maternal request for pain relief, this study group performed The Randomized Epidural Analgesia in Term delivering women trial (TREAT). In this noninferiority trial, women were randomly allocated to receive either routine EA or analgesia on request. To improve the decision making of these women and their health care professionals it would be very helpful to find out, whether EA started before the woman's request for pain relief does or does not generally result in more labour disadvantages and/or complications. A proactive policy of offering EA before request could also be of great advantage for many women delivering in hospitals in The Netherlands, where a 24 hours service of EA is not possible yet.

It is of crucial importance that information about the possibilities of pain relief during labour is given based on scientific results. In this thesis we investigate the effects and risk of the use of EA during labour. 


\section{Relevance}

This study is of scientific relevance. Several clinical questions were answered and contribute to clinical obstetrical practice. Firstly, we gained insight into the factors contributing to EA preference. Especially labour pain coping seems to be an important factor in the decision process to choose for EA. Secondly, a ten-year population based study, showed EA trends related to operative deliveries in The Netherlands. A near triplication of EA use in the Netherlands in ten years was accompanied by relatively stable rates of operative deliveries. The association between EA and operative delivery became weaker. Besides, a systematic review showed no increased risk of CS or IVD for women receiving early $\mathrm{EA}$ in comparison with women receiving late $\mathrm{EA}$. The timing of administration EA does not seem to be important. However, offering routine EA is likely to increase the rate of operative deliveries when compared with analgesia on request. We found maternal intra-partum fever to be a mediator in the relationship between EA and neonatal sepsis. Finally, a literature review was written about chronic pain after labour and delivery.

This study is of economic relevance because the increasing knowledge about the effect of offering routine EA on labour outcome prevents introducing EA as a standard. With increasing labour EA use worldwide, it is important to study the impact of EA on society in terms of health care costs and productivity losses. Evidence on the economic consequences of routine EA is lacking at the moment in literature. Several other effects on costs can be expected from early EA. If EA increases the risk for medical complications, this will increase the health care costs of a liberal policy of EA. On the other hand, planned EA might cause a shift of women requesting EA to office hours, thus preventing the need for EA during night time, which is more expensive. Another upcoming study within this project will focus on the economic evaluation and cost-effectiveness of routine labour EA compared with labour analgesia on request.

The results of this study are of societal relevance because they are additional to the current knowledge about EA and labour outcome and contribute specific information about the Dutch labouring population. Guideline implementation of these results contributes to improvement of the counselling of women with an EA request. 


\section{Target groups}

These research results are of interest to pregnant women and their partners in addition to obstetricians, midwives, obstetric anaesthesiologist and paediatricians.

\section{Activities/Products/Innovation}

On the basis of our results the national Dutch CBO guideline about labour pain treatment can be further improved. Education material about labour EA can be updated. Childbirth classes can be developed which give specific information about labour pain treatment, advantages and disadvantages of EA and can focus on labour pain coping as this latter factor seems to be important in the decision process to choose for EA. Childbirth classes can help them prepare for stresses that may arise during labour and delivery.

\section{Schedule and implementation}

Guideline improvement will be implemented by the Dutch Society of Obstetrics and Gynaecology. This national guideline is online available. The studies of this thesis are published in scientific journals. Our results will help to implement methods for pain relief in the Dutch society. This thesis will contribute to improved information about the effects of EA on labour outcome and increase the knowledge of obstetrical caregivers. Women should be well informed about the options of labour pain treatment, advantages and disadvantages. They must be involved in the choices for pain relief. Shared-decision making will contribute to increased patient satisfaction. Labouring women should not feel 'guilty' about the fact that they request for labour EA. All Dutch hospitals must be able to offer 24/7 EA to labouring women. This requires a change in the logistics and organization of the obstetric anaesthesia in The Netherlands. 

Chapter 1 provides a general introduction about labour pain, epidural analgesia and the policy of labour pain management in the Netherlands and also the aim of the thesis is described. Labour pain is considered to be one of the most serious types of pain and is compared with amputation pain. Labour pain arises partly as a result of visceral pain (uterine contractions cause activation of mechano - and chemoreceptors) and somatic pain (descending presenting part causes distension vagina, pelvic floor and perineum). Labour pain can be controlled by non-pharmacological methods and pharmacological methods. Epidural analgesia is the most effective method of pain relief. This thesis will elaborate on the effects of epidural analgesia on labour outcome. After infiltration of a local anaesthetic, a catheter is placed into the epidural space, usually at L3-L4 or L4-L5. In the Netherlands, the request for epidural analgesia has increased from 5.4\% in 2003 to $17.9 \%$ in 2012 . Although epidural analgesia appears to be the most effective method in reducing labour pain, unintended adverse effects also accompany epidural analgesia. Women who received labour epidural analgesia are at increased risk in the use of oxytocin, maternal hypotension, motor blockade, maternal fever, longer second stage of labour and instrumental vaginal delivery. The risk of having a caesarean section is not increased. Unfortunately, studies performed up to now only investigated the impact of epidural analgesia after maternal request for pain relief. Such studies are biased by the fact that these women request pain relief possibly because of non-progressing labour or labour complications. As more women demand pain free labour, it is important to have a clear understanding of the benefits, but also the risks and complications of epidural analgesia. The lack of evidence about the effect of routine epidural analgesia on labour outcome was the onset of "The Randomised Epidural Analgesia in Term delivering women trial (TREAT)".

The aim of the TREAT trial was to compare routine epidural analgesia in labouring women with pain relief on maternal request on the risk of operative delivery, labour and neonatal outcomes.

Chapter 2 examines variables related to women's prelabour preference for epidural analgesia in the Netherlands and Belgium, 2 neighbouring countries with a comparable socio-economic and cultural background. Dutch women in midwifery $(n=164)$ or 
obstetrical care $(n=162)$, and Belgian women $(n=188)$ of 36 weeks gestation or more with a singleton in cephalic presentation completed questionnaires on demographic factors, received labour analgesia information, perceived attitude of the caregiver towards epidural analgesia, pain catastrophising and coping with labour pain. Prelabour epidural analgesia preference was 9.9\% in Dutch midwifery care, $25.5 \%$ in Dutch obstetrical care and $38.3 \%$ in Belgian care ( $p$ value $<0.001$ ). In the Netherlands, maternal age of 35 years or older (OR 4.95; 95\% confidence interval $(\mathrm{Cl}) 2.03$ to 12.08), positive attitude of the caregiver towards epidural analgesia (OR 5.83; 95\%-Cl 2.57 to 13.23) and a lower degree of coping (OR 3.61; 95\%-Cl 2.24 to 5.82) were independently associated with prelabour epidural analgesia preference.

In Belgium, only a lower degree of coping was associated with prelabour epidural analgesia preference (OR 4.06; 95\%-Cl 2.45 to 6.73). In the Netherlands as well as in Belgium, women with a lower degree of coping had a higher prelabour epidural analgesia preference.

Chapter 3 describes the trends of labour epidural analgesia and rate of operative deliveries during a 10 -years period in a retrospective national cohort with data from the Dutch perinatal registry. Besides, the association between epidural analgesia and operative delivery was assessed in nulliparous and multiparous women. Women who delivered between January 1, 2000 and January 1, 2010 from a singleton in cephalic presentation between 37 weeks, 0 days and 42 weeks, 0 days were included in the study. In the Netherlands, 1798943 women delivered during the study period. Of these, 1378 458 women fulfilled the inclusion criteria, of which 616063 (44.7\%) nulliparous and 762 395 (55.3\%) multiparous women. Labour EA was used in $11.9 \%(n=73548)$ nulliparous women, and in 3.6\% $(n=27329)$ multiparous women.

In nulliparous women, the request for labour epidural analgesia increased from $7.7 \%$ in 2000 to $21.9 \%$ in 2009 , while rates of instrumental vaginal delivery and caesarean section did not change much $(-3.3 \%$ and $+2.8 \%$, respectively). In multiparous women, epidural analgesia use increased from $2.4 \%$ in 2000 to $6.8 \%$ in 2009, while the rates of instrumental vaginal delivery and caesarean section changed slightly $(-0.7 \%$ and $+0.8 \%$, respectively). Results of multivariable logistic regression analysis showed a significant decline in the association between epidural analgesia and unplanned caesarean section from OR 2.35 
(95\%-Cl, 2.18 to 2.54$)$ to OR $1.69(95 \%-\mathrm{Cl}, 1.60$ to 1.79$)$ in nulliparous and OR 3.17 (95\%$\mathrm{Cl}, 2.79$ to 3.61$)$ to $\mathrm{OR} 2.56(95 \%-\mathrm{Cl}, 2.34$ to 2.81$)$ in multiparous. An inverse association between epidural analgesia and an instrumental delivery was found in nulliparous (OR, $0.76 ; 95 \%-\mathrm{Cl}, 0.75$ to 0.78 ). The overall risk of an instrumental vaginal delivery was increased in multiparous women (OR, 2.08; 95\%-Cl, 2.00 to 2.16). Both associations grew slightly weaker during the study period.

In conclusion, the association between epidural analgesia and unplanned caesarean section weakened in a 10-year period with simultaneously an almost tripled epidural analgesia use in nulliparous as well as multiparous women. These results suggest that epidural analgesia is not an important causal factor for unplanned caesarean section. The observed trends much more reflect a shift in Dutch obstetric policy from restrictive labour pain treatment policy to a more liberal use of epidural analgesia.

Chapter 4 describes the results of a systematic review regarding the relation between the timing of epidural analgesia and the rate of operative deliveries. Six studies were selected of which five randomised controlled trials and one retrospective cohort study which examined the effect of early epidural analgesia (defined as a cervical dilatation of $3 \mathrm{~cm}$ or less) and late administration of $(>3 \mathrm{~cm})$ on the mode of delivery in nulliparous women at 36 weeks of gestation or more. Finally a total of 15399 nulliparous women with spontaneous or induced labour with a request for analgesia were included. The risk of caesarean delivery (pooled risk ratio 1.02, 95\% Cl $0.96-1.08$ ) or instrumental vaginal delivery (pooled risk ratio $0.96,95 \%$-Cl 0.89 to 1.05 ) was not significantly different between groups.

In conclusion, this systematic review showed no increase in the risk of caesarean delivery or instrumental vaginal delivery if epidural analgesia was administered early at labour, as compared to late administration of epidural analgesia.

Chapter 5 provides the results of The Randomised Epidural Analgesia in Term (TREAT) delivering women trial, which studied the effect of routine use of epidural analgesia early during labour on risk of operative delivery compared with analgesia on request. The primary non-inferiority outcome was the rate of operative deliveries (defined as 
instrumental vaginal delivery or unplanned caesarean section). Participating women were randomly allocated to either routine epidural analgesia or analgesia on request before labour started before labour started. A total of 488 women were randomly allocated to the routine epidural analgesia $(n=233)$ or analgesia on request group $(n=$ 255). In the routine epidural analgesia group, $89.3 \%$ (208/233) women received epidural analgesia. In the analgesia on request group, $76.1 \%$ (194/255) women received analgesia, of which $38.1 \%$ (74/194) received opiates, 31.4\% (61/194) received epidural analgesia at first analgesia request, and 30.4\% (59/194) received epidural analgesia at second request. According to the intention-to-treat analysis, 34.8\% (81/233) women in the routine epidural analgesia group experienced an operative delivery, compared with $26.7 \%$ (68/255) in the analgesia on request group (difference $8.1 \%, 95 \%-\mathrm{Cl}-0.1 \%$ to $16.3 \%$ ). The difference in rate of operative deliveries according to the per-protocol analysis was statistically significant (difference $8.9 \%, 95 \% \mathrm{Cl}-0.4 \%$ to $17.4 \%$ ). Inferiority of routine epidural analgesia could not be rejected as in both analyses the upper bound of the confidence interval exceeded the pre-specified inferiority criterion of $+10 \%$. Routine use of epidural analgesia resulted in significantly more epidural analgesia related adverse effects like maternal hypotension and motor blockade. No differences in adverse labour and neonatal outcomes were found between both groups.

This trial could not demonstrate non-inferiority of routine epidural analgesia use. We concluded that routine use of epidural analgesia is not justified according to these results.

Chapter 6 presents the association between neonatal sepsis and labour epidural analgesia. In a retrospective cohort study, 453 women delivering with epidural analgesia were matched on parity with 453 women delivering without epidural analgesia. Significantly more neonates born in the epidural analgesia group had fever $\geq 38.0^{\circ} \mathrm{C}$ $(11.6 \%$ vs. $1.8 \%, p<0.001)$ at birth. The incidence of neonatal sepsis was significantly higher in the epidural analgesia group (6.0\% vs. 2.2\%; OR 2.81, 95\%-CI 1.34 to 5.87 ; $\mathrm{p}=$ 0.006), but the incidence of neonatal sepsis defined as a positive blood culture alone, was not $(0.4 \%$ vs. $0 \% ; p=0.250)$. Multivariable logistic regression analysis, controlling for matching variable parity and $\geq 18$ hours of ruptured membranes, demonstrated that epidural analgesia remained significantly associated with an increased risk of neonatal 
sepsis (adjusted OR of 2.43, 95\%-CI 1.15 to $5.13 ; \mathrm{p}=0.020$ ).

In the epidural analgesia group as well as the non-epidural analgesia group, the incidence of neonatal sepsis was significantly higher in mothers with intrapartum fever compared with afebrile mothers ( $11.0 \%$ vs. $2.9 \%$ in epidural analgesia group, $p=0.004 ; 8.2 \%$ vs. $1.3 \%$ in non-epidural analgesia group, $\mathrm{p}=0.006$ ).

In conclusion, a positive association between neonatal sepsis and labour epidural analgesia was found possibly mediated by maternal intra-partum fever.

Chapter 7 is a literature review that reflects on acute pain in relation to obstetrics and the development of chronic pain in general. Besides, the prevalence and predictors of chronic pain after labour and delivery are discussed. Labour pain is a complex phenomenon with sensory, emotional, and perceptive components and can be regarded as one of the most serious kinds of pain. Different strategies to approach acute labour pain have been developed. Chronic pain after labour and delivery have not been studied so extensively. Prevalence rates of chronic pain after caesarean section are between 6 and 12\% and after vaginal delivery $4 \%$ and $10 \%$. Predictors for chronic pain after caesarean section and delivery are previous chronic pain, undergoing caesarean section under general anaesthesia and higher recall of post-operative pain. As labour pain is rated as one of the most serious kinds of acute pain one could make a prediction about chronic pain after labour and delivery. We speculate that effective treatment of labour pain with epidural analgesia could prevent the development of chronic pain.

Future studies should focus on the long-term effects of different analgesic regiments on the development of chronic pain after labour and delivery.

Chapter 8 describes a general discussion and answers the research questions of this thesis. Conclusions of this thesis, implications for clinical practice and future perspectives are discussed. 

11 Samenvatting

.

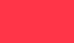

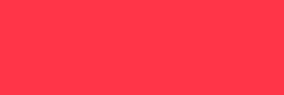

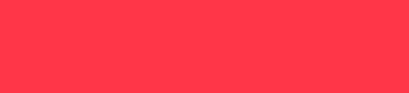

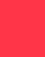

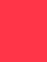

.
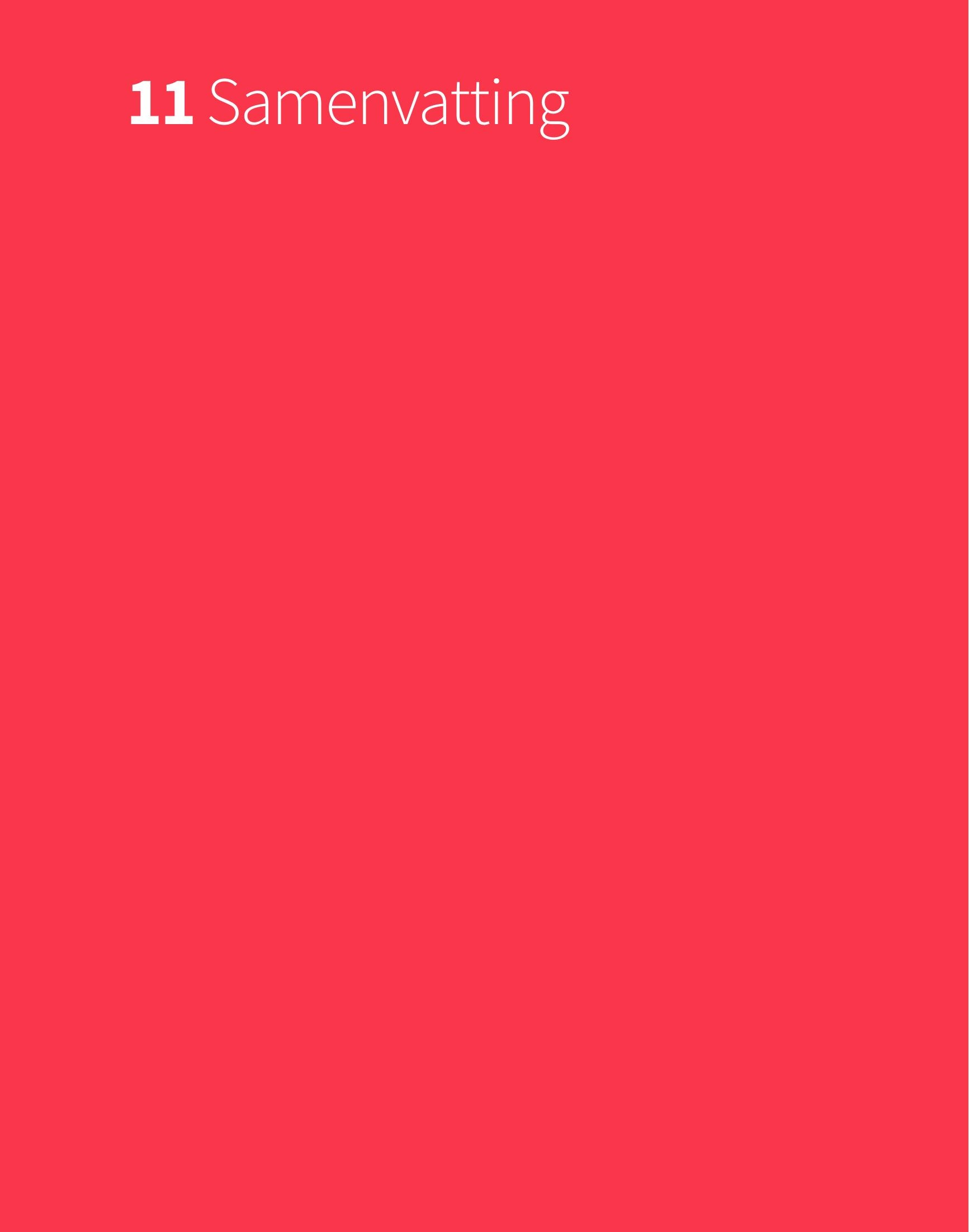
Hoofdstuk 1 geeft een algemene inleiding over baringspijn, epidurale analgesie en het beleid rondom pijnstilling tijdens de bevalling in Nederland. Daarnaast worden de onderzoeks vragen gesteld die dit proefschrift onderzoekt. Baringspijn wordt beschouwd als een van de ernstigste vormen van pijn en wordt vergeleken met amputatiepijn. Baringspijn ontstaat deels ten gevolge van viscerale pijn (uterus contracties veroorzaken activatie van mechano- en chemoreceptoren) en somatische pijn (indaling van het voorliggend deel veroorzaakt distentie van de vagina, bekkenbodem en het perineum). Baringspijn kan worden bestreden door middel van niet-farmacologische methoden en farmacologische methoden. Epidurale analgesie is de meest effectieve vorm van pijnbestrijding. Dit proefschrift zal verder ingaan op het effect van epidurale analgesie op de uitkomst van de baring. Na lokale verdoving van de huid, wordt een catheter in de epidurale ruimte gebracht, meestal tussen L3-L4 of L4-L5. In Nederland, is het verzoek voor epidurale analgesie tijdens de baring de laatste jaren toegenomen van 5.4\% in 2003 tot $17.9 \%$ in 2012 . Hoewel epidurale analgesie behoort tot de meest effectieve methode om baringspijn te bestrijden gaat het ook gepaard met bijwerkingen. Er bestaat een toegenomen kans in het gebruik van oxytocine, maternale hypotensie, motorisch blok, maternale koorts, langere uitdrijvingsduur en vaginale kunstverlossing bij vrouwen die tijdens de bevalling epidurale analgesie krijgen. Het risico op een sectio caesarea was niet verhoogd. Helaas onderzoeken deze studies het effect van epidurale analgesie bij vrouwen die een epidurale verdoving 'nodig' hadden. Deze studies kunnen daarom een bias bevatten omdat deze vrouwen mogelijk verzochten om pijnstilling omdat er bijvoorbeeld sprake was van een niet-vorderende baring of barings complicaties. Gezien het feit dat een toenemend aantal vrouwen een pijnloze bevalling wenst, is het belangrijk om de voordelen, maar ook de risico's en complicaties van epidurale analgesie duidelijk te begrijpen. Het gebrek aan bewijs over het effect van routinematig plaatsen van epidurale analgesie op de uitkomst van de baring heeft geleid tot het opzetten van "The Randomised Epidural Analgesia in Term delivering women trial (TREAT)". Het doel van de TREAT trial was vergelijken van het routinematig toedienen van epidurale analgesie met pijnstilling op maternaal verzoek tijdens de bevalling op het risico van een kunstverlossing en uitkomst van de bevalling en neonaat. 
Hoofdstuk 2 onderzoekt variabelen gerelateerd aan de antepartum keuze van vrouwen voor epidurale analgesie in Nederland en België, twee aangrenzende landen met een vergelijkbare socio-economische en culturele achtergrond. Nederlandse vrouwen onder controle van een verloskundige $(n=164)$ of gynaecoloog $(n=162)$ en Belgische vrouwen $(n=188)$ met een amenorroeduur van 36 weken of meer, zwanger van een eenling in hoofdligging, vulden vragenlijsten in met betrekking tot demografische factoren, informatie over pijnstilling tijdens de bevalling, attitude van de zorgverlener ten opzichte van epidurale analgesie, catastroferen over pijn en coping met bevallingspijn. Antepartum koos 9.9\% van de Nederlandse vrouwen onder controle bij de verloskundige, $25,5 \%$ van de Nederlandse vrouwen onder controle bij een gynaecoloog en $38.3 \%$ van de Belgische vrouwen voor epidurale analgesie ( $p$ value $<0.001$ ). In Nederland, waren maternale leeftijd $\geq 35$ jaar (OR 4.95; 95\% betrouwbaarheidsinterval (BI) 2.03 tot 12.08), een positieve attitude van de zorgverlener ten aanzien van epidurale analgesie (OR 5.83; 95\%-BI 2.57 tot 13.23 ) en een lagere mate van coping onafhankelijk gerelateerd met de antepartum keuze voor epidurale analgesie. In België, was alleen een lagere mate van coping geassocieerd met de antepartum keuze voor epidurale analgesie (OR 4.06; 95\%-BI 2.45 tot 6.73). In zowel Nederland alsook België, kiezen vrouwen met een lagere mate van coping vaker voor epidurale analgesie.

Hoofdstuk 3 beschrijft de trends van het gebruik van epidurale analgesie tijdens de bevalling en aantal kunstverlossingen in een retrospectief landelijk cohort met data van de stichting perinatale registratie Nederland gedurende een periode van 10 jaar. Tevens werd de associatie tussen epidurale analgesie en kunstverlossingen in nulliparae en multiparae onderzocht. Alle vrouwen die bevielen tussen 1 januari 2000 en 1 januari 2010 van een eenling in hoofdligging tussen $37^{+0}$ en $42^{+0}$ weken amenorroeduur werden geïncludeerd in de studie. Gedurende de studie periode bevielen 1789943 vrouwen in Nederland. Hiervan voldeden 1378458 vrouwen aan de inclusie criteria, waarvan 616063 (44.7\%) nulliparae en 762395 (55.3\%) multiparae. In de groep nulliparae kreeg $11.9 \%(n=73548)$ epidurale analgesie en 3.6\% $(n=27329)$ in de groep multiparae. Bij nulliparae nam het verzoek voor epidurale analgesie tijdens de bevalling toe van $7.7 \%$ in 2000 tot $21.9 \%$ in 2009, terwijl het aantal vaginale instrumentele bevallingen en sectio 
caesarea niet veel veranderde $(-3.3 \%$ en $+2.8 \%$, respectievelijk). Het gebruik van epidurale analgesie bij multiparae steeg van $2.4 \%$ in 2000 tot $6.8 \%$ in 2009 , terwijl het aantal vaginale instrumentele bevallingen en sectio caesarea eveneens nauwelijks veranderde $(-0.7 \%$ en $+0.8 \%$, respectievelijk). Multivariabele logistische regressie analyse toonde een significante afname $(p<0.001)$ gedurende 10 jaar in de associatie tussen epidurale analgesie en een secundaire sectio caesarea van OR 2.35 (95\%-BI, 2.18 tot 2.54) naar OR 1.69 (95\%-BI, 1.60 tot 1.79) in nulliparae en OR 3.17 (95\%-BI, 2.79 tot 3.61) naar OR 2.56 (95\%-BI, 2.34 tot 2.81) in de groep multiparae. Er werd een omgekeerde relatie gevonden tussen epidurale analgesie en een vaginale instrumentele bevalling bij nulliparae (overall OR, 0.76; 95\%-BI, 0.75 tot 0.78). In de groep multiparae was het risico op een vaginale instrumentele bevalling verhoogd (overall OR, 2.08; 95\%-BI, 2.00 tot 2.16). Beide associaties werden zwakker gedurende de studie periode.

Concluderend was er een afname in de associatie tussen epidurale analgesie en secundaire sectio caesarea in een periode van 10 jaar met gelijktijdig een bijna verdriedubbeling van het gebruik van epidurale analgesie bij zowel nulliparae alsook multiparae. Deze resultaten veronderstellen dat er geen belangrijke causale relatie is tussen epidurale analgesie en secundaire sectio caesarea. De waargenomen trends weerspiegelen een verandering in het obstetrisch beleid in Nederland van een restrictief beleid rondom pijnstilling naar een meer liberaler gebruik van epidurale analgesie.

Hoofdstuk 4 beschrijft de resultaten van een systematisch review waarin de relatie tussen het tijdstip van toedienen van epidurale analgesie op het risico op een kunstverlossing wordt onderzocht. Er werden zes studies geselecteerd waarvan vijf randomised controlled trials en één retrospectieve cohort studie die het effect onderzochten van vroege toediening van epidurale analgesie (gedefinieerd als een ontsluiting van $3 \mathrm{~cm}$ of minder) en late toediening van EA $(>3 \mathrm{~cm})$ op de modus van de partus in nulliparae met een amenorroeduur van $\geq 36$ weken. In totaal werden 15399 nulliparae met een spontaan begin van de baring of middels inleiding en een verzoek tot pijnstilling geïncludeerd. Het risico op een sectio caesarea (pooled risk ratio 1.02, 95\%-BI 0.96 tot 1.08 ) of vaginale kunstverlossing (pooled risk ratio $0.96,95 \%-B I 0.89$ tot 1.05 ) was niet significant verschillend tussen de beide groepen. 
Concluderend, toont dit systematische review geen verhoogd risico op een sectio caesarea of vaginale kunstverlossing indien epidurale analgesie vroeg tijdens de baring wordt gegeven in vergelijking met late plaatsing van epidurale analgesie.

Hoofdstuk 5 geeft de uitkomsten van The Randomised Epidural Analgesia in Term (TREAT) delivering women trial waarin effect van het routinematig toepassen van epidurale analgesie vroeg tijdens de baring op het optreden van kunstverlossingen in vergelijking met pijnstilling op verzoek werd onderzocht. De primaire non-inferiority uitkomstmaat was het aantal kunstverlossingen (gedefinieerd als vaginale kunstverlossing of secundaire sectio caesarea).

Vrouwen werden voorafgaand aan de baring at random toegewezen aan enerzijds routinematig epidurale analgesie of anderzijds pijnstilling op verzoek. In totaal werden 488 vrouwen gerandomiseerd in enerzijds de groep met routinematig epidurale analgesie ( $n=233$ ) en anderzijds pijnstilling op verzoek $(n=255)$. In de routine epidurale analgesie groep kreeg 89.3\% (208/233) van de vrouwen epidurale analgesie. In de groep pijnstilling op verzoek, kreeg 76.1\% (194/255) van de vrouwen pijnstilling waarvan 38.1\% (74/194) opiaten, 31.4\% (61/194) epidurale analgesie bij het 1e verzoek tot pijnstilling (61/194) en 30.4\% (59/194) bij het 2e verzoek tot pijnstilling.

Volgens de intention-to-treat analyse, beviel in de groep vrouwen met primair epidurale analgesie $34.8 \%(81 / 233)$ met een kunstverlossing in vergelijking met $26.7 \%(68 / 255)$ in de groep vrouwen met pijnstilling op verzoek (verschil in percentage 8.1\%, 95\%-BI -0.1\% tot $16.3 \%$ ). Het verschil in aantal kunstverlossingen was statistisch significant in de perprotocol analyse (verschil in percentage 8.9\%, 95\%-BI 0.4\% tot $17.4 \%$ ). Omdat in beide analyses de bovenste grens van het betrouwbaarheidsinterval de inferiority marge van $10 \%$ overschrijdt, kan de hypothese dat routinematig toedienen van epidurale analgesie inferieur is niet worden verworpen. Routinematig toepassen van epidurale analgesie leidt tot meer bijwerkingen gerelateerd aan epidurale analgesie zoals maternale hypotensie en motorisch blok. Er werd geen verschil in complicaties bij de bevalling en neonatale uitkomst gevonden tussen beide groepen. Deze studiekan non-inferiority van routinematig epidurale analgesie gebruik niet aantonen. We concludeerden dat routinematig toepassen van epidurale analgesie gezien deze bevindingen niet geadviseerd moet worden. 
Hoofdstuk 6 beslaat de resultaten van de relatie tussen neonatale sepsis en epidurale analgesie tijdens de bevalling. In een retrospectieve cohort studie werden 453 vrouwen die tijdens de bevalling epidurale analgesie ontvingen gematched op basis van vaginale pariteit met 453 vrouwen die geen epidurale analgesie ontvingen tijdens de bevalling. Significant meer neonaten geboren in de epidurale analgesie groep hadden koorts $\geq$ $38.0^{\circ} \mathrm{C}(11.6 \%$ vs. $1.8 \%, \mathrm{p}<0.001)$ bij de geboorte. De incidentie van neonatale sepsis was significant hoger in de epidurale analgesie groep (6.0 \% vs. $2.2 \%$; OR 2.81, $95 \%$-BI 1.34 tot $5.87 ; p=0.006)$, maar de incidentie van neonatale sepsis gedefinieerd als alleen een positieve bloedkweek niet ( $0.4 \%$ vs. $0 \%$; $p=0.250)$. Multivariate logistische regressie analyse met correctie voor pariteit en $\geq 18$ uur gebroken vliezen, toonde aan dat epidurale analgesie een significante relatie vertoont met een verhoogd risico op neonatale sepsis (adjusted OR 2.43, $95 \%$-BI 1.15 tot 5.13; $\mathrm{p}=0.020$ ). De incidentie van neonatale sepsis was significant hoger indien er sprake was van maternale intrapartum koorts in vergelijking met moeders zonder koorts in zowel de EA-groep als de non-EA- groep (11.0\% vs. 2.9\% in epidurale analgesie groep, $\mathrm{p}=0.004 ; 8.2 \%$ vs. $1.3 \%$ in non-epidurale analgesie groep, $\mathrm{p}=$ 0.006).

We concludeerden dat de associatie tussen een verhoogd risico op neonatale sepsis bij vrouwen met epidurale analgesie tijdens de bevalling, mogelijk gemedieerd wordt door maternale intrapartum koorts.

Hoofdstuk 7 is een literatuur overzicht waarin acute pijn in relatie tot de verloskunde en de ontwikkeling van chronische pijn in het algemeen aan bod komt. Daarnaast worden de prevalentie en voorspellende factoren voor het ontstaan van chronische pijn na de bevalling besproken. Bevallingspijn is een complex fenomeen waarin sensorische, emotionele en ook perceptie factoren een rol spelen en kan worden beschouwd als een van de meest ernstige vormen van pijn. Verschillende strategieën om acute pijn tijdens de bevalling te benaderen zijn ontwikkeld. Er is weinig onderzoek verricht naar chronische pijn na de bevalling. De prevalentie van chronische pijn na een sectio caesarea ligt tussen de $6 \%$ en $12 \%$ en na een vaginale bevalling tussen $4 \%$ en $10 \%$. Voorspellers voor chronische pijn na een sectio caesarea en bevalling zijn eerder bestaande chronische pijn, het plaatsvinden van de sectio caesarea onder algehele anesthesie en het rapporteren 
van hogere pijn scores postoperatief. Aangezien baringspijn beschouwd wordt als een van de meest ernstige vormen van acute pijn, kan dit gebruikt worden om een voorspelling te maken met betrekking tot chronische pijn na de bevalling. We vermoeden dat effectieve pijnbestrijding tijdens de bevalling met epidurale analgesie de ontwikkeling van chronische pijn kan voorkomen. Toekomstige studies moeten zich richten op de lange termijn effecten van verschillende methoden van pijnbestrijding op de ontwikkeling van chronische pijn na de bevalling.

Hoofdstuk 8 geeft een algemene beschrijving en antwoorden op de vraagstellingen van dit proefschrift. Conclusies van dit proefschrift, de klinische implicaties en toekomst visie worden besproken. 


\section{Publications}

\section{Journals}

Wassen M.L.H., Mertens H.J.M.M. Hyperemesis gravidarum.

Ned Tijdschr Obst Gyn 2007; 120:25-31.

Ned Tijdschr Obst Gyn huisartseneditie September 2008:35-39.

Wassen M.M.L.H., Kampschöer P.H.N.M., Delaere K.P.J. Transobturator tape (TOT): niet altijd een onschuldig bandje. Ned Tijdschr Obst Gyn 2008;121:111-114.

Wassen M.M.L.H, Roumen F.J.M.E. Epidurale analgesie tijdens de baring. Zeer effectief maar niet zonder bijwerkingen. TvV 2009;september:19-22.

Vermelis J.M.F.W., Wassen M.M.L.H, Fiddelers A.A.A., Nijhuis J.G., Marcus M.A.E. Prevalence and predictors of chronic pain after labor and delivery. Cur Opin Anaesthesiol 2010;23:295-299.

T. De Neef, A. Franx, M.M.L.H. Wassen, F.J.M.E. Roumen. Epidurale analgesie en vaginale kunstverlossing. Ned Tijdschr Obst Gyn 2010;123:107-108.

S. Broersen, Wassen M. Ruggenprik, niet altijd 24 u per dag beschikbaar. Medisch Contact 2010;65:1952.

M.M.L.H. Wassen, C. Buijs, J.G. Nijhuis. Beschikbaarheid epidurale analgesie tijdens de bevalling in Nederland anno 2010. Ned Tijdschr Obst Gyn 2010;123:397-400.

Weemhoff M, Wassen MM, Korsten L, Serroyen J, Kampschöer PH, Roumen FJ. Postoperative catheterization after anterior colporrhaphy: 2 versus 5 days. A multicentre randomized controlled trial. Int Urogynecol J 2011;22:477-483.

Wassen MMLH, Zuijlen J, Roumen FJME, Smits LJM, Marcus MA, Nijhuis JG. Early versus late epidural analgesia and risk on instrumental delivery in nulliparous women: a systematic review. BJOG 2011;118:655-651.

Wassen MMLH, Zuijlen J, Roumen FJME, Smits LJM, Marcus MA, Nijhuis JG. Response to Letter 2011-LT-9652. BJOG 2011;118:1541-1542. 
Goossens SMTA, Wassen MMLH, Vandevijver NMA, Bouckaert PXJM. Appendicitits acuta in de zwangerschap ten gevolge van ectopische decidua: beschrijving van een casus. Ned Tijdschr Obst Gyn 2011;124:191-196.

Verhoeven MO, Wassen MMLH, Mol BW, Wouters MGAJ. Verslag Oranjedag 2011. Ned Tijdschr Obst Gyn 2011;124:478-480.

Wassen MMLH, Miggiels CMG, Devlieger R, Gyselaers W, Mertens HJ, Hasaart TH, Wijnen E, De Reu PA, Roumen FJME, Nijhuis JG, Smits L, Scheepers HCJ. Women's antepartum preference for epidural analgesia during labor. J Psychosom Obstet Gynecol 2013;34:22-28.

Wassen MMLH, Smits LJM, Scheepers HCJ, Marcus MAE, Van Neer J, Nijhuis JG, Roumen FJME. Routine labour epidural analgesia versus labour analgesia on request: a randomised non-inferiority trial. BJOG 2014; May 22. doi:10.1111/1471-0528.12854. [epub ahead of print].

Wassen MMLH, Winkens B, Dorssers EMI, Marcus MA, Moonen RMJ, Roumen FJME. Neonatal sepsis is mediated by maternal fever in labour epidural analgesia. J Obstet Gynaecol 2014;17:1-5.

Wever A, Wassen M. Gevolgen van drugsgebruik op de zwangerschap, neonaat en lactatie: een literatuuroverzicht. TVV 2014;4:66-71.

Wassen MMLH, Hukkelhoven CWPM, Scheepers HCJ, Smits LJM, Nijhuis JG, Roumen FJME. Epidural analgesia and operative delivery: a ten-year population-based cohort study in the Netherlands. Eur J Obstet Gynecol Reprod Biol. Accepted

\section{Book chapter}

MMLH Wassen, FJME Roumen. The Randomised Epidural Analgesia in Term delivering women trial (TREAT). In Slager, E, editor: Reproductieve geneeskunde, gynaecologie en obstetrie anno 2009. Haarlem: DCHG, partner in medische communicatie, 2009:626-630.

MMLH Wassen, FJME Roumen. The Randomised Epidural Analgesia in Term delivering women trial (TREAT). In Slager, E, editor: Reproductieve geneeskunde, gynaecologie en obstetrie anno 2013. Haarlem: DCHG, partner in medische communicatie, 2013:892-897. 
Wassen M. Epidurale analgesie tijdens de baring: trends en relatie met kunstverlossingen. Stichting Perinatale Registratie Nederlands Grote lijnen 1999-2012. Utrecht: Stichting Perinatale Registratie Nederland, 2013:64-67.

\section{Oral presentations}

MMLH Wassen, FJME Roumen. The Randomised Epidural Analgesia in Term delivering women trial (TREAT). 17e congres infertiliteit, gynaecologie en obstetrie, Doelen, 2009, Rotterdam.

FJME Roumen, MMLH Wassen, EMI Dorssers, B Winkens. Epidural analgesia during labor: effect on maternal and neonatal temperature. FIGO, 2009, Cape Town, South Africa.

MMLH Wassen, EMI Dorssers, B Winkens, FJME Roumen. Epidurale analgesie: effect op maternale en neonatale temperatuur. Jonge onderzoekerssessie, Gynaecongres, 2009, Papendal.

MMLH Wassen, FJME Roumen. The Randomised Epidural Analgesia in Term delivering women trial (TREAT): a non-inferiority trial. 19e congres infertiliteit, gynaecologie en obstetrie, Doelen, 2013, Rotterdam.

\section{Poster presentations}

Wassen MMLH, Dorssers EMI, Winkens B, Roumen FJME. Epidural analgesia during labor: effect on maternal and neonatal temperature. Gynaecongres, 2009, Papendal.

Wassen MMLH, Hukkelhoven C, Scheepers LH, Smits L, Nijhuis JG, Roumen FJME.

Epidural analgesia during labor: impact on rates of cesarean and instrumental vaginal delivery: the results of a nationwide cohort study in the Netherlands. Society of Maternal and Fetal Medicine, 31th Annual Meeting San Francisco, 2011, USA. 


\section{Curriculum Vitae}

Martine Wassen werd geboren op 17 februari 1977 in het Sint Barbaraziekenhuis in Geleen. In 1995 slaagde zevoor het VWO aan het St. Janscollege te Hoensbroek. Na uitgeloot te zijn voor de studie Geneeskunde, begon zij met de studie Gezondheidswetenschappen aan de Universiteit Maastricht. Binnen de doctoraalfase werd de studierichting Biologische Gezondheidkunde gekozen. Na een afstudeeronderzoek op de afdeling medische microbiologie behaalde ze in september

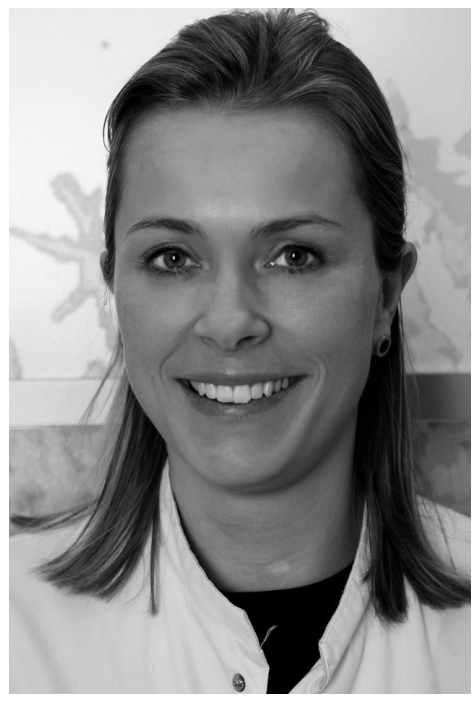
1999 haar doctoraal. Direct daarna, begon zij na viermaal uitgeloot te zijn alsnog met de studie Geneeskunde. Ze voltooide de opleiding als basisarts met 3 maanden keuzeonderwijs Obstetrie aan "the University of the West Indies" te Trinidad in 2004. In september 2004 begon zij als assistent geneeskundige niet-in-opleiding binnen de maatschap gynaecologie van het Maaslandziekenhuis te Sittard en nadien in het Atrium Medisch Centrum Parkstad. Zij is getrouwd met Luuk de Win op 17-06-2006. Vanaf 1 oktober 2006 startte zij met de opleiding tot gynaecoloog. Na 2 jaar opleiding in het Atrium Medisch Centrum te Parkstad (opleider dr. Roumen, plaatsvervangend opleider dr. Salemans), werd de opleiding voortgezet in het MUMC (opleider Prof. Essed/ Prof Kruitwagen, plaatsvervangend opleider dr. Dunselman). Op 6 maart 2009 werd zoon Beau geboren in Rotterdam. Ze won tijdens het Gynaecongres in Arnhem in november 2009 de prijs voor beste poster en presentatie van het artikel: 'Epidurale analgesie tijdens de baring: effect op maternale en neonatale temperatuur.' Dochter Noa werd geboren op 31 mei 2011 in Maastricht. De opleiding tot gynaecoloog voltooide zij op 18 oktober 2012. In december 2012 won zij de clinicus van het jaar verkiezing voor beste arts-assistent perifeer, uitgeroepen door co-assistenten. Ze is sinds 1 januari 2013 werkzaam als gynaecoloog in het Orbis Medisch Centrum. Het onderzoek naar het effect van epidurale analgesie op de uitkomst van de baring heeft geresulteerd in dit proefschrift. 


\section{Dankwoord}

'Het verschil tussen een non-funded en een funded-proposal is persistence' (S. Scherjon. Editorial. NTOG 2009;02:27) Er stond mij nog een heel avontuur te wachten. Echter de ervaring heeft mij geleerd dat persistence van de promovendus maar een zeer klein onderdeel is en dat het succes van non-funded onderzoek vooral mogelijk wordt gemaakt door de steun, het doorzettingsvermogen en de goodwill van vele anderen.

Prof. dr. J.G. Nijhuis, uw inbreng tijdens dit promotie traject waren naast uw klinische expertise binnen de obstetrie, ook zeker uw enthousiasme en motiverende woorden. $U$ inspireerde en dacht altijd na over nieuwe initiatieven zoals op een ochtend tijdens de overdracht het idee om een preferentie onderzoek uit te voeren tussen Nederland en België. Het idee bleek achteraf eenvoudiger dan de praktische uitvoering in de Belgische ziekenhuizen. Een ding is in ieder geval duidelijk, die Belgen plaatsen een stuk sneller epiduralen dan dat ze een simpel vragenlijst onderzoek goedkeuren. Bedankt dat u mijn promotor wilde zijn.

Dr. F.J.M.E. Roumen, beste Frans, in 2006 begon ik als AGNIO in het Atrium medisch centrum Parkstad. Het idee en de basis van het "EAT" project en later "TREAT" onderzoek zijn jouw werk. Ik rolde in het onderzoek nadat de 1e ronde ZONMW subsidie was goedgekeurd. Ruim 6 maanden later, volgde helaas een grote teleurstelling en werd deze subsidie aanvraag afgewezen. Deze afwijzing bleek echter een tussenstation en er werden nieuwe plannen gemaakt om alsnog dit ons inziens belangrijke project te starten. Het was soms een bittere strijd met de nodige teleurstellingen en misschien wel "tegen" werkingen waarbij de naam "EAT" misschien toch een beter acroniem was geweest. Het vertrouwen in de voltooiing van dit proefschrift heb je echter nooit opgegeven. "Martine, dat boekje komt er wel”. En zie hier het resultaat. Dank voor je altijd kritische blik, waardevolle feedback, doortastendheid, volhardendheid en onvoorwaardelijke steun om dit onderzoek succesvol af te ronden.

Dr. L.J.M. Smits, beste Luc, als methodoloog en epidemioloog had jij altijd een scherpe visie op het onderzoek. Jij beschikt over de gave om op een bescheiden manier de 
juiste opmerkingen te maken, te relativeren en een kritische noot te plaatsen. Jouw commentaar, resulteerde bij mij altijd in een stukje bezinning om terug tot de kern van het onderzoek te komen. "Resultaten leiden vaak tot een fase van ontnuchtering, later komt een fase van berusting", zei je tegen mij op een ochtend bij het bespreken van de resultaten van de TREAT. Het laatste half jaar kwam al mijn email in jouw ${ }^{\star} S^{\star} P^{\star} A^{\star} M^{\star}$ box. Was dit een stille hint...?

Prof. dr. M. Marcus, uw input vanuit anaesthesiologisch oogpunt, zelfs nu uit Doha Qatar was onontbeerlijk bij het schrijven van dit proefschrift. Bedankt voor uw vertrouwen en steun.

Dr. L. Scheepers, beste Liesbeth, jij bent aanvankelijk aan de zijlijn betrokken geweest bij het onderzoek. Echter, meer op weg ging jij voor mij een belangrijkere rol spelen. Je was altijd oprecht geïnteresseerd in de voortgang van de onderzoeken en dacht hierin ook altijd actief met me mee. Vooral jouw vaak vernieuwende blik en scherpe visie waren waardevolle aanvullingen. Daarnaast wist je me altijd te motiveren en op te peppen bij tegenslagen. Ik heb dit altijd zeer gewaardeerd. Bedankt.

De leescommissie, Prof. dr. W.F.F.H. Buhre, dr. E. de Miranda, dr. K.M. Paarlberg, Prof. dr. M.E.A. Spaanderman en Prof. dr. L.J.I. Zimmermann, wil ik bedanken voor de beoordeling van dit proefschrift.

Celine Lardenoije, lieve schwjeitaap. Ik hoor nu veel mensen zeggen, wat...? WALA...? Vanaf het begin waren we maatjes, samen dolle pret op de verloskamers als ANIOS in het Maaslandziekenhuis. Jij besloot al eerder af te zwaaien naar Maastricht en ik ging als ANIOS naar het Atrium. Gelukkig mochten we, helaas maar kort weer samenwerken in het MUMC+ en later weer in het Orbis. Je zult altijd een "maatje" voor me zijn, ook op afstand. Bedankt dat jij mijn paranimf wilt zijn.

Luc Wassen, lieve broer. Wat een eer dat jij vandaag mijn paranimf bent. Je hebt me vaak geholpen; computer problemen, het TREAT logo gemaakt en nu ook in de afrondende fase van het boekje ben je betrokken geweest bij de layout. Ik ben enorm trots op je. Samen met je allerliefste Toos en Manisha staan jullie aan het begin van een nieuwe fase in jullie leven. Heel veel geluk samen. 
Annemarie Vermelis, al snel raakte jij betrokken binnen het TREAT onderzoek als AIOS Anaesthesiologie in het MUMC+. Jouw onderzoek naar chronische pijn werd een onderdeel binnen de TREAT studie. Dit gaf al snel een gevoel van saamhorigheid. Dank voor de momenten dat ik vakinhoudelijk met je kon sparren, maar vooral ook mocht klagen over het leven van een promoverende werkende moeder.

Jolanda Willems, "Ms Holmes", zonder jouw bijdrage aan de dataverzameling en inclusie was het nooit gelukt. Doe bis inne sjat!!! Kim Notten in jouw kortdurende carrière als research nurse ging je fanatiek aan de slag en ronselde de eerste TREAT inclusies in het MUMC+. Nathalie en Monique dank voor jullie fanatisme en inzet om vrouwen voor de TREAT te includeren en jullie volhardendheid om tot het einde te helpen met de afronding hiervan.

Jolijn van Neer, bedankt dat jij bij de opstart van de TREAT zo behulpzaam bent geweest bij de dataverzameling toen ik naar het MUMC+ vertrok voor mijn opleiding. Dit was een hele geruststelling.

Kim Bonouvrié, destijds als co-assistant toonde jij interesse in het onderzoek en vol enthousiasme ging je aan de slag met het vervolgonderzoek van de TREAT resultaten. Recent heb je besloten dat je toekomst niet binnen de Gynaecologie ligt. Ik wens je heel veel succes in de verdere toekomst.

De maatschap gynaecologie, verpleegkundigen en verloskundigen van het Atrium Medisch Centrum Parkstad, bedankt voor jullie bijdrage en steun aan de TREAT en jullie interesse in de voortgang van het onderzoek. Het was geen eenvoudige klus om de inclusie af te ronden en heeft frequent geresulteerd in frustraties bij menigeen, maar mede dankzij jullie steun is het gelukt. Peter, ooit sloeg jij je vleugels over mij uit als je "opleidingsdochter". Bedankt voor je betrokkenheid destijds bij mijn opleiding in het Atrium en de vaak wijze woorden. Nicol, nadat ik Wesley ontving van jou, leek het onderzoek toch in een versnelling te komen....Simmie nu ben jij aan de beurt, je mag hem hebben.

Paul en Frans, ondanks dat het "routinematig" plaatsen van epidurale analgesie vaak plaats moest vinden in de nachtelijke uren, hebben jullie deze taak tot het einde van de studie volbracht. Dank! 
Alle arts-assistenten uit het Atrium Medisch Centrum Parkstad, in het bijzonder; de Heerlense meisjes, Jorik en Harold, arts-assistenten en stafleden van het MUMC+ voor de geleverde inclusies en steun tijdens mijn onderzoek. Christine bedankt voor jouw bijzondere enthousiasme tijdens de inclusie periode. Lester, op de SMFM in San Francisco, voelden wij ons beiden toch wel een stel "provinciaaltjes". Op naar jouw boekje, want ook zonder BW blijkt het mogelijk om te promoveren.

Stafleden en arts-assistenten Anaesthesiologie van het MUMC+ bedankt voor jullie bereidheid voor het plaatsen van epiduralen 24/7.

Sander van Kuijk, dank voor je hulp bij het maken van een aantal figuren. Die "diva" bevalling staat gereserveerd... Ik hoor het wel.

Mijn collega's in het Orbis Medisch Centrum, mijn huidige werkplek. Al vroeg hadden jullie vertrouwen in mij als maat. Bedankt voor jullie steun tijdens de afronding van mijn promotie. Ik hoop dat we elkaar in de toekomst kunnen blijven stimuleren en inspireren. Polimedewerksters, verpleegkundigen, OK dames, klinisch verloskundigen en artsassistenten van het Orbis; het is geweldig om in zo'n inspirerende club met een enorme betrokkenheid van eenieder te mogen werken.

Lieve vrienden en vriendinnen, het schrijven van dit boekje heeft heel wat vrije tijd gekost. Ik vind het altijd zo cliché om dit te lezen in proefschriften, maar helaas is het de realiteit. Lieve vriendinnetjes, onze stelling luidt: "je hoeft niet altijd bij elkaar te zijn om er voor elkaar te zijn". Pietje, jouw briljante uitspraak tijdens een avondje eten mbt mijn promotie zal ik nooit meer vergeten: "ach, uiteindelijk is het toch een kwestie van samenvoegen Tini”. Ja hoor, dat klopt zeker!! Het is nu samengevoegd. Lieve Suus en Piet, het is tijd voor betere tijden...minder agendapunten, meer tijd voor gezellige dingen. De beker moet achter slot en grendel..

Lieve Marjo en Nettie, wat een geluk dat jullie in ons gezin zijn gekomen. Zonder jullie steun zou het thuis een stuk minder soepel verlopen.

Lieve Erik, Mieke, Stef, Denise, Britt en Chloé, bedankt voor jullie steun en interesse in mijn onderzoek. Het was vaak abracadabra waar ik allemaal mee bezig was. Het is nu klaar. 
Mijn lieve mama en papa, zonder jullie was er nooit een studie geneeskunde gekomen. $\mathrm{Na} 4$ jaar te zijn uitgeloot werd ik uiteindelijk toegelaten. Het stalken en treiteren van een groepje ambtenaren in Groningen leidde uiteindelijk tot een definitief jawoord en toelating tot de studie Geneeskunde was een feit. Dolgelukkig was ik. Altijd hebben jullie me gesteund om mijn doelen te realiseren en nu uiteindelijk te promoveren. Jullie zijn onmisbaar geweest bij het voltooien van mijn opleiding en dit proefschrift. Jullie staan altijd voor ons gezinnetje klaar. Nooit was iets teveel. Ik ben heel dankbaar dat ik dit samen met jullie kan delen. Laten we nog lang samen genieten. Bedankt!

Beau en Noa, wat zijn jullie leuk, lief, mooi, grappig, twee wondertjes, ... Een genot en vreugde om met jullie samen te zijn en jullie te zien opgroeien. Echter het besef van jullie rijkdom, heeft mij ook kwetsbaar gemaakt. Ik wil er voor altijd voor jullie zijn.

En tenslotte mijn allerliefste, Luuk. We zijn al lang samen en jij hebt daarom al mijn wedstrijden hordelopen langs de zijlijn meebeleefd. Onze werelden waarin we werken staan soms haaks tegenover elkaar, dit is niet altijd eenvoudig, maar ik hoop dat we elkaar kunnen blijven stimuleren om onze dromen te verwezenlijken. Je hebt me veel geleerd en gesteund in al die jaren. Jij wist me altijd op de juiste momenten terug te fluiten om even een moment rust te nemen. "Leg het nou maar even een avond op het randje" zei je dan. Er heeft heel vaak iets op dat "randje" gelegen, maar uiteindelijk is het niet blijven liggen en is er een kaft omheen geslagen. Nu weer meer tijd voor pret. Dikke zoen. 




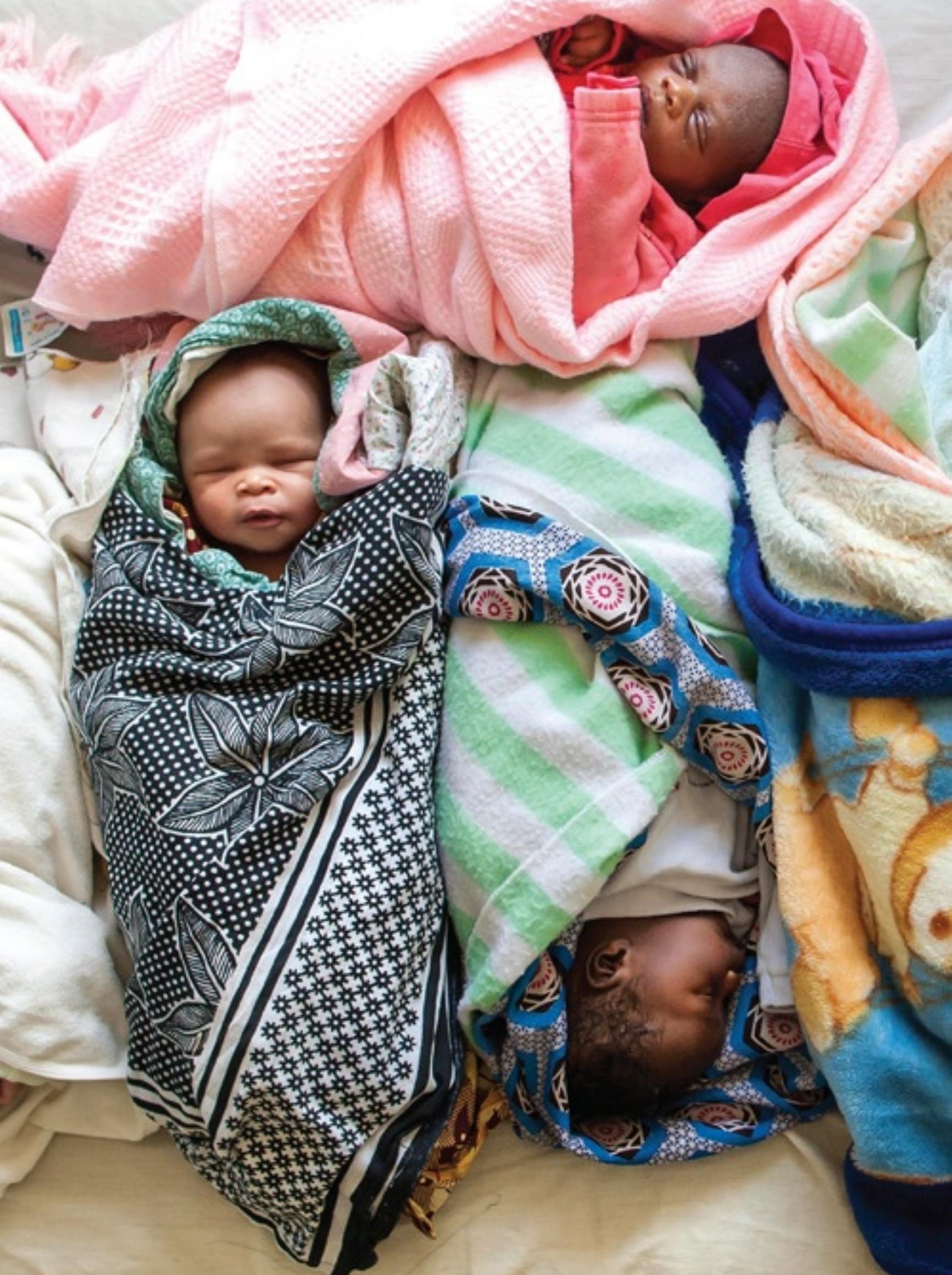

